\title{
Messenger RNA profile analysis deciphers new Esrrb responsive genes in prostate cancer cells
}

Yuan Lu ${ }^{1,2,5}$, Jilong Li $i^{2,3,4}$, Jianlin Cheng ${ }^{2,3,4}$ and Dennis B. Lubahn ${ }^{1,2^{*}}$

\begin{abstract}
Background: Orphan nuclear receptor estrogen related receptor $\beta$ (Esrrb or ERR $\beta$ ) is well known in stem cells and early embryonic development. However, little is known about its function in cancer.

Method: We investigated the mRNA profile alterations induced by Esrrb expression and its synthetic ligand DY131 in human prostate cancer DU145 cells via RNA-Seq analysis.

Results: We distinguished 67 mRNAs differentially expressed by Esrrb alone. Although DY131 alone did not change any gene, treatment of DY131 in the presence of Esrrb altered 1161 mRNAs. These observations indicated Esrrb had both ligand-independent and ligand-dependent activity. When Esrrb was expressed, DY131 treatment further regulated 15 Esrrb-altered mRNAs. DY131 acted as an antagonist for 11 of 15 mRNAs (wdr52, f13a1, pxdn, spns2, loc100506599, tagln, loc441454, tkel1, sema3f, zcwpw2, sdc2) and as an agonist for 4 of the 15 mRNAs (rarres3, oasl, padi2, $d d \times 60)$. Gene ontology analyses showed altered genes are related to transcription and translation regulation, cell proliferation and apoptosis regulation, and cellular metabolism.
\end{abstract}

Conclusion: Our results characterized mRNA profiles in DU145 prostate cancer cells driven by Esrrb expression and Esrrb ligand DY131, and provided multiple markers to characterize Esrrb's function in Esrrb research.

Keywords: Estrogen related receptor, RNA-Seq, Prostate cancer, Gene expression profile, DY131, Transcription regulation, Nuclear receptor

\section{Background}

Esrrb encodes nuclear receptor estrogen related receptor $\beta$ (Esrrb), which belongs to the nuclear receptor family. Esrrb acts as a transcription factor by binding to a specific DNA sequence estrogen related receptor response element (ERRE), which is also known as steroid factor response element (SFRE), or half site estrogen response element $[1,2]$.

Esrrb, first cloned in 1988, was not intensively studied until recent years. Knocking out of Esrrb was embryonic lethal due to placental malformation [3]. Though early studies showed a very limited range of tissues with positive Esrrb expression, recent studies reported that short

\footnotetext{
*Correspondence: lubahnd@missouri.edu

1 Department of Biochemistry, University of Missouri, Columbia,

MO 65211, USA

Full list of author information is available at the end of the article
}

form Esrrb alternative splicing isoform had a broad range of expression [4]. Esrrb was found to be a core-reprogramming factor to reprogram Pluripotent Stem Cells (iPSCs) [3-6]. c-myc and klf4 of the OSKM (oct4, sox2, klf4, c-myc) core-reprogramming factors can be replaced by Esrrb [5, 6]. Esrrb was also recently reported to drive sox 2 transcription and induce iPSC in a single cell system [7].

Tumorigenesis and tumor progression are related to Esrrb. Esrrb was shown to be down-regulated in prostate cancer epithelium compared to normal prostate tissue [8-10]. Its re-expression in DU145 and LNCaP cells was shown to stimulate tumor suppressor $c d k n 1 a$ (p21) concentration. Also, Esrrb can inhibit Estrogen Receptor transcriptional activity in uterine endometrial cancer cells and Nrf2-Keap signaling pathway in breast cancer cells [11, 12].

There are a handful of transcriptome-wide expression survey data from Esrrb knockdown in both human 
iPSCs and mouse embryonic stem cells [13-16]. Known Esrrb controlled genes include $k l f 4, c-m y c, c d k n 1 a$ and cyp19a1, but Esrrb target genes in cancer cells are still not known.

This manuscript focuses on the discovery of Esrrb ligand-independent and Esrrb ligand-dependent target genes. We performed RNA-Seq analysis to characterize Esrrb regulated mRNAs in a prostate cancer cell line and we found the treatment of DY131 expanded Esrrb's transcriptional regulation activity to many more genes.

\section{Results}

Establishment of the Esrrb stably transfected DU145 cells

Esrrb expression vector or control pcDNA3.1 (Zeo+) vector were transfected into DU145 cells. After 3 weeks of Zeocine selection, we characterized the Esrrb status by reverse transcriptase (RT)-PCR, qPCR and western blot analysis (Fig. 1a-c). Our results showed that Esrrb was successfully expressed in DU145-Esrrb cells. Although RNA-Seq showed that DU145-pc3.1 cells had a very small amount of Esrrb expressed (count per

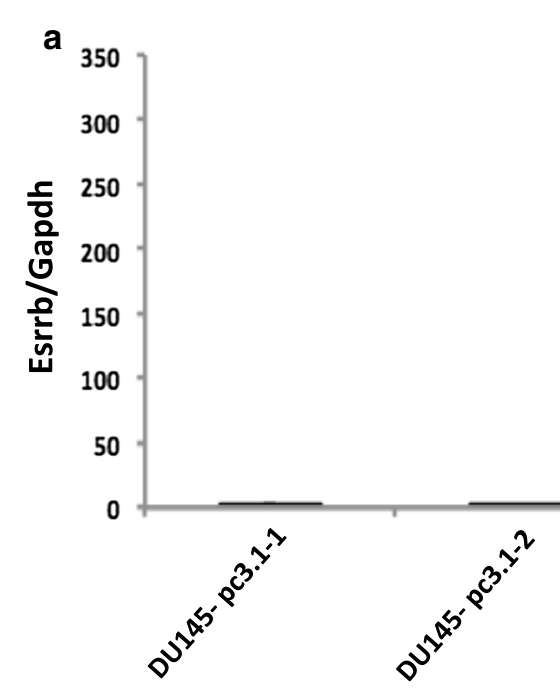

b

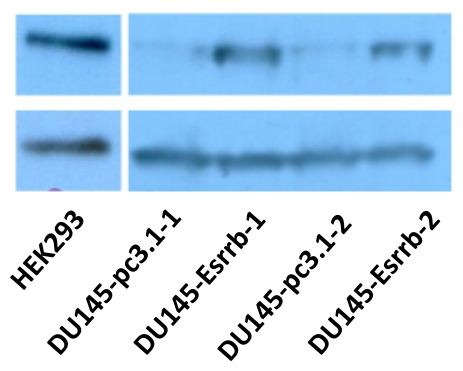

ESRRB

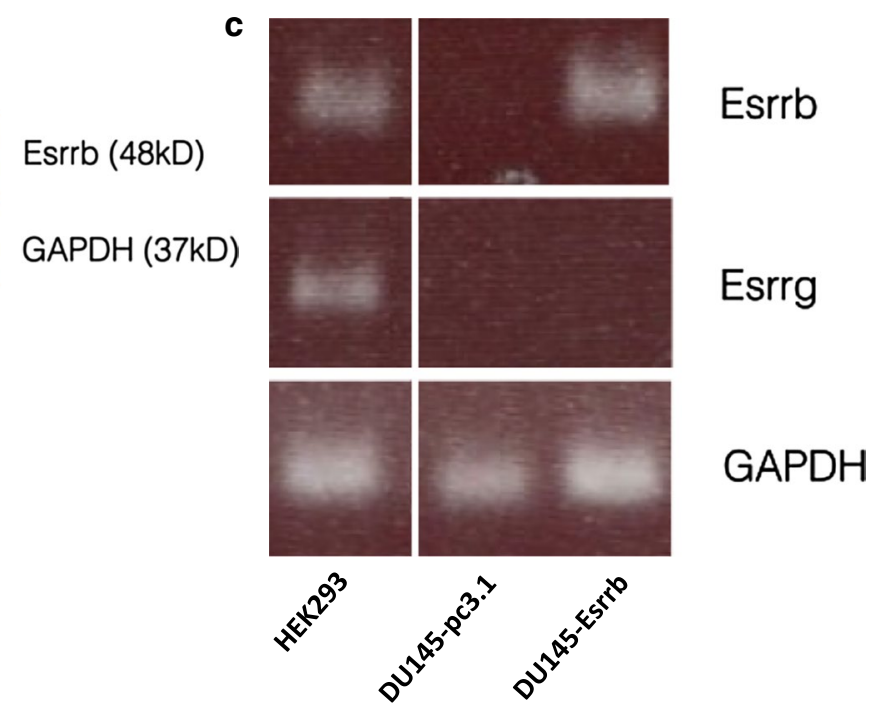

Fig. 1 Characterization of Esrrb-expressing cancer cell line. Esrrb status of two independent replicates of stable transfected control DU145-pc3.1 and DU145-Esrrb cells are tested by $\mathbf{a}$ quantitative PCR $\mathbf{b}$ Western blot and $\mathbf{c}$ reverse transcriptase PCR. a Relative mRNA concentrations of Esrrb were measured by qPCR, Esrrb transcripts concentration were determined by standard curve method and Esrrb concentration were first normalized to the concentration of house keeping gene GAPDH, then normalized to Esrrb/GAPDH ratio of DU145-pc3.1 cells. b Total protein was extracted form HEK293, DU145-Esrrb and control DU145-pc3.1 cells. Protein concentration of Esrrb was determined by western blot using GAPDH as internal control. c RT-PCR was performed on total RNA extracted from HEK293, DU145-esrrb and control DU145-pc3.1 cells. Esrrb was expressed in DU145Esrrb cells, while Esrrg is not expressed in either DU145-pc3.1 and DU145-Esrrb cells 
million read $<1$ ), the Esrrb concentration is below the detection limit of RT-PCR and western blot. Compared to HEK293 cells, which expressed endogenous Esrrb, overexpression of Esrrb in DU145 cells raised the Esrrb protein concentration to a comparable physiological concentration (Fig. 1b). In addition, our RT-PCR results and RNA-seq results confirmed the estrogen related receptor gamma (Esrrg) was not expressed in DU145 cells. The absence of Esrrg eliminated any possible functional contamination by Esrrg in our Esrrb studies (Fig. 1c).

\section{Esrrb expression alters mRNA profile}

To distinguish genes regulated by Esrrb, we performed RNA-Seq analysis on cDNA libraries constructed from two biological replicates of both DU145-pc3.1 and DU145-Esrrb cells. Spearman ranking correlation analysis showed that the expression of Esrrb in DU145 created a distinct transcriptome compared to control DU145pc3.1 cells (Fig. 2a). We found 67 genes (21 genes upregulated, 46 genes down-regulated) altered due to Esrrb expression (Fig. 2b; Table 1). Seven genes that are among the most changed genes (zcwpw2, hoxb8, tagln, f13a1, $p x d n$, aox 1 , and bmp4, as well as tgf $\beta$ as a negative control) were confirmed by qPCR (Fig. 3). Gene ontology (GO) analysis shows that the products of Esrrb driven differentially expressed genes fell into functional categories of regulation of cell development as well as immune responses (Table 2).

\section{DY131 requires Esrrb to affect gene expression}

To get a more comprehensive understanding of Esrrbregulated genes and characterize Esrrb's potential ligand dependent activity, control DU145-pc3.1 and DU145Esrrb cells were treated with Esrrb/Esrrg synthetic ligand DY131. Since both qPCR and RNA-seq show Esrrb transcript concentration is extremely low in DU145 cells and Esrrg is absent, and Esrrb protein concentration is also below the detection limit of western-blot analysis, it was not surprising to observe DY131 treatment without Esrrb expressed did not result in any gene differentially expressed (Fig. 4a). After we applied DY131 to DU145Esrrb cells, we found DY131 treatment most significantly modified the transcriptome (Figs. 2a, 4b). Further comparison of DU145-Esrrb cells alone to DY131-treated DU145-Esrrb cells detected 1161 altered mRNAs (861 down-regulated, 300 up-regulated). 15 of them overlapped with Esrrb-induced mRNA alterations (Fig. 4c, d; Table 3). We defined an Esrrb agonist as a ligand that moves the mRNA concentration in the direction as Esrrb does; and an antagonist moves the concentration in the opposite direction as Esrrb does. By comparing the trend of the altered genes induced by Esrrb expression and
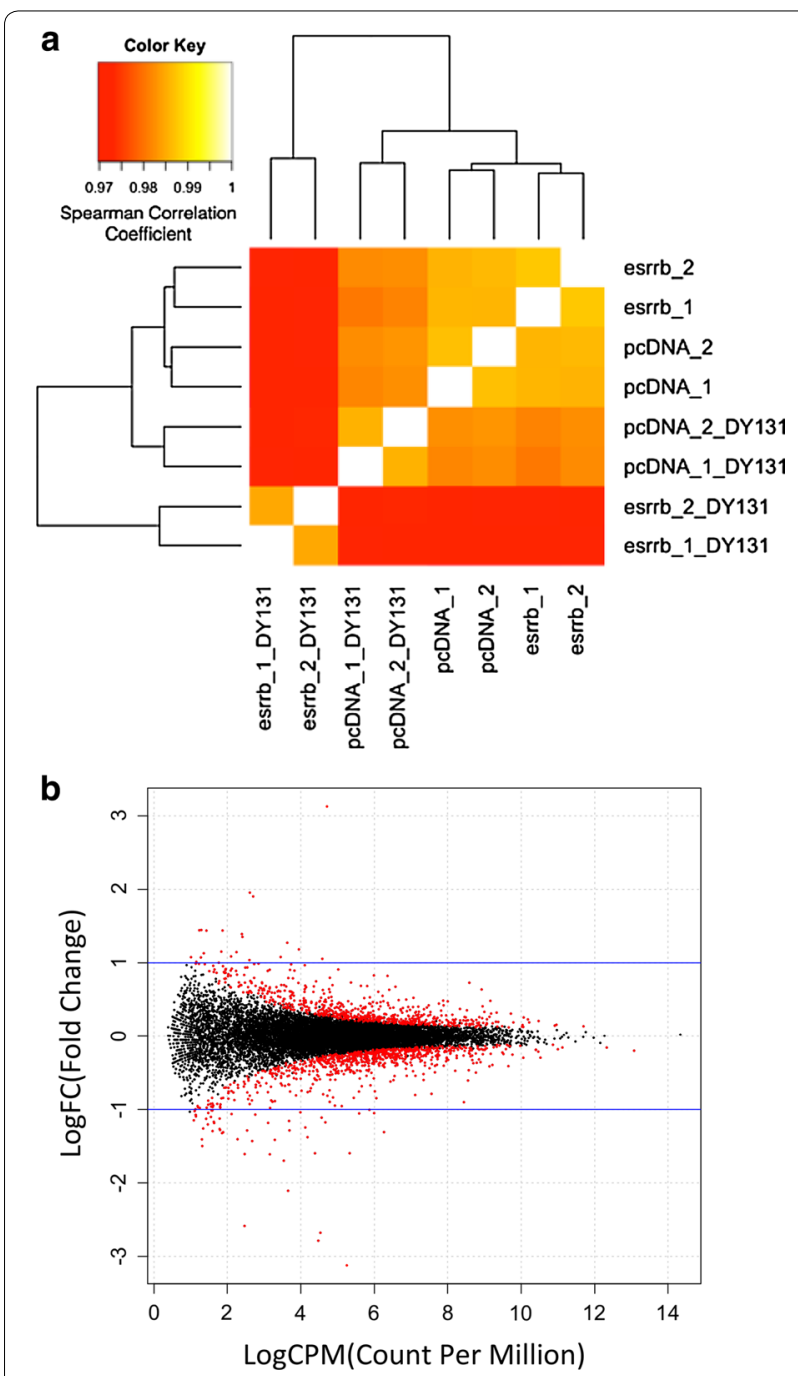

Fig. 2 Transcriptome correlation and Esrrb altered mRNAs. a Transcriptome correlation analysis was performed using Spearman Ranking Correlation. Color represents the correlation coefficient. DY131 treatment to DU145-Esrrb cells results in the lowest correlation coefficient with DU145-pc3.1 cells. b Dot plot of Esrrb-induced gene expression alteration. Genes expressed at adequate level are tested for differential gene expression test. The plot was made by plotting the Log2FC (fold change) against the Log2 cpm (count-per-million) difference. Red color marks the genes that are significant differentially expressed (FDR < 0.05), and the blue lines marked the Log2FC cutoff value (Log2FC $>1$ or Log2FC < - 1). 67 genes passed both thresholds

DY131 treatment, DY131 acts as an agonist for 4 of the 15 genes, and an antagonist for 11 of the 15 genes (Fig. $4 \mathrm{~d}$ ). There are another 1146 mRNAs changed with both Esrrb and DY131 treatment compared to Esrrb alone, indicating their responses is ligand-dependent (Table 3).

GO analysis showed Esrrb-dependent DY131 up-regulated genes were important for regulation of transcription, regulation of apoptosis and proliferation, and a 
Table 1 Esrrb altered mRNAs

\begin{tabular}{|c|c|c|c|}
\hline Gene symbol & $\log F C$ & $P$ value & FDR \\
\hline $\mathrm{AOX} 1$ & -3.49 & $4.89 E-184$ & $3.19 \mathrm{E}-180$ \\
\hline PXDN & -2.79 & $4.45 E-87$ & $1.16 \mathrm{E}-83$ \\
\hline F13A1 & -2.68 & $9.28 \mathrm{E}-114$ & $4.04 \mathrm{E}-110$ \\
\hline BMP4 & -2.59 & $1.69 E-29$ & $1.16 \mathrm{E}-26$ \\
\hline NPTX1 & -2.11 & $1.06 \mathrm{E}-46$ & $1.73 E-43$ \\
\hline SPNS2 & -1.70 & $8.70 E-31$ & $7.09 E-28$ \\
\hline DDX60 & -1.61 & $2.43 E-15$ & $4.46 \mathrm{E}-13$ \\
\hline NEFL & -1.61 & $1.84 \mathrm{E}-13$ & $2.85 E-11$ \\
\hline OASL & -1.60 & $1.30 E-25$ & 7.07E-23 \\
\hline IFIT3 & -1.60 & $4.29 E-42$ & $5.09 E-39$ \\
\hline WDR52 & -1.50 & $1.85 \mathrm{E}-06$ & $7.40 \mathrm{E}-05$ \\
\hline C3 & -1.43 & $7.81 \mathrm{E}-09$ & $5.73 \mathrm{E}-07$ \\
\hline LOC344887 & -1.41 & $5.01 \mathrm{E}-20$ & $1.49 \mathrm{E}-17$ \\
\hline PCDHB15 & -1.41 & $6.25 E-06$ & 0.00020978 \\
\hline CXorf57 & -1.41 & $1.78 \mathrm{E}-10$ & $1.92 \mathrm{E}-08$ \\
\hline IFI6 & -1.38 & $1.09 \mathrm{E}-19$ & $2.91 E-17$ \\
\hline CXCR4 & -1.32 & $3.23 \mathrm{E}-06$ & 0.00011537 \\
\hline GBP1 & -1.31 & $1.43 \mathrm{E}-07$ & 7.57E-06 \\
\hline IGFBP3 & -1.31 & $3.19 E-89$ & $1.04 \mathrm{E}-85$ \\
\hline ZSCAN12P1 & -1.30 & 0.00015585 & 0.00302695 \\
\hline RNF128 & -1.29 & $1.58 \mathrm{E}-10$ & $1.73 E-08$ \\
\hline SAMD9 & -1.29 & $2.69 E-22$ & $1.13 E-19$ \\
\hline UNC5A & -1.28 & $8.28 \mathrm{E}-07$ & $3.62 \mathrm{E}-05$ \\
\hline$M \times 2$ & -1.27 & $1.68 \mathrm{E}-06$ & $6.86 \mathrm{E}-05$ \\
\hline SSBP2 & -1.26 & $5.96 \mathrm{E}-05$ & 0.00141054 \\
\hline MX1 & -1.25 & $5.99 E-22$ & $2.37 E-19$ \\
\hline SULT4A1 & -1.20 & $4.94 \mathrm{E}-05$ & 0.00120711 \\
\hline DPYD & -1.19 & $1.35 \mathrm{E}-05$ & 0.00040257 \\
\hline NEBL & -1.18 & $1.16 \mathrm{E}-12$ & $1.62 \mathrm{E}-10$ \\
\hline TAGLN & -1.18 & $5.48 \mathrm{E}-30$ & $3.97 E-27$ \\
\hline INA & -1.17 & $2.47 \mathrm{E}-05$ & 0.0006739 \\
\hline BMF & -1.16 & $3.32 \mathrm{E}-05$ & 0.00085559 \\
\hline ESRP1 & -1.13 & 0.00014206 & 0.00283503 \\
\hline GJA3 & -1.12 & $1.38 E-05$ & 0.00040614 \\
\hline IFIT2 & -1.11 & $1.02 \mathrm{E}-19$ & $2.76 \mathrm{E}-17$ \\
\hline LOC 1005065 & -1.10 & $8.53 \mathrm{E}-05$ & 0.0018618 \\
\hline RARRES3 & -1.07 & $1.84 \mathrm{E}-07$ & $9.68 \mathrm{E}-06$ \\
\hline TMEM45A & -1.06 & $4.69 E-06$ & 0.00016245 \\
\hline LGALS3BP & -1.05 & $4.57 \mathrm{E}-17$ & $9.63 \mathrm{E}-15$ \\
\hline ERAP2 & -1.05 & $1.83 \mathrm{E}-50$ & $3.41 E-47$ \\
\hline WNT10A & -1.05 & 0.00024417 & 0.00440189 \\
\hline PADI2 & -1.04 & $1.13 E-17$ & $2.55 E-15$ \\
\hline REEP1 & -1.01 & 0.00024704 & 0.0044413 \\
\hline AMIGO2 & -1.01 & $8.26 E-45$ & $1.08 \mathrm{E}-41$ \\
\hline HES1 & -0.98 & $1.30 \mathrm{E}-07$ & 7.01E-06 \\
\hline FRMD4B & -0.98 & 0.00014442 & 0.00284746 \\
\hline NRIP3 & 0.97 & $4.28 \mathrm{E}-14$ & $6.90 \mathrm{E}-12$ \\
\hline HOXB8 & 0.98 & $3.60 E-11$ & $4.33 E-09$ \\
\hline KCNQ5 & 0.98 & 5.87E-08 & $3.55 \mathrm{E}-06$ \\
\hline
\end{tabular}

Table 1 continued

\begin{tabular}{|c|c|c|c|}
\hline Gene symbol & $\log F C$ & P value & FDR \\
\hline COX6B2 & 0.99 & $1.24 \mathrm{E}-07$ & $6.77 \mathrm{E}-06$ \\
\hline PPFIBP2 & 1.04 & $6.38 \mathrm{E}-07$ & $2.92 \mathrm{E}-05$ \\
\hline KIAA1199 & 1.06 & $1.21 \mathrm{E}-25$ & $6.89 E-23$ \\
\hline BST1 & 1.08 & $4.97 E-13$ & $7.30 \mathrm{E}-11$ \\
\hline LOC1001336 & 1.13 & 0.00019921 & 0.00370382 \\
\hline SMOC1 & 1.15 & $1.52 \mathrm{E}-06$ & $6.32 \mathrm{E}-05$ \\
\hline LOC441454 & 1.15 & $9.40 \mathrm{E}-06$ & 0.00029713 \\
\hline DDIT4L & 1.18 & $2.28 \mathrm{E}-10$ & $2.39 E-08$ \\
\hline SEMA3F & 1.27 & $2.08 \mathrm{E}-20$ & $6.96 \mathrm{E}-18$ \\
\hline DUOX1 & 1.35 & 5.37E-09 & $4.25 \mathrm{E}-07$ \\
\hline ARHGAP24 & 1.39 & $6.40 E-10$ & $6.01 E-08$ \\
\hline CDHR1 & 1.44 & $2.04 \mathrm{E}-06$ & $7.93 \mathrm{E}-05$ \\
\hline SDC2 & 1.44 & $1.49 E-08$ & $1.04 \mathrm{E}-06$ \\
\hline SH3RF3 & 1.44 & $1.32 \mathrm{E}-05$ & 0.00039562 \\
\hline PRSS8 & 1.45 & $6.96 \mathrm{E}-06$ & 0.00022989 \\
\hline TKTL1 & 1.90 & $3.68 \mathrm{E}-21$ & $1.33 E-18$ \\
\hline FGB & 1.96 & $5.57 E-22$ & 2.27E-19 \\
\hline ZCWPW2 & 5.22 & $3.47 E-215$ & $4.53 \mathrm{E}-211$ \\
\hline
\end{tabular}

majority of down-regulated genes are related to oxidation and reduction, metabolism and translation elongation (Table 4; Additional file 1: Table S1).

\section{Discussion}

Esrrb has gained lots of attention in recent years because of its biological function in stem cells and its ability to reprogram somatic cells to iPSC with oct 4 and sox $2[6,13$, 17-21]. Several other functions of Esrrb have also been discovered including alteration of energy balance, estrogen receptor and glucocorticoid receptor transcription function modulation, Keap1-Nrf2 signaling inhibition, and tumorigenesis in prostate cancer and endometrial adenocarcinoma [9-12, 22-25]. But transcriptome-wide Esrrb function and Esrrb-regulated genes in cancer cells are not well studied.

Esrrb was reported by Chan et al. as a tumor suppressor in DU145 and LNCaP prostate cancer cells using both in vitro and in vivo models [9]. Expression of Esrrb induced $p 21 / c d k n 1 a$ by directly binding to an ERRE in $p 21 / c d k n 1 a$ 's promoter, arrested cell cycle at S-phase, and significantly inhibited cell growth $[9,26]$. Interestingly, we did not find p21/cdkn1a up-regulation after Esrrb expression alone, but after we treated DU145 cells with $3 \mu \mathrm{M}$ DY131, we observed a significant increase of $p 21 / c d k n 1 a$ mRNA (Table 3; Additional file 2: Figure S1). Scrutinizing the data revealed that Chan's lab cultured their cells with full serum, while we used charcoalstripped serum for cell culture and DY131 treatment [9]. 


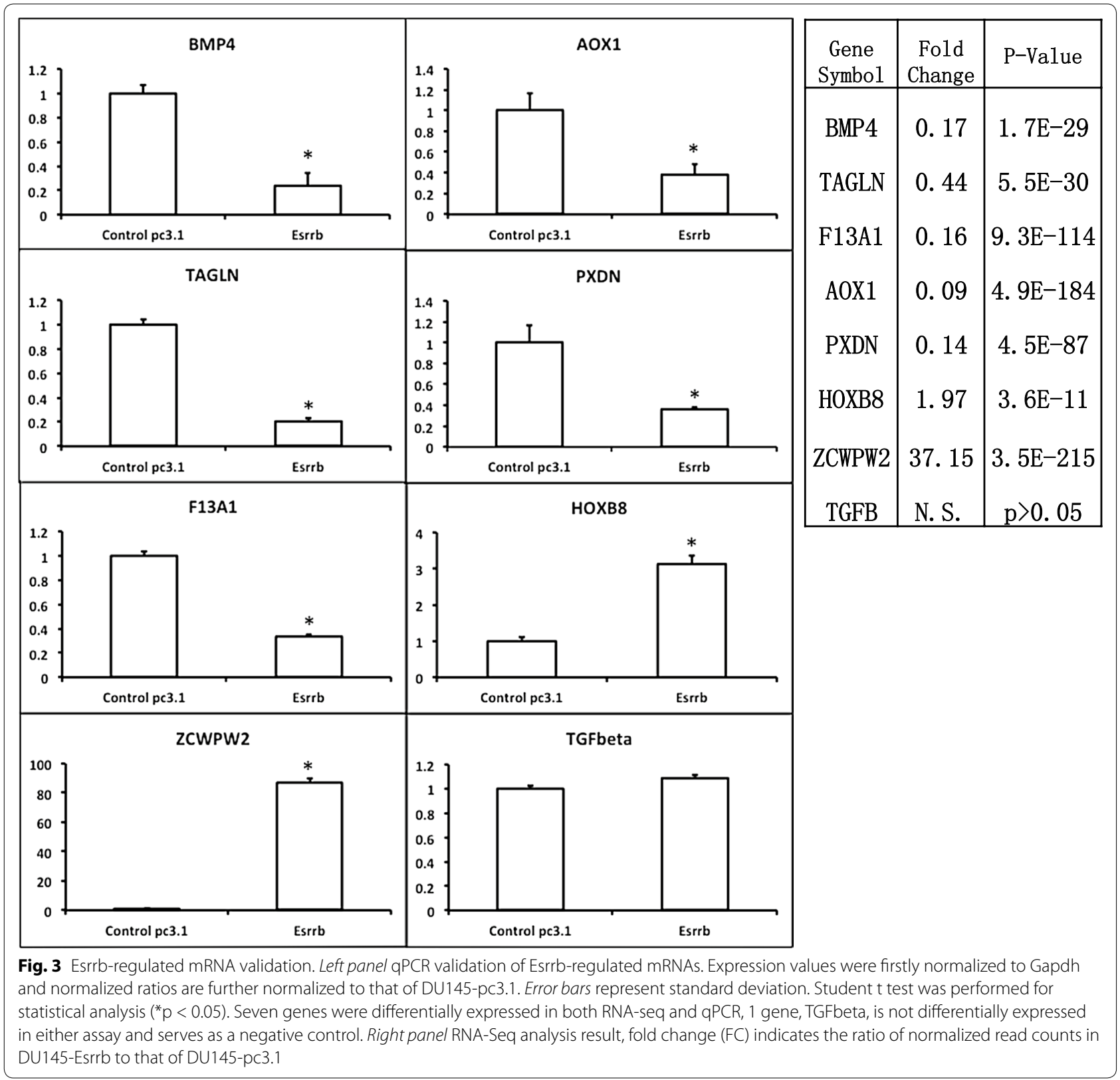

This implies that there is a compound or factor that can be removed by charcoal treatment modulated Esrrb's activity $[27,28]$.

From the Esrrb-regulated gene list, we found a few target genes that are related to the known function of Esrrb. Kiaa1199 encoded gene product has been shown to associate with cellular mortality. A kiaa1199 mutation was reported to relate to nonsyndromic hearing loss. Considering the significant effect of Esrrb mutations on human hearing loss, kiaa1199 could be a mediator of Esrrb mutant related hearing loss [29-32] [33-36]. Another interesting Esrrb responsive gene is tagln (Transgelin). It was inhibited by Esrrb while DY131 treatment relieved the inhibition. Tagln was reported to promote DU145 cell migration and invasion, indicating Esrrb can also affect DU145 cell behavior by affecting tagln [37].

Judging by the numbers of altered genes induced by Esrrb with or without DY131, and the result that DY131 did not alter any mRNA in the absence of Esrrb, we conclude that DY131 activity is Esrrb-dependent. 
Table 2 Gene ontology analysis of Esrrb altered mRNAs

\begin{tabular}{|c|c|c|}
\hline Term & Count & P value \\
\hline GO:0060284 regulation of cell development & 5 & 0.006 \\
\hline GO:0006955 immune response & 8 & 0.012 \\
\hline GO:0009611 response to wounding & 7 & 0.012 \\
\hline GO:0042542 response to hydrogen peroxide & 3 & 0.017 \\
\hline GO:0050767 regulation of neurogenesis & 4 & 0.022 \\
\hline $\begin{array}{l}\text { GO:0006800 oxygen and reactive oxygen species } \\
\text { metabolic process }\end{array}$ & 3 & 0.024 \\
\hline $\begin{array}{l}\text { GO:0060052 neurofilament cytoskeleton organiza- } \\
\text { tion }\end{array}$ & 2 & 0.029 \\
\hline GO:0000302 response to reactive oxygen species & 3 & 0.03 \\
\hline $\begin{array}{l}\text { GO:0051960 regulation of nervous system develop- } \\
\text { ment }\end{array}$ & 4 & 0.032 \\
\hline GO:0031960 response to corticosteroid stimulus & 3 & 0.038 \\
\hline GO:0010035 response to inorganic substance & 4 & 0.038 \\
\hline GO:0045661 regulation of myoblast differentiation & 2 & 0.039 \\
\hline $\begin{array}{l}\text { GO:0048667 cell morphogenesis involved in neuron } \\
\text { differentiation }\end{array}$ & 4 & 0.04 \\
\hline
\end{tabular}

\section{Conclusions}

In conclusion, we characterized the transcriptome alteration induced by Esrrb expression as well as Esrrb with its ligand DY131 in prostate cancer cells. We conclude Esrrb-target synthetic ligand requires Esrrb to generate its gene expression modulation effect. Finally, analysis of Esrrb target genes indicates Esrrb may be an important factor in regulating cell proliferation.

\section{Methods}

\section{Cell culture and reagents}

DU145 (ATCC Number: HTB-81) and HEK293 (ATCC number: CRL-1571) cells were obtained from the American Type Culture Collection (ATCC). DU145 cells were cultured in RPMI1640 media (Invitrogen, Grand Island, NY, USA) with 10 \% Fetal Bovine Serum (FBS) (GE Healthcare Life Sciences, Logan, UT, USA). HEK293 cells were cultured in Eagle's Minimal Essential Medium (DMEM) (Invitrogen, Grand Island, NY, USA) with $10 \%$ FBS. $70 \%$ confluent DU145 cells were transfected with either pcDNA3.1-zeo $(+)$-Esrrb expression vector [4], or control empty vector pcDNA3.1-zeo $(+)$ (Promega, Madison, WI, USA). Empty vector or Esrrb expression vector transfected DU145 cells were maintained in medium containing $150 \mu \mathrm{g} / \mathrm{ml}$ Zeocine (Invitrogen, Grand Island, NY, USA) for 3 weeks for selection. Two biological replicates of DU145 cells transfected with Esrrb were pooled together respectively and were named DU145-Esrrb. Two biological replicates of DU145 cells transfected with control vector were pooled together respectively and were named DU145-pc3.1. Total RNA and protein were collected from cells after they are confluent in $60 \mathrm{~mm}$ petri dishes, cultured with phenol-red free RPMI1640 with 10 \% Charcoal-stripped FBS [38]. For DY131 (Tocris Bioscience, Bristol, UK) treatment, cells are plated in $60 \mathrm{~mm}$ petri dishes until confluent; DU145-pc3.1 and DU145Esrrb are incubated with $3 \mu \mathrm{M}$ DY131 diluted in medium with charcoal-stripped FBS for indicated length of time.

\section{Western-blot}

Total protein was isolated from DU145-pc3.1, and DU145-Esrrb cells. $20 \mu \mathrm{g}$ protein was loaded on $9 \%$ SDS gels. After the proteins were transferred to nitrocellulose membrane, the membrane was blocked and then incubated with 1:2000 diluted monoclonal anti-Esrrb mouse IgG (R\&D system, Cat. no: PP-H6705-00) and 1:2000 diluted polyclonal anti-GPADH rabbit IgG (Santa Cruz, Dallas, TX, USA, Cat. no: sc-25777) at 4 degrees overnight. The membrane was then washed and incubated with anti-mouse or anti-rabbit secondary antibody. Chemoluminescence (Promega, Madison, WI, USA) signals were collected using x-ray films (Fisher Scientific, Pittsburg, PA, USA).

\section{Reverse transcriptase PCR and quantitative PCR}

Total RNA was isolated and purified from DU145-pc3.1 and DU145-Esrrb using RNeasy kit (Qiagen, Venlo, Netherlands). $1000 \mathrm{ng}$ of total RNA was used to create cDNA libraries using Superscript III Reverse Transciptase with random primers and oligodT (Invitrogen, Grand Island, NY, USA). Esrrb mRNA concentration was determined using quantitative PCR (qPCR) (iQ SYBR, BioRad, Hercules, CA, USA) on ABI7500 system (Applied Biosystems, Foster City, CA, USA). PCR condition: $95^{\circ}, 30 \mathrm{~s}$; $60^{\circ}, 40 \mathrm{~s} ; 72^{\circ}, 40 \mathrm{~s}$. Each qPCR test was performed three times on each of the two biological replicates. Primer sequences: zcwpw2 (Genbank: NM_001040432): forward primer: AACAGGGTTGTCTGTGAGACGGA; reverse primer: TGCAGGAGCTTCTGGGCTGC. hoxb8 (Genbank: NM_024016): forward primer: GATGCGCC CGCAAGCAGC; reverse primer: CCCAGGGCGT GCGATACCTC. tagln (Genbank: NM_001001522): forward primer: ATGCCCCGGATGACTTGGCT; reverse primer: GCCATGTCTGGGGAAAGCTCCT. f13a1 (Genbank: NM_000129): forward primer: TGTTCCGT GAAATCCGGCCC; reverse primer: TGCACGTCC AG CTCGCCATA. $p x d n$ (Genbank: NM_012293): forward primer: GCAAGCATTTAA GGGACTTGCCT CT; reverse primer: GCAAAAATAGCCTCTCGAGCTT CGG. aox1 (Genbank: NM_001159): forward primer: TACGTGAACGGCCGCAAGGT; reverse primer: TGGCTGGGTGATGCCTTATCCT. bmp4 (Genbank: NM_001202): forward primer: CCACCACGAAGAA CA TCTGGAG; reverse primer: GCCCCTTTCCCAAT CAGGGC. tgf $\beta$ : (Genbank: NM_000660) forward 


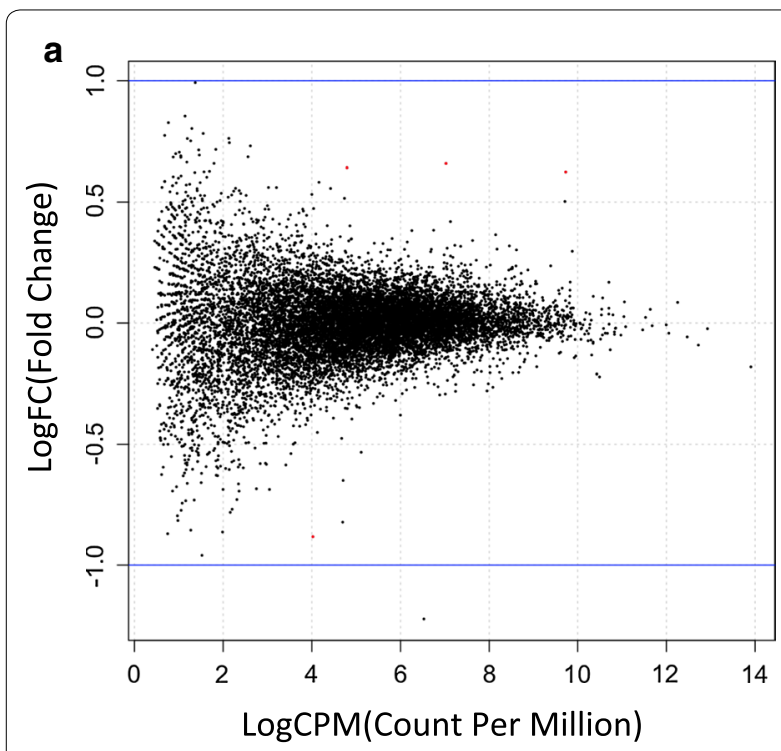

C

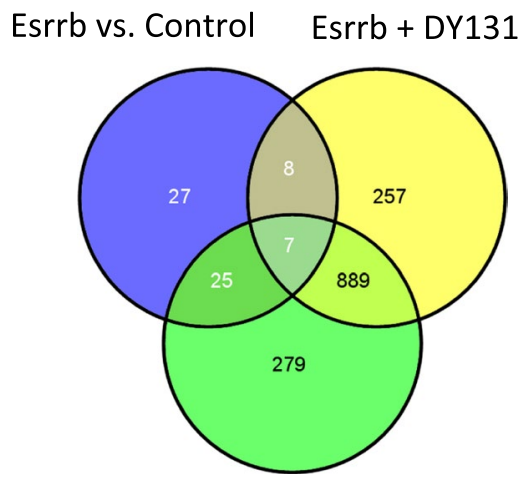

Esrrb + DY131 vs. Control
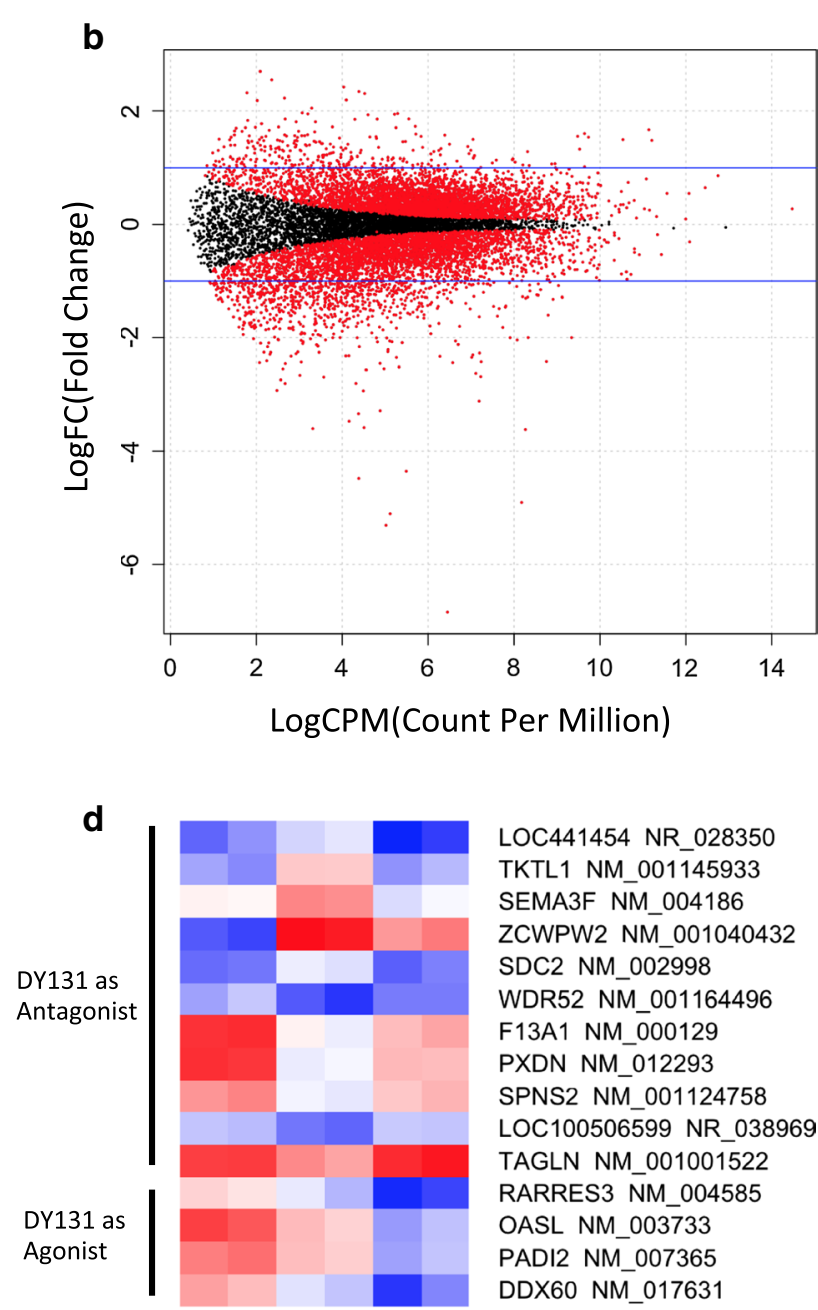

LOC441454 NR 028350 TKTL1 NM_001145933 SEMA3F NM 004186 ZCWPW2 NM_001040432 SDC2 NM_002998 WDR52 NM_001164496 F13A1 NM 000129 PXDN NM_012293 SPNS2 NM_001124758 LOC100506599 NR_038969 TAGLN NM 001001522 RARRES3 NM 004585 OASL NM 003733 PADI2 NM_007365 DDX60 NM 017631

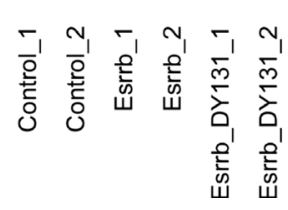

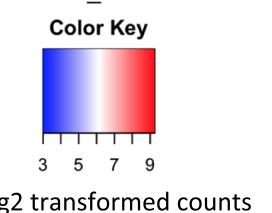

Fig. 4 mRNA alteration by DY131 requires Esrrb expression. a DY131 treatment alone did not alter the expression of any gene. In contrast, when Esrrb was expressed, b DY131 altered 1161 mRNAs. c Venn Diagram of pairwise comparisons of altered mRNAs showed 15 ( $p=0.0014)$ Esrrb altered mRNAs can be further regulated by DY131 treatment (overlap between Esrrb vs. control and Esrrb + DY131 vs. Esrrb). d Heat map of mRNA concentration of the 15 genes that response to both Esrrb expression as well as DY131 treatment. Log2-transformed normalized read counts of these 15 genes were color coded. DY131 is an agonist for 4 mRNAs that are responsive to Esrrb, while it is an antagonist of Esrrb in regulating the other 11 mRNAs

primer: AGTGGACATC AACGGGTTCAC; reverse primer: CGCACGCAGCAGTTCTTCTC. gapdh: (Genbank: NM_001256799); forward primer: ACCCACT CCTCCACCTTTG; reverse primer: CTCTTGTGCT CTTGCTGGG. Esrrb: (Genbank: NM_004452) forward primer: CAAGAAGCTCAAGGTGGAGAAGGAGGAG; reverse primer: CGGTCTGTCC GTTTGTCTGTCTGTA GGT. Esrrg: (Genbank: NM_001134285) forward primer:
ACCATGAATGGCCATCAGA A; reverse primer: ACC AGCTGAGGGTTCAGGTAT.

\section{Deep sequencing and differentially expressed genes}

$2500 \mathrm{ng}$ total RNA from two biological replicates was used to generate cDNA libraries using TruSeq Stranded mRNA Sample Preparation kits (Illumina, San Diego, CA, USA). RNA quality and fragment sizing of cDNA 
Table 3 DY131 altered mRNAs when Esrrb is expressed

\begin{tabular}{|c|c|c|c|}
\hline Gene symbol & $\log F C$ & P value & FDR \\
\hline MTRNR2L8 & -6.83 & 0 & 0 \\
\hline MTRNR2L10 & -5.31 & $9.85 E-242$ & $4.62 E-239$ \\
\hline SNHG5 & -5.11 & $1.21 \mathrm{E}-277$ & $6.66 \mathrm{E}-275$ \\
\hline RPS29 & -4.91 & 0 & 0 \\
\hline SEC61G & -4.48 & $2.94 \mathrm{E}-165$ & $7.90 E-163$ \\
\hline RPL36A & -4.35 & 2.3501596881585 & $0.00 E+00$ \\
\hline RPL12 & -3.62 & 0 & 0 \\
\hline TMEM212 & -3.60 & $1.12 \mathrm{E}-56$ & $4.20 \mathrm{E}-55$ \\
\hline ESRG & -3.58 & $6.76 \mathrm{E}-114$ & $9.61 \mathrm{E}-112$ \\
\hline NEDD8-MDP1 & -3.47 & $7.24 \mathrm{E}-102$ & $7.97 \mathrm{E}-100$ \\
\hline FOS & -3.34 & $2.98 \mathrm{E}-53$ & $9.94 \mathrm{E}-52$ \\
\hline SLIRP & -3.28 & $1.01 \mathrm{E}-127$ & $1.85 E-125$ \\
\hline MTRNR2L1 & -3.12 & 0 & 0 \\
\hline LGALS3 & -2.94 & $3.19 \mathrm{E}-115$ & $4.69 E-113$ \\
\hline SYTL1 & -2.93 & $9.57 E-29$ & $1.23 \mathrm{E}-27$ \\
\hline CLIC3 & -2.80 & $7.42 \mathrm{E}-29$ & $9.60 \mathrm{E}-28$ \\
\hline WISP2 & -2.80 & $7.36 \mathrm{E}-56$ & $2.71 \mathrm{E}-54$ \\
\hline ABCD3 & -2.74 & $5.71 \mathrm{E}-21$ & $4.79 E-20$ \\
\hline TNNT1 & -2.69 & $4.26 \mathrm{E}-53$ & $1.42 \mathrm{E}-51$ \\
\hline RPL31 & -2.68 & 0 & 0 \\
\hline ASS1 & -2.66 & $2.78 \mathrm{E}-30$ & $3.82 \mathrm{E}-29$ \\
\hline EGR1 & -2.63 & 0 & 0 \\
\hline PSMA1 & -2.57 & $3.99 \mathrm{E}-89$ & $3.55 E-87$ \\
\hline MRPL4 & -2.56 & $5.21 \mathrm{E}-98$ & $5.36 \mathrm{E}-96$ \\
\hline $\mathrm{ACPI}$ & -2.55 & $8.68 \mathrm{E}-27$ & $1.02 \mathrm{E}-25$ \\
\hline USMG5 & -2.54 & $4.08 E-124$ & $6.97 \mathrm{E}-122$ \\
\hline CRIP1 & -2.52 & $7.63 \mathrm{E}-155$ & 1.76E-152 \\
\hline STAT4 & -2.46 & $5.11 \mathrm{E}-22$ & $4.64 \mathrm{E}-21$ \\
\hline NDUFA11 & -2.45 & $2.16 \mathrm{E}-93$ & $2.05 E-91$ \\
\hline SCFD1 & -2.44 & $6.21 E-304$ & 4.14E-301 \\
\hline CYBA & -2.44 & $5.78 \mathrm{E}-17$ & $3.76 \mathrm{E}-16$ \\
\hline NAPSA & -2.43 & $2.66 \mathrm{E}-17$ & $1.77 \mathrm{E}-16$ \\
\hline RPL13AP5 & -2.43 & 0 & 0 \\
\hline RPL9 & -2.42 & 0 & 0 \\
\hline TCTEX1D2 & -2.41 & $6.26 \mathrm{E}-19$ & $4.62 E-18$ \\
\hline MKNK2 & -2.35 & $4.60 \mathrm{E}-83$ & $3.57 \mathrm{E}-81$ \\
\hline RPL 18 & -2.35 & 0 & 0 \\
\hline MUC1 & -2.33 & $2.97 \mathrm{E}-73$ & $1.75 \mathrm{E}-71$ \\
\hline SEPP1 & -2.33 & 4.57E-14 & $2.42 \mathrm{E}-13$ \\
\hline PDE9A & -2.32 & $1.44 \mathrm{E}-65$ & $7.05 E-64$ \\
\hline SEMA6B & -2.32 & $1.67 \mathrm{E}-53$ & $5.59 E-52$ \\
\hline RPS15A & -2.30 & 0 & 0 \\
\hline CNTN1 & -2.29 & $3.68 \mathrm{E}-18$ & $2.58 \mathrm{E}-17$ \\
\hline CA11 & -2.28 & $8.82 E-26$ & $9.90 E-25$ \\
\hline TXN & -2.27 & 0 & 0 \\
\hline LOC728730 & -2.26 & $4.28 \mathrm{E}-15$ & $2.45 E-14$ \\
\hline GSTM1 & -2.26 & $3.08 \mathrm{E}-39$ & $6.17 \mathrm{E}-38$ \\
\hline MACROD1 & -2.26 & $5.25 \mathrm{E}-17$ & $3.42 \mathrm{E}-16$ \\
\hline CBLC & -2.25 & $5.56 \mathrm{E}-23$ & $5.30 E-22$ \\
\hline SUCLG2 & -2.24 & $7.28 \mathrm{E}-112$ & $9.70 E-110$ \\
\hline PDCD4 & -2.21 & $4.54 \mathrm{E}-103$ & $5.13 \mathrm{E}-101$ \\
\hline NDUFB2 & -2.16 & $8.58 \mathrm{E}-73$ & $4.91 \mathrm{E}-71$ \\
\hline C4orf48 & -2.16 & $1.10 E-16$ & $7.00 E-16$ \\
\hline
\end{tabular}

Table 3 continued

\begin{tabular}{|c|c|c|c|}
\hline Gene symbol & $\log F C$ & $P$ value & FDR \\
\hline PIR-FIGF & -2.15 & $1.69 E-35$ & $2.92 \mathrm{E}-34$ \\
\hline DHRS3 & -2.13 & $4.91 E-20$ & $3.92 \mathrm{E}-19$ \\
\hline RPL38 & -2.12 & 4.53E-247 & $2.20 E-244$ \\
\hline COX17 & -2.11 & $5.14 \mathrm{E}-26$ & $5.86 \mathrm{E}-25$ \\
\hline NFE2 & -2.10 & $7.00 E-10$ & $2.63 \mathrm{E}-09$ \\
\hline RAB26 & -2.09 & $1.66 \mathrm{E}-09$ & $6.04 E-09$ \\
\hline NAPRT1 & -2.09 & $1.48 \mathrm{E}-116$ & $2.20 E-114$ \\
\hline CDK5 & -2.08 & $1.31 E-28$ & $1.67 \mathrm{E}-27$ \\
\hline NUCB2 & -2.08 & $2.91 \mathrm{E}-88$ & $2.49 \mathrm{E}-86$ \\
\hline CEBPD & -2.07 & $5.29 E-83$ & $4.08 \mathrm{E}-81$ \\
\hline DYNC2LI1 & -2.07 & $5.50 \mathrm{E}-21$ & $4.63 E-20$ \\
\hline RPL34 & -2.06 & $6.26 \mathrm{E}-174$ & $1.88 \mathrm{E}-171$ \\
\hline SNRPF & -2.06 & 3.85E-103 & $4.39 E-101$ \\
\hline BCKDHB & -2.05 & $9.69 \mathrm{E}-26$ & $1.09 \mathrm{E}-24$ \\
\hline ANXA1 & -2.04 & 0 & 0 \\
\hline RARS2 & -2.04 & $4.40 E-37$ & $8.15 E-36$ \\
\hline CYP4F11 & -2.04 & $1.11 \mathrm{E}-18$ & $8.08 \mathrm{E}-18$ \\
\hline SPC24 & -2.03 & $1.42 \mathrm{E}-17$ & $9.58 \mathrm{E}-17$ \\
\hline PTP4A3 & -2.02 & $4.47 E-19$ & $3.34 E-18$ \\
\hline LOC728190 & -2.02 & $1.35 E-12$ & $6.39 E-12$ \\
\hline PSME1 & -2.01 & $1.62 E-81$ & $1.20 \mathrm{E}-79$ \\
\hline POLE2 & -2.00 & $3.59 E-57$ & $1.37 \mathrm{E}-55$ \\
\hline NSMCE4A & -2.00 & $1.78 \mathrm{E}-61$ & $7.54 \mathrm{E}-60$ \\
\hline FRA10AC1 & -2.00 & $6.45 E-43$ & $1.50 \mathrm{E}-41$ \\
\hline RPS12 & -2.00 & $2.44 \mathrm{E}-295$ & $1.47 \mathrm{E}-292$ \\
\hline MTRNR2L2 & -2.00 & 4.85E-167 & 1.33E-164 \\
\hline TYMP & -2.00 & $1.58 \mathrm{E}-35$ & $2.74 \mathrm{E}-34$ \\
\hline RPL11 & -2.00 & 0 & 0 \\
\hline CCDC152 & -1.99 & $6.61 E-10$ & $2.49 E-09$ \\
\hline MXD3 & -1.96 & $3.65 E-27$ & $4.38 E-26$ \\
\hline IL17RC & -1.95 & $3.51 E-23$ & $3.39 E-22$ \\
\hline GRB7 & -1.95 & $1.64 E-32$ & $2.49 \mathrm{E}-31$ \\
\hline LOC441454 & -1.94 & $8.75 E-10$ & $3.24 \mathrm{E}-09$ \\
\hline PCCA & -1.94 & $1.00 E-21$ & $8.91 \mathrm{E}-21$ \\
\hline ACBD4 & -1.94 & $2.15 E-40$ & $4.51 \mathrm{E}-39$ \\
\hline APLP1 & -1.93 & $7.74 \mathrm{E}-24$ & $7.77 \mathrm{E}-23$ \\
\hline QARS & -1.93 & $2.90 E-156$ & $6.93 E-154$ \\
\hline STX8 & -1.93 & $7.69 \mathrm{E}-26$ & $8.67 \mathrm{E}-25$ \\
\hline TM2D1 & -1.92 & $8.60 \mathrm{E}-25$ & $9.14 \mathrm{E}-24$ \\
\hline C17orf61 & -1.92 & $1.03 E-53$ & $3.49 \mathrm{E}-52$ \\
\hline LOC100507156 & -1.91 & $2.19 E-24$ & $2.27 E-23$ \\
\hline KCNAB2 & -1.89 & 1.65E-43 & $3.93 E-42$ \\
\hline CERS4 & -1.88 & $1.66 \mathrm{E}-27$ & $2.01 E-26$ \\
\hline C18orf8 & -1.86 & $1.06 \mathrm{E}-73$ & $6.36 E-72$ \\
\hline NOTCH3 & -1.86 & $1.46 \mathrm{E}-16$ & $9.26 \mathrm{E}-16$ \\
\hline LHPP & -1.86 & $1.93 \mathrm{E}-12$ & $9.03 E-12$ \\
\hline GNG7 & -1.85 & $2.37 \mathrm{E}-13$ & $1.19 \mathrm{E}-12$ \\
\hline RTN2 & -1.85 & $2.10 E-09$ & 7.55E-09 \\
\hline SEMA3B & -1.84 & $2.45 E-16$ & $1.52 \mathrm{E}-15$ \\
\hline IL6 & -1.84 & $5.35 \mathrm{E}-17$ & $3.49 \mathrm{E}-16$ \\
\hline LOC644961 & -1.84 & $1.43 \mathrm{E}-11$ & $6.24 \mathrm{E}-11$ \\
\hline$J P X$ & -1.83 & $7.74 \mathrm{E}-11$ & $3.17 E-10$ \\
\hline CHCHD6 & -1.83 & $7.00 E-19$ & $5.14 \mathrm{E}-18$ \\
\hline
\end{tabular}


Table 3 continued

\begin{tabular}{|c|c|c|c|}
\hline Gene symbol & $\log \mathrm{FC}$ & $P$ value & FDR \\
\hline PNPLA6 & -1.83 & $3.33 \mathrm{E}-86$ & $2.77 \mathrm{E}-84$ \\
\hline FBLN1 & -1.82 & $5.31 \mathrm{E}-33$ & $8.33 E-32$ \\
\hline SIDT2 & -1.81 & $5.19 \mathrm{E}-40$ & $1.07 E-38$ \\
\hline DEPTOR & -1.81 & $1.85 \mathrm{E}-10$ & 7.26E-10 \\
\hline ZNF826P & -1.81 & $1.25 E-08$ & $4.21 \mathrm{E}-08$ \\
\hline TTC39A & -1.81 & $4.87 \mathrm{E}-17$ & $3.18 \mathrm{E}-16$ \\
\hline TM7SF2 & -1.81 & $1.91 \mathrm{E}-67$ & $9.80 \mathrm{E}-66$ \\
\hline ELMO3 & -1.81 & $2.54 \mathrm{E}-22$ & $2.33 \mathrm{E}-21$ \\
\hline OOEP & -1.81 & $8.06 \mathrm{E}-10$ & $3.00 E-09$ \\
\hline DNAJC17 & -1.81 & $1.40 E-14$ & $7.72 \mathrm{E}-14$ \\
\hline TCEA2 & -1.80 & $1.83 \mathrm{E}-36$ & $3.29 E-35$ \\
\hline SLC22A18 & -1.80 & $1.89 E-19$ & $1.45 E-18$ \\
\hline ALDH3B1 & -1.80 & $3.28 \mathrm{E}-68$ & $1.70 E-66$ \\
\hline LOC100130872 & -1.80 & $6.08 \mathrm{E}-10$ & $2.30 E-09$ \\
\hline ETFA & -1.79 & $1.34 \mathrm{E}-136$ & $2.74 E-134$ \\
\hline THYN1 & -1.79 & $9.07 \mathrm{E}-41$ & $1.92 E-39$ \\
\hline AKR1C3 & -1.78 & $1.37 \mathrm{E}-10$ & $5.47 \mathrm{E}-10$ \\
\hline MT1F & -1.78 & $1.45 \mathrm{E}-08$ & 4.86E-08 \\
\hline PIP5KL1 & -1.78 & $2.53 \mathrm{E}-10$ & $9.85 \mathrm{E}-10$ \\
\hline ATP5D & -1.78 & $1.68 \mathrm{E}-44$ & 4.13E-43 \\
\hline TMEM120A & -1.77 & $1.49 \mathrm{E}-25$ & $1.64 \mathrm{E}-24$ \\
\hline OSBPL5 & -1.77 & $3.00 E-09$ & $1.06 \mathrm{E}-08$ \\
\hline TENC1 & -1.77 & $2.65 \mathrm{E}-18$ & $1.89 \mathrm{E}-17$ \\
\hline $\mathrm{EPHX} 2$ & -1.76 & $3.95 \mathrm{E}-14$ & $2.10 E-13$ \\
\hline WDR83 & -1.76 & $4.37 \mathrm{E}-26$ & $4.99 E-25$ \\
\hline RUVBL2 & -1.75 & $8.63 E-147$ & $1.95 E-144$ \\
\hline KAZALD1 & -1.75 & $6.39 E-22$ & $5.77 \mathrm{E}-21$ \\
\hline RPA3 & -1.74 & $6.68 \mathrm{E}-41$ & $1.42 E-39$ \\
\hline NOXA1 & -1.74 & $1.23 \mathrm{E}-09$ & $4.49 E-09$ \\
\hline TMEM110-MUSTN1 & -1.74 & $5.21 \mathrm{E}-08$ & $1.65 \mathrm{E}-07$ \\
\hline CACNA2D2 & -1.74 & $8.47 \mathrm{E}-10$ & $3.14 \mathrm{E}-09$ \\
\hline DICER1-AS1 & -1.73 & $5.04 \mathrm{E}-10$ & $1.91 \mathrm{E}-09$ \\
\hline ABHD14A-ACY1 & -1.73 & $1.20 E-36$ & $2.19 \mathrm{E}-35$ \\
\hline GRAMD2 & -1.73 & $5.14 \mathrm{E}-08$ & $1.63 \mathrm{E}-07$ \\
\hline PPIH & -1.73 & $2.97 \mathrm{E}-19$ & $2.25 E-18$ \\
\hline STXBP2 & -1.73 & $2.73 \mathrm{E}-72$ & $1.55 \mathrm{E}-70$ \\
\hline C10orf10 & -1.73 & $3.54 \mathrm{E}-21$ & $3.02 E-20$ \\
\hline PLA2G6 & -1.73 & $5.59 \mathrm{E}-14$ & $2.93 \mathrm{E}-13$ \\
\hline CHEK2 & -1.72 & $1.79 \mathrm{E}-46$ & $4.82 \mathrm{E}-45$ \\
\hline SPAG4 & -1.72 & $2.30 E-15$ & $1.34 \mathrm{E}-14$ \\
\hline coG6 & -1.71 & $9.36 \mathrm{E}-37$ & $1.71 \mathrm{E}-35$ \\
\hline TBC1D17 & -1.71 & $7.78 \mathrm{E}-24$ & $7.79 E-23$ \\
\hline IFT52 & -1.71 & $6.78 \mathrm{E}-38$ & $1.30 E-36$ \\
\hline GARNL3 & -1.71 & $7.22 \mathrm{E}-11$ & $2.96 \mathrm{E}-10$ \\
\hline DLST & -1.70 & $2.44 \mathrm{E}-25$ & 2.67E-24 \\
\hline ACSF2 & -1.69 & $3.58 \mathrm{E}-13$ & $1.77 \mathrm{E}-12$ \\
\hline RYR1 & -1.69 & $4.48 \mathrm{E}-09$ & $1.57 \mathrm{E}-08$ \\
\hline LOC100134713 & -1.68 & $3.06 \mathrm{E}-12$ & $1.41 \mathrm{E}-11$ \\
\hline P2RY6 & -1.68 & $7.55 E-21$ & $6.27 \mathrm{E}-20$ \\
\hline RARRES3 & -1.68 & $3.75 E-07$ & $1.09 E-06$ \\
\hline C11orf80 & -1.67 & $5.34 \mathrm{E}-14$ & $2.81 \mathrm{E}-13$ \\
\hline ELF3 & -1.67 & $2.30 \mathrm{E}-48$ & $6.58 \mathrm{E}-47$ \\
\hline ADCK4 & -1.67 & $2.68 \mathrm{E}-40$ & $5.60 E-39$ \\
\hline
\end{tabular}

Table 3 continued

\begin{tabular}{|c|c|c|c|}
\hline Gene symbol & $\log \mathrm{FC}$ & $P$ value & FDR \\
\hline GLB1L & -1.67 & $5.33 \mathrm{E}-14$ & $2.80 \mathrm{E}-13$ \\
\hline LPPR3 & -1.67 & $1.58 \mathrm{E}-24$ & $1.66 \mathrm{E}-23$ \\
\hline CDK7 & -1.67 & $1.76 E-36$ & $3.16 \mathrm{E}-35$ \\
\hline SLC6A3 & -1.66 & $8.34 \mathrm{E}-08$ & $2.58 \mathrm{E}-07$ \\
\hline ADAM22 & -1.66 & $2.07 E-12$ & $9.64 \mathrm{E}-12$ \\
\hline EIF3K & -1.66 & $1.65 \mathrm{E}-98$ & $1.73 \mathrm{E}-96$ \\
\hline S100A4 & -1.65 & $7.75 E-10$ & $2.89 \mathrm{E}-09$ \\
\hline ANXA6 & -1.65 & $2.84 \mathrm{E}-85$ & $2.35 E-83$ \\
\hline IFT140 & -1.65 & $1.33 \mathrm{E}-25$ & $1.48 \mathrm{E}-24$ \\
\hline PDIA5 & -1.65 & $1.47 \mathrm{E}-23$ & $1.44 \mathrm{E}-22$ \\
\hline FADS3 & -1.65 & $2.21 E-48$ & $6.32 \mathrm{E}-47$ \\
\hline KCNK15 & -1.64 & $4.58 \mathrm{E}-21$ & $3.89 E-20$ \\
\hline FKBP10 & -1.64 & $8.94 \mathrm{E}-41$ & $1.89 E-39$ \\
\hline ACSS2 & -1.64 & 1.07E-94 & $1.06 \mathrm{E}-92$ \\
\hline GSTA4 & -1.64 & $2.80 E-31$ & $4.04 \mathrm{E}-30$ \\
\hline KCNMB4 & -1.64 & $8.53 E-07$ & $2.38 \mathrm{E}-06$ \\
\hline RPLP2 & -1.63 & $3.48 \mathrm{E}-220$ & $1.52 \mathrm{E}-217$ \\
\hline UROS & -1.63 & $2.54 E-42$ & $5.73 E-41$ \\
\hline IFT27 & -1.63 & $4.67 E-19$ & $3.49 \mathrm{E}-18$ \\
\hline TRAPPC9 & -1.63 & $6.82 E-28$ & $8.44 \mathrm{E}-27$ \\
\hline ADAMTSL4 & -1.62 & $5.48 \mathrm{E}-43$ & $1.28 \mathrm{E}-41$ \\
\hline EIF3E & -1.62 & $3.34 \mathrm{E}-248$ & $1.69 E-245$ \\
\hline ACY1 & -1.62 & $2.83 E-30$ & $3.87 E-29$ \\
\hline MT1X & -1.62 & $4.27 E-24$ & $4.36 \mathrm{E}-23$ \\
\hline LOC643406 & -1.61 & $4.55 \mathrm{E}-16$ & $2.79 \mathrm{E}-15$ \\
\hline FBXO36 & -1.61 & $1.48 \mathrm{E}-14$ & $8.12 \mathrm{E}-14$ \\
\hline PACSIN1 & -1.61 & $5.93 \mathrm{E}-08$ & $1.87 \mathrm{E}-07$ \\
\hline NIT2 & -1.61 & $4.39 \mathrm{E}-45$ & $1.10 \mathrm{E}-43$ \\
\hline FUZ & -1.60 & $3.08 \mathrm{E}-12$ & $1.42 \mathrm{E}-11$ \\
\hline RPL37 & -1.60 & $2.00 \mathrm{E}-301$ & $1.27 E-298$ \\
\hline $\mathrm{ALDH} 4 \mathrm{~A} 1$ & -1.60 & $2.17 E-17$ & $1.45 E-16$ \\
\hline PDCD5 & -1.60 & $6.19 \mathrm{E}-65$ & $2.92 \mathrm{E}-63$ \\
\hline MFSD3 & -1.60 & $3.51 \mathrm{E}-31$ & $5.00 \mathrm{E}-30$ \\
\hline EML3 & -1.60 & $1.27 E-64$ & $5.92 \mathrm{E}-63$ \\
\hline PSMA3 & -1.60 & $1.93 \mathrm{E}-96$ & $1.96 \mathrm{E}-94$ \\
\hline TRPT1 & -1.59 & $2.64 \mathrm{E}-23$ & $2.56 \mathrm{E}-22$ \\
\hline ALDH6A1 & -1.59 & $9.68 \mathrm{E}-21$ & $8.00 \mathrm{E}-20$ \\
\hline LOC283038 & -1.59 & $3.12 \mathrm{E}-11$ & $1.32 \mathrm{E}-10$ \\
\hline $\mathrm{BDH} 2$ & -1.59 & $1.27 \mathrm{E}-17$ & $8.59 E-17$ \\
\hline $\mathrm{SDHB}$ & -1.59 & $1.43 \mathrm{E}-70$ & $7.78 \mathrm{E}-69$ \\
\hline ARHGEF25 & -1.59 & $1.35 E-29$ & $1.79 E-28$ \\
\hline CYS1 & -1.58 & $4.38 \mathrm{E}-08$ & $1.40 \mathrm{E}-07$ \\
\hline C8orf45 & -1.58 & $4.42 \mathrm{E}-08$ & $1.41 \mathrm{E}-07$ \\
\hline GLTSCR2 & -1.57 & $4.94 \mathrm{E}-46$ & $1.30 E-44$ \\
\hline JMJD8 & -1.57 & $3.93 \mathrm{E}-28$ & $4.90 E-27$ \\
\hline ANKRD24 & -1.57 & $1.17 \mathrm{E}-07$ & $3.56 \mathrm{E}-07$ \\
\hline SNURF & -1.57 & $6.25 E-68$ & $3.23 \mathrm{E}-66$ \\
\hline SNRPN & -1.57 & $6.43 E-68$ & $3.31 \mathrm{E}-66$ \\
\hline RCN3 & -1.57 & $1.28 \mathrm{E}-15$ & $7.56 \mathrm{E}-15$ \\
\hline LACTB2 & -1.57 & $2.50 \mathrm{E}-78$ & $1.75 \mathrm{E}-76$ \\
\hline HSF4 & -1.56 & $1.23 \mathrm{E}-13$ & $6.27 E-13$ \\
\hline ENDOV & -1.56 & $4.24 \mathrm{E}-09$ & $1.48 \mathrm{E}-08$ \\
\hline CPT1C & -1.55 & $4.07 E-07$ & $1.17 \mathrm{E}-06$ \\
\hline
\end{tabular}


Table 3 continued

\begin{tabular}{|c|c|c|c|}
\hline Gene symbol & $\log \mathrm{FC}$ & $P$ value & FDR \\
\hline ITFG1 & -1.55 & $1.10 \mathrm{E}-88$ & $9.66 \mathrm{E}-87$ \\
\hline IL11RA & -1.55 & $2.61 \mathrm{E}-11$ & $1.12 \mathrm{E}-10$ \\
\hline FRG1 & -1.55 & $2.08 \mathrm{E}-08$ & $6.87 \mathrm{E}-08$ \\
\hline CCDC104 & -1.54 & $8.93 E-31$ & $1.25 E-29$ \\
\hline CERS1 & -1.54 & 4.07E-08 & $1.30 \mathrm{E}-07$ \\
\hline GDF1 & -1.54 & 4.07E-08 & $1.30 \mathrm{E}-07$ \\
\hline USP4 & -1.54 & 4.05E-13 & $2.00 E-12$ \\
\hline PLCD1 & -1.54 & $6.66 \mathrm{E}-14$ & $3.47 \mathrm{E}-13$ \\
\hline PBXIP1 & -1.54 & $5.25 E-37$ & $9.70 E-36$ \\
\hline NDUFC1 & -1.54 & $1.61 \mathrm{E}-42$ & $3.66 \mathrm{E}-41$ \\
\hline CEP70 & -1.54 & $5.71 \mathrm{E}-59$ & $2.29 E-57$ \\
\hline MFSD4 & -1.54 & $2.40 \mathrm{E}-07$ & $7.10 \mathrm{E}-07$ \\
\hline ARPC4-TTLL3 & -1.53 & $3.34 \mathrm{E}-25$ & $3.64 \mathrm{E}-24$ \\
\hline XRCC1 & -1.53 & $7.89 \mathrm{E}-35$ & $1.33 E-33$ \\
\hline CLDN4 & -1.52 & $2.47 \mathrm{E}-20$ & $2.00 E-19$ \\
\hline VWA5A & -1.52 & 7.77E-10 & $2.90 E-09$ \\
\hline PC & -1.52 & $1.73 E-20$ & $1.41 \mathrm{E}-19$ \\
\hline MMP11 & -1.52 & $1.58 \mathrm{E}-09$ & $5.74 \mathrm{E}-09$ \\
\hline C9orf84 & -1.52 & $1.04 \mathrm{E}-28$ & $1.33 \mathrm{E}-27$ \\
\hline SLC37A2 & -1.52 & $1.08 \mathrm{E}-06$ & $2.99 \mathrm{E}-06$ \\
\hline SUPT3H & -1.52 & $5.13 \mathrm{E}-12$ & $2.33 E-11$ \\
\hline SLC44A3 & -1.52 & $1.17 \mathrm{E}-11$ & $5.15 E-11$ \\
\hline UNC93B1 & -1.52 & $6.48 \mathrm{E}-37$ & $1.19 E-35$ \\
\hline SLC38A6 & -1.52 & $1.32 \mathrm{E}-13$ & $6.69 E-13$ \\
\hline NDUFA1 & -1.51 & $4.88 \mathrm{E}-40$ & $1.01 \mathrm{E}-38$ \\
\hline TMEM205 & -1.51 & $4.08 \mathrm{E}-37$ & $7.58 \mathrm{E}-36$ \\
\hline ZCRB1 & -1.51 & $2.46 \mathrm{E}-88$ & $2.13 E-86$ \\
\hline BRSK1 & -1.50 & $7.65 E-10$ & $2.86 \mathrm{E}-09$ \\
\hline HDAC5 & -1.50 & $3.47 \mathrm{E}-33$ & $5.53 \mathrm{E}-32$ \\
\hline RNASEH2B & -1.50 & $1.90 E-22$ & 1.76E-21 \\
\hline CLASRP & -1.50 & $4.14 \mathrm{E}-23$ & $3.98 \mathrm{E}-22$ \\
\hline CAMK1 & -1.50 & $1.12 \mathrm{E}-21$ & $1.00 E-20$ \\
\hline C11orf10 & -1.49 & $1.26 \mathrm{E}-42$ & $2.91 \mathrm{E}-41$ \\
\hline PRKCSH & -1.49 & $5.06 \mathrm{E}-129$ & $9.41 \mathrm{E}-127$ \\
\hline PMF1-BGLAP & -1.49 & $3.71 \mathrm{E}-34$ & $6.12 E-33$ \\
\hline NFASC & -1.49 & $1.16 \mathrm{E}-05$ & $2.86 \mathrm{E}-05$ \\
\hline LTBP4 & -1.49 & $2.21 E-61$ & $9.29 \mathrm{E}-60$ \\
\hline LAMA5 & -1.49 & $2.31 E-160$ & $6.08 E-158$ \\
\hline LRSAM1 & -1.49 & $5.65 E-26$ & $6.42 \mathrm{E}-25$ \\
\hline $\mathrm{CTSH}$ & -1.48 & $6.14 \mathrm{E}-31$ & $8.67 \mathrm{E}-30$ \\
\hline HEXB & -1.48 & $7.22 \mathrm{E}-108$ & $8.96 \mathrm{E}-106$ \\
\hline MGST2 & -1.48 & 1.97E-09 & 7.13E-09 \\
\hline $\mathrm{FAH}$ & -1.48 & $8.07 \mathrm{E}-22$ & $7.23 E-21$ \\
\hline PEX7 & -1.48 & $2.91 \mathrm{E}-14$ & $1.56 \mathrm{E}-13$ \\
\hline C5 & -1.48 & $1.05 \mathrm{E}-11$ & $4.64 \mathrm{E}-11$ \\
\hline ACADS & -1.48 & $2.02 \mathrm{E}-21$ & $1.76 \mathrm{E}-20$ \\
\hline IFT43 & -1.47 & $9.38 \mathrm{E}-15$ & $5.24 \mathrm{E}-14$ \\
\hline JAK3 & -1.47 & $6.46 \mathrm{E}-12$ & $2.90 E-11$ \\
\hline MRPL39 & -1.47 & $1.89 E-45$ & $4.88 \mathrm{E}-44$ \\
\hline SLC43A1 & -1.47 & $3.84 \mathrm{E}-08$ & $1.23 \mathrm{E}-07$ \\
\hline EFEMP2 & -1.47 & $9.20 \mathrm{E}-07$ & $2.56 \mathrm{E}-06$ \\
\hline SSBP4 & -1.47 & $1.48 \mathrm{E}-14$ & $8.14 \mathrm{E}-14$ \\
\hline IMMP1L & -1.47 & $1.82 \mathrm{E}-07$ & $5.46 \mathrm{E}-07$ \\
\hline
\end{tabular}

Table 3 continued

\begin{tabular}{|c|c|c|c|}
\hline Gene symbol & $\log \mathrm{FC}$ & $P$ value & FDR \\
\hline GPR108 & -1.47 & $1.33 \mathrm{E}-60$ & $5.50 \mathrm{E}-59$ \\
\hline WDR54 & -1.46 & $4.01 \mathrm{E}-38$ & $7.75 E-37$ \\
\hline ARHGAP8 & -1.46 & $4.37 \mathrm{E}-14$ & $2.32 \mathrm{E}-13$ \\
\hline RPL35A & -1.46 & $8.72 E-183$ & $2.76 \mathrm{E}-180$ \\
\hline GBP2 & -1.46 & $7.43 E-12$ & $3.31 \mathrm{E}-11$ \\
\hline TECR & -1.46 & $1.15 E-73$ & $6.86 \mathrm{E}-72$ \\
\hline $\mathrm{AUH}$ & -1.46 & $1.97 \mathrm{E}-08$ & $6.54 \mathrm{E}-08$ \\
\hline PRR5-ARHGAP8 & -1.46 & $1.99 \mathrm{E}-14$ & $1.08 \mathrm{E}-13$ \\
\hline LINC00263 & -1.45 & $7.89 \mathrm{E}-17$ & $5.07 \mathrm{E}-16$ \\
\hline PDLIM2 & -1.45 & $2.48 \mathrm{E}-44$ & $6.06 \mathrm{E}-43$ \\
\hline RASA2 & -1.45 & $1.41 \mathrm{E}-19$ & $1.09 \mathrm{E}-18$ \\
\hline PTPN6 & -1.45 & $1.25 E-36$ & $2.27 \mathrm{E}-35$ \\
\hline PARL & -1.45 & $2.07 \mathrm{E}-65$ & $1.00 E-63$ \\
\hline CERCAM & -1.45 & $1.71 \mathrm{E}-74$ & $1.04 \mathrm{E}-72$ \\
\hline RPL37A & -1.45 & $3.14 \mathrm{E}-201$ & $1.14 \mathrm{E}-198$ \\
\hline ARRDC3 & -1.45 & $2.82 \mathrm{E}-84$ & $2.26 \mathrm{E}-82$ \\
\hline NAE1 & -1.45 & $1.38 \mathrm{E}-78$ & $9.72 \mathrm{E}-77$ \\
\hline MYZAP & -1.45 & $7.55 \mathrm{E}-09$ & $2.60 E-08$ \\
\hline $\mathrm{FBXO} 2$ & -1.44 & $3.57 \mathrm{E}-23$ & $3.45 \mathrm{E}-22$ \\
\hline C1QL1 & -1.44 & $1.45 \mathrm{E}-18$ & $1.05 \mathrm{E}-17$ \\
\hline FDPS & -1.44 & $1.12 E-208$ & 4.30E-206 \\
\hline FER1L4 & -1.44 & $2.19 \mathrm{E}-34$ & $3.63 E-33$ \\
\hline TMEM8B & -1.44 & $2.90 E-24$ & $3.00 E-23$ \\
\hline THOC6 & -1.44 & $1.49 E-31$ & $2.17 \mathrm{E}-30$ \\
\hline DMPK & -1.43 & $9.94 \mathrm{E}-26$ & $1.1 \mathrm{IE}-24$ \\
\hline RNF181 & -1.43 & $1.88 \mathrm{E}-42$ & $4.26 \mathrm{E}-41$ \\
\hline GUK1 & -1.43 & $3.52 \mathrm{E}-94$ & $3.37 \mathrm{E}-92$ \\
\hline GHDC & -1.43 & $2.52 \mathrm{E}-15$ & $1.47 \mathrm{E}-14$ \\
\hline GRAMD1A & -1.43 & $1.76 \mathrm{E}-70$ & $9.52 \mathrm{E}-69$ \\
\hline SYTL2 & -1.43 & $3.67 \mathrm{E}-25$ & $3.98 \mathrm{E}-24$ \\
\hline LEPR & -1.43 & $7.79 E-22$ & $7.01 \mathrm{E}-21$ \\
\hline FL22184 & -1.43 & $9.59 \mathrm{E}-18$ & $6.57 \mathrm{E}-17$ \\
\hline EXOSC9 & -1.42 & $5.87 \mathrm{E}-47$ & $1.59 \mathrm{E}-45$ \\
\hline MMAB & -1.42 & $2.1 \mathrm{IE}-37$ & $4.00 E-36$ \\
\hline KRT86 & -1.42 & $1.20 \mathrm{E}-05$ & $2.96 \mathrm{E}-05$ \\
\hline ABHD1 & -1.42 & $7.52 \mathrm{E}-08$ & $2.34 \mathrm{E}-07$ \\
\hline HOOK2 & -1.42 & $1.59 \mathrm{E}-22$ & $1.48 \mathrm{E}-21$ \\
\hline PCSK4 & -1.42 & $1.40 E-10$ & $5.56 \mathrm{E}-10$ \\
\hline TMC6 & -1.42 & $1.82 \mathrm{E}-28$ & $2.31 \mathrm{E}-27$ \\
\hline GDPD1 & -1.42 & $6.19 \mathrm{E}-06$ & 1.57E-05 \\
\hline LRRC23 & -1.42 & $5.41 \mathrm{E}-11$ & $2.25 \mathrm{E}-10$ \\
\hline PION & -1.42 & $3.83 E-12$ & $1.75 \mathrm{E}-11$ \\
\hline $\mathrm{BCL} 7 \mathrm{C}$ & -1.42 & $9.48 \mathrm{E}-37$ & $1.73 E-35$ \\
\hline YPEL3 & -1.41 & $2.79 E-10$ & $1.08 \mathrm{E}-09$ \\
\hline RAD51B & -1.41 & $7.17 \mathrm{E}-15$ & $4.03 E-14$ \\
\hline ANXA4 & -1.41 & $3.39 E-64$ & $1.55 \mathrm{E}-62$ \\
\hline B4GALNT4 & -1.41 & $8.74 \mathrm{E}-13$ & $4.18 \mathrm{E}-12$ \\
\hline COX7B & -1.41 & $1.11 \mathrm{E}-66$ & $5.56 \mathrm{E}-65$ \\
\hline PRKCZ & -1.41 & $1.76 \mathrm{E}-15$ & $1.03 E-14$ \\
\hline RAB4B & -1.41 & $2.43 \mathrm{E}-21$ & $2.10 E-20$ \\
\hline C4orf34 & -1.40 & $1.44 \mathrm{E}-38$ & $2.81 \mathrm{E}-37$ \\
\hline STXIO & -1.40 & $2.42 \mathrm{E}-15$ & $1.41 \mathrm{E}-14$ \\
\hline CRELD2 & -1.40 & $5.50 E-24$ & $5.57 \mathrm{E}-23$ \\
\hline
\end{tabular}


Table 3 continued

\begin{tabular}{|c|c|c|c|}
\hline Gene symbol & $\log \mathrm{FC}$ & P value & FDR \\
\hline ATP5E & -1.39 & $6.27 \mathrm{E}-93$ & $5.87 \mathrm{E}-91$ \\
\hline ESD & -1.39 & $1.48 \mathrm{E}-75$ & $9.39 E-74$ \\
\hline MIA-RAB4B & -1.39 & $1.84 \mathrm{E}-21$ & $1.61 \mathrm{E}-20$ \\
\hline NDUFA13 & -1.39 & $5.54 \mathrm{E}-58$ & $2.17 \mathrm{E}-56$ \\
\hline SNX14 & -1.39 & $3.32 \mathrm{E}-75$ & $2.09 E-73$ \\
\hline MRPL13 & -1.39 & $2.86 \mathrm{E}-44$ & $6.97 E-43$ \\
\hline PTPRH & -1.39 & $7.14 \mathrm{E}-18$ & $4.93 E-17$ \\
\hline BBS5 & -1.39 & $2.36 \mathrm{E}-32$ & $3.55 \mathrm{E}-31$ \\
\hline LMBRD1 & -1.38 & $4.17 \mathrm{E}-25$ & $4.50 E-24$ \\
\hline $\mathrm{IQCH}$ & -1.38 & $4.75 E-08$ & $1.51 \mathrm{E}-07$ \\
\hline LMTK3 & -1.38 & $4.13 E-14$ & $2.19 \mathrm{E}-13$ \\
\hline MIR497HG & -1.38 & $6.24 \mathrm{E}-12$ & $2.81 \mathrm{E}-11$ \\
\hline C6orf70 & -1.38 & $3.13 \mathrm{E}-25$ & $3.41 \mathrm{E}-24$ \\
\hline FGGY & -1.38 & $5.12 \mathrm{E}-07$ & $1.46 \mathrm{E}-06$ \\
\hline UNC5CL & -1.38 & $1.66 \mathrm{E}-08$ & $5.52 \mathrm{E}-08$ \\
\hline DUT & -1.38 & $8.03 E-114$ & $1.13 E-111$ \\
\hline $\mathrm{P} 2 \mathrm{RX} 4$ & -1.38 & $2.17 E-20$ & $1.76 \mathrm{E}-19$ \\
\hline HHIPL2 & -1.38 & $4.20 \mathrm{E}-06$ & $1.09 \mathrm{E}-05$ \\
\hline $\operatorname{COX} 5 \mathrm{~A}$ & -1.38 & $3.09 \mathrm{E}-79$ & $2.21 \mathrm{E}-77$ \\
\hline CKLF & -1.37 & $6.08 \mathrm{E}-34$ & $9.94 \mathrm{E}-33$ \\
\hline CRYZL1 & -1.37 & $7.16 \mathrm{E}-27$ & $8.45 E-26$ \\
\hline GSTM4 & -1.37 & $6.05 E-20$ & $4.80 E-19$ \\
\hline DNAH14 & -1.37 & $3.44 \mathrm{E}-11$ & $1.45 E-10$ \\
\hline TCTN1 & -1.37 & $6.80 E-12$ & $3.05 E-11$ \\
\hline CBX3P2 & -1.36 & $2.01 \mathrm{E}-06$ & $5.42 \mathrm{E}-06$ \\
\hline PTH1R & -1.36 & 0.000133911 & 0.000291689 \\
\hline SEMA6C & -1.36 & $2.31 \mathrm{E}-09$ & $8.29 E-09$ \\
\hline PIR & -1.36 & $2.10 E-31$ & $3.03 E-30$ \\
\hline DRAP1 & -1.36 & $2.70 \mathrm{E}-101$ & $2.90 E-99$ \\
\hline SCP2 & -1.36 & $1.15 E-12$ & $5.47 \mathrm{E}-12$ \\
\hline GMDS & -1.36 & $8.89 E-18$ & $6.10 E-17$ \\
\hline FRG1B & -1.36 & $9.55 E-13$ & $4.56 \mathrm{E}-12$ \\
\hline DECR1 & -1.35 & $4.15 E-35$ & $7.08 \mathrm{E}-34$ \\
\hline CTAGE5 & -1.35 & 4.25E-40 & $8.82 E-39$ \\
\hline NPM3 & -1.35 & $1.82 \mathrm{E}-40$ & $3.82 E-39$ \\
\hline AASS & -1.35 & $2.75 \mathrm{E}-05$ & $6.49 E-05$ \\
\hline ZC3H6 & -1.35 & $1.1 \mathrm{IE}-29$ & $1.48 \mathrm{E}-28$ \\
\hline C6orf203 & -1.35 & $2.06 \mathrm{E}-08$ & $6.82 \mathrm{E}-08$ \\
\hline ADAMTS13 & -1.35 & $1.19 \mathrm{E}-11$ & $5.23 E-11$ \\
\hline UBXN11 & -1.35 & $2.01 E-06$ & $5.42 \mathrm{E}-06$ \\
\hline C10orf54 & -1.35 & $3.00 E-63$ & $1.32 \mathrm{E}-61$ \\
\hline LSS & -1.35 & $7.02 \mathrm{E}-41$ & $1.49 \mathrm{E}-39$ \\
\hline $\mathrm{KLC} 4$ & -1.35 & $7.74 \mathrm{E}-09$ & $2.66 \mathrm{E}-08$ \\
\hline ITGB3BP & -1.35 & $6.76 \mathrm{E}-11$ & $2.78 \mathrm{E}-10$ \\
\hline TKTL1 & -1.35 & $2.72 \mathrm{E}-12$ & $1.26 \mathrm{E}-11$ \\
\hline C10orf55 & -1.34 & $1.16 \mathrm{E}-63$ & $5.16 \mathrm{E}-62$ \\
\hline CRELD1 & -1.34 & $1.99 \mathrm{E}-20$ & $1.62 \mathrm{E}-19$ \\
\hline ADSSL1 & -1.34 & $2.20 E-21$ & $1.91 \mathrm{E}-20$ \\
\hline ALKBH7 & -1.34 & $1.62 \mathrm{E}-27$ & $1.97 \mathrm{E}-26$ \\
\hline AIFM3 & -1.34 & $5.13 \mathrm{E}-07$ & $1.47 \mathrm{E}-06$ \\
\hline LLGL2 & -1.34 & $2.44 \mathrm{E}-09$ & $8.76 \mathrm{E}-09$ \\
\hline SLC27A1 & -1.34 & $1.99 \mathrm{E}-13$ & $9.99 E-13$ \\
\hline ZBTB8OS & -1.34 & $5.50 \mathrm{E}-20$ & 4.37E-19 \\
\hline
\end{tabular}

Table 3 continued

\begin{tabular}{|c|c|c|c|}
\hline Gene symbol & $\log F C$ & $P$ value & FDR \\
\hline ANKRD13D & -1.34 & $7.36 E-25$ & $7.86 \mathrm{E}-24$ \\
\hline C6orf57 & -1.34 & $3.31 \mathrm{E}-07$ & $9.64 \mathrm{E}-07$ \\
\hline GCAT & -1.33 & $8.16 \mathrm{E}-10$ & $3.04 \mathrm{E}-09$ \\
\hline TEX9 & -1.33 & $1.32 \mathrm{E}-05$ & $3.23 \mathrm{E}-05$ \\
\hline MAP2K5 & -1.33 & $9.00 \mathrm{E}-11$ & $3.66 \mathrm{E}-10$ \\
\hline SLC27A2 & -1.33 & $2.27 E-21$ & $1.97 \mathrm{E}-20$ \\
\hline LTBP3 & -1.33 & $2.53 E-43$ & $5.95 E-42$ \\
\hline LOC100287559 & -1.33 & $4.09 E-05$ & $9.47 \mathrm{E}-05$ \\
\hline IFITM10 & -1.33 & $9.64 \mathrm{E}-09$ & $3.28 \mathrm{E}-08$ \\
\hline CRYL1 & -1.33 & $6.22 \mathrm{E}-10$ & $2.34 \mathrm{E}-09$ \\
\hline USH1C & -1.33 & $4.48 \mathrm{E}-09$ & $1.57 \mathrm{E}-08$ \\
\hline ZC3H12D & -1.33 & 0.000330901 & 0.000684453 \\
\hline $\mathrm{ERI} 2$ & -1.32 & 7.33E-09 & $2.53 \mathrm{E}-08$ \\
\hline TBX6 & -1.32 & 0.000899671 & 0.001760238 \\
\hline WBSCR22 & -1.32 & $1.53 \mathrm{E}-55$ & $5.53 \mathrm{E}-54$ \\
\hline GNB2L1 & -1.32 & $2.65 \mathrm{E}-272$ & 1.40E -269 \\
\hline LOC100131089 & -1.32 & $3.24 \mathrm{E}-08$ & $1.05 \mathrm{E}-07$ \\
\hline EGFL7 & -1.32 & $8.28 \mathrm{E}-37$ & $1.52 \mathrm{E}-35$ \\
\hline PIM3 & -1.31 & $6.31 \mathrm{E}-67$ & $3.18 \mathrm{E}-65$ \\
\hline NUCB1 & -1.31 & $1.86 \mathrm{E}-79$ & $1.34 \mathrm{E}-77$ \\
\hline FDXR & -1.31 & $1.08 \mathrm{E}-19$ & $8.38 \mathrm{E}-19$ \\
\hline EMID1 & -1.31 & $2.72 \mathrm{E}-09$ & $9.72 \mathrm{E}-09$ \\
\hline PIBF1 & -1.31 & $2.54 \mathrm{E}-16$ & $1.58 \mathrm{E}-15$ \\
\hline $\mathrm{HIBCH}$ & -1.30 & $1.13 E-15$ & $6.72 E-15$ \\
\hline RPS7 & -1.30 & $4.23 E-158$ & $1.05 E-155$ \\
\hline BIK & -1.30 & $5.76 \mathrm{E}-06$ & $1.47 \mathrm{E}-05$ \\
\hline TCP11L2 & -1.30 & $9.98 \mathrm{E}-07$ & $2.77 \mathrm{E}-06$ \\
\hline TSNAX-DISC1 & -1.30 & $6.33 E-22$ & $5.72 \mathrm{E}-21$ \\
\hline OMA1 & -1.30 & $1.35 E-25$ & $1.50 E-24$ \\
\hline LOC100506990 & -1.30 & $3.51 E-09$ & $1.24 \mathrm{E}-08$ \\
\hline TSTD1 & -1.30 & $7.46 \mathrm{E}-28$ & $9.23 \mathrm{E}-27$ \\
\hline KISS1R & -1.30 & 0.000386067 & 0.000792495 \\
\hline BCKDHA & -1.29 & $2.10 E-43$ & $4.98 \mathrm{E}-42$ \\
\hline B9D1 & -1.29 & $3.14 E-13$ & $1.56 \mathrm{E}-12$ \\
\hline ZNF695 & -1.29 & $8.45 E-10$ & $3.14 \mathrm{E}-09$ \\
\hline TMEM63B & -1.29 & $2.19 E-69$ & $1.17 \mathrm{E}-67$ \\
\hline MOSPD3 & -1.29 & $8.70 E-19$ & $6.37 \mathrm{E}-18$ \\
\hline RNASE4 & -1.29 & $2.00 E-27$ & $2.42 \mathrm{E}-26$ \\
\hline UGGT2 & -1.29 & $6.04 E-21$ & $5.06 \mathrm{E}-20$ \\
\hline SEMA3F & -1.29 & $2.32 \mathrm{E}-19$ & 1.77E-18 \\
\hline RPS24 & -1.29 & $6.92 \mathrm{E}-214$ & $2.83 \mathrm{E}-211$ \\
\hline DAK & -1.29 & $4.77 \mathrm{E}-62$ & $2.04 \mathrm{E}-60$ \\
\hline LOC100130691 & -1.29 & 0.000198722 & 0.0004236 \\
\hline CTU2 & -1.29 & $1.68 \mathrm{E}-13$ & $8.48 \mathrm{E}-13$ \\
\hline PLD3 & -1.29 & $7.26 \mathrm{E}-45$ & $1.81 E-43$ \\
\hline RHOV & -1.29 & $2.06 E-15$ & $1.20 \mathrm{E}-14$ \\
\hline CHPT1 & -1.29 & $5.19 E-67$ & $2.64 \mathrm{E}-65$ \\
\hline ACSM3 & -1.29 & $3.03 \mathrm{E}-11$ & $1.29 \mathrm{E}-10$ \\
\hline RPS25 & -1.28 & $4.03 E-185$ & $1.31 \mathrm{E}-182$ \\
\hline OASL & -1.28 & $2.48 \mathrm{E}-11$ & 1.06E-10 \\
\hline RPLP1 & -1.28 & $7.23 E-219$ & $3.05 E-216$ \\
\hline C19orf79 & -1.28 & $2.43 \mathrm{E}-11$ & $1.04 \mathrm{E}-10$ \\
\hline IL20RB & -1.28 & $1.18 \mathrm{E}-09$ & 4.32E-09 \\
\hline
\end{tabular}


Table 3 continued

\begin{tabular}{|c|c|c|c|}
\hline Gene symbol & $\log \mathrm{FC}$ & P value & FDR \\
\hline CACNG6 & -1.28 & $1.23 \mathrm{E}-05$ & $3.02 E-05$ \\
\hline TBCE & -1.28 & $1.40 E-28$ & $1.78 \mathrm{E}-27$ \\
\hline FBXO16 & -1.28 & 0.00019181 & 0.000409623 \\
\hline LOC100505549 & -1.28 & $9.29 E-06$ & $2.31 E-05$ \\
\hline LOC100507218 & -1.28 & 0.000213956 & 0.000453549 \\
\hline TLR5 & -1.28 & 0.000112273 & 0.000247109 \\
\hline EML2 & -1.28 & $1.54 \mathrm{E}-14$ & $8.42 \mathrm{E}-14$ \\
\hline NPM1 & -1.28 & $3.12 E-138$ & $6.48 E-136$ \\
\hline GAA & -1.28 & $1.30 E-32$ & $1.99 E-31$ \\
\hline NKD2 & -1.28 & $4.23 \mathrm{E}-10$ & $1.61 \mathrm{E}-09$ \\
\hline CRIP2 & -1.28 & $8.19 E-11$ & $3.34 \mathrm{E}-10$ \\
\hline LOC100132891 & -1.27 & $6.71 \mathrm{E}-07$ & $1.89 E-06$ \\
\hline ALG5 & -1.27 & $2.16 \mathrm{E}-16$ & $1.35 E-15$ \\
\hline PXK & -1.27 & $1.02 \mathrm{E}-14$ & $5.67 \mathrm{E}-14$ \\
\hline ADA & -1.27 & $6.1 \mathrm{IE}-14$ & $3.20 E-13$ \\
\hline GALE & -1.27 & $3.38 \mathrm{E}-45$ & $8.55 E-44$ \\
\hline PHGDH & -1.27 & $3.96 \mathrm{E}-113$ & $5.44 \mathrm{E}-111$ \\
\hline CREG2 & -1.27 & 0.000426556 & 0.000871508 \\
\hline MSLN & -1.27 & $2.53 \mathrm{E}-19$ & $1.93 \mathrm{E}-18$ \\
\hline GDPD5 & -1.27 & $1.22 \mathrm{E}-12$ & $5.80 \mathrm{E}-12$ \\
\hline ITGA7 & -1.27 & 5.07E-06 & 1.30E-05 \\
\hline LIG1 & -1.27 & $1.36 \mathrm{E}-27$ & $1.66 \mathrm{E}-26$ \\
\hline LRTOMT & -1.26 & $4.37 \mathrm{E}-06$ & $1.13 E-05$ \\
\hline C17orf49 & -1.26 & $1.37 \mathrm{E}-44$ & $3.39 E-43$ \\
\hline HMGN5 & -1.26 & $5.93 \mathrm{E}-07$ & $1.69 \mathrm{E}-06$ \\
\hline LOC100505624 & -1.26 & $4.04 \mathrm{E}-10$ & $1.55 E-09$ \\
\hline CATSPER1 & -1.25 & 0.000949224 & 0.00184719 \\
\hline TLE2 & -1.25 & $2.35 E-16$ & $1.46 \mathrm{E}-15$ \\
\hline CES3 & -1.25 & $5.98 \mathrm{E}-07$ & $1.70 E-06$ \\
\hline TTC35 & -1.25 & $7.52 \mathrm{E}-30$ & $1.01 \mathrm{E}-28$ \\
\hline C6orf72 & -1.25 & $2.65 E-33$ & $4.23 E-32$ \\
\hline RPS19 & -1.25 & $1.01 E-168$ & $2.84 E-166$ \\
\hline EVI5L & -1.25 & $3.82 E-23$ & $3.68 \mathrm{E}-22$ \\
\hline LOC81691 & -1.25 & $7.76 \mathrm{E}-11$ & 3.17E-10 \\
\hline PLEKHH3 & -1.25 & $5.91 \mathrm{E}-39$ & $1.17 \mathrm{E}-37$ \\
\hline LOC100507501 & -1.24 & $1.34 \mathrm{E}-06$ & $3.67 \mathrm{E}-06$ \\
\hline SLC25A5-AS1 & -1.24 & $2.22 \mathrm{E}-20$ & $1.80 E-19$ \\
\hline RPS8 & -1.24 & $1.41 \mathrm{E}-201$ & $5.25 E-199$ \\
\hline PPP1R7 & -1.24 & $3.54 \mathrm{E}-37$ & $6.58 \mathrm{E}-36$ \\
\hline MAGED2 & -1.24 & $4.04 \mathrm{E}-41$ & $8.64 \mathrm{E}-40$ \\
\hline CSTF3 & -1.24 & $1.10 E-12$ & $5.24 \mathrm{E}-12$ \\
\hline LINC00467 & -1.24 & $1.39 \mathrm{E}-17$ & $9.42 \mathrm{E}-17$ \\
\hline MAD2L2 & -1.24 & $4.26 \mathrm{E}-29$ & $5.54 \mathrm{E}-28$ \\
\hline PCCB & -1.24 & $2.05 E-53$ & $6.87 \mathrm{E}-52$ \\
\hline SEZ6L2 & -1.24 & $1.72 \mathrm{E}-27$ & $2.09 E-26$ \\
\hline FKBP2 & -1.24 & $8.99 E-30$ & $1.20 E-28$ \\
\hline DOCK6 & -1.24 & $4.80 \mathrm{E}-35$ & $8.13 E-34$ \\
\hline WIPI1 & -1.24 & $2.07 \mathrm{E}-06$ & $5.57 \mathrm{E}-06$ \\
\hline $\mathrm{ECH} 1$ & -1.23 & $5.12 \mathrm{E}-76$ & $3.32 \mathrm{E}-74$ \\
\hline OCEL1 & -1.23 & $7.19 \mathrm{E}-14$ & $3.74 \mathrm{E}-13$ \\
\hline ZNF385C & -1.23 & $2.37 \mathrm{E}-06$ & $6.31 \mathrm{E}-06$ \\
\hline ATP8B3 & -1.23 & $6.42 \mathrm{E}-24$ & $6.47 \mathrm{E}-23$ \\
\hline PAFAH1B2 & -1.23 & $8.05 E-25$ & $8.57 \mathrm{E}-24$ \\
\hline
\end{tabular}

Table 3 continued

\begin{tabular}{|c|c|c|c|}
\hline Gene symbol & $\log \mathrm{FC}$ & $P$ value & FDR \\
\hline TM4SF19-TCTEX1D & -1.23 & $1.23 \mathrm{E}-05$ & $3.02 \mathrm{E}-05$ \\
\hline SRPX & -1.23 & $5.84 \mathrm{E}-11$ & $2.42 \mathrm{E}-10$ \\
\hline SLC39A11 & -1.23 & $3.03 E-21$ & $2.60 \mathrm{E}-20$ \\
\hline TMEM41B & -1.22 & $5.82 \mathrm{E}-09$ & $2.02 E-08$ \\
\hline PADI2 & -1.22 & $3.51 \mathrm{E}-11$ & $1.48 \mathrm{E}-10$ \\
\hline STX4 & -1.22 & $8.39 E-28$ & $1.03 E-26$ \\
\hline MAP4K2 & -1.22 & $1.86 \mathrm{E}-20$ & $1.51 \mathrm{E}-19$ \\
\hline PXMP4 & -1.22 & $2.50 \mathrm{E}-07$ & $7.39 E-07$ \\
\hline TCIRG1 & -1.22 & $2.38 \mathrm{E}-41$ & $5.15 E-40$ \\
\hline SERPING1 & -1.22 & $8.23 \mathrm{E}-08$ & $2.55 \mathrm{E}-07$ \\
\hline IFI35 & -1.22 & $4.92 \mathrm{E}-13$ & $2.41 \mathrm{E}-12$ \\
\hline DPY19L1P1 & -1.22 & $3.99 \mathrm{E}-07$ & $1.15 \mathrm{E}-06$ \\
\hline MAN2B1 & -1.22 & $5.94 \mathrm{E}-48$ & $1.67 E-46$ \\
\hline FAF1 & -1.22 & $5.28 \mathrm{E}-51$ & $1.65 E-49$ \\
\hline $\mathrm{ZDHHC1}$ & -1.22 & $2.34 \mathrm{E}-06$ & $6.25 \mathrm{E}-06$ \\
\hline NAAA & -1.21 & $4.63 \mathrm{E}-11$ & $1.93 \mathrm{E}-10$ \\
\hline EFCAB11 & -1.21 & $4.21 \mathrm{E}-05$ & $9.73 \mathrm{E}-05$ \\
\hline $\mathrm{HSCB}$ & -1.21 & $1.67 \mathrm{E}-12$ & $7.85 \mathrm{E}-12$ \\
\hline FBXW9 & -1.21 & $2.21 \mathrm{E}-05$ & $5.28 \mathrm{E}-05$ \\
\hline ZNF467 & -1.21 & $1.19 \mathrm{E}-09$ & $4.36 \mathrm{E}-09$ \\
\hline ILVBL & -1.21 & $1.32 \mathrm{E}-44$ & $3.28 \mathrm{E}-43$ \\
\hline SDR16C5 & -1.21 & $4.72 \mathrm{E}-17$ & $3.09 E-16$ \\
\hline IQGAP2 & -1.21 & $6.21 \mathrm{E}-07$ & $1.76 \mathrm{E}-06$ \\
\hline SRGAP3 & -1.21 & $2.76 \mathrm{E}-05$ & $6.50 \mathrm{E}-05$ \\
\hline EGF & -1.21 & 0.000108319 & 0.000238866 \\
\hline ERGIC3 & -1.21 & $2.97 \mathrm{E}-63$ & $1.31 \mathrm{E}-61$ \\
\hline CYFIP2 & -1.21 & $3.35 E-14$ & $1.79 \mathrm{E}-13$ \\
\hline BCAS3 & -1.21 & $5.34 \mathrm{E}-23$ & $5.11 \mathrm{E}-22$ \\
\hline DOCK11 & -1.21 & $3.15 \mathrm{E}-11$ & $1.33 \mathrm{E}-10$ \\
\hline SLC37A1 & -1.21 & $1.67 \mathrm{E}-07$ & $5.02 \mathrm{E}-07$ \\
\hline HSD17B4 & -1.21 & 1.16E-54 & $4.10 \mathrm{E}-53$ \\
\hline NT5M & -1.21 & $7.71 \mathrm{E}-05$ & 0.000172918 \\
\hline SERINC5 & -1.20 & $2.82 \mathrm{E}-06$ & $7.46 \mathrm{E}-06$ \\
\hline CCDC85B & -1.20 & $9.58 \mathrm{E}-95$ & $9.54 \mathrm{E}-93$ \\
\hline ALDH7A1 & -1.20 & $1.18 \mathrm{E}-61$ & $5.00 E-60$ \\
\hline OPLAH & -1.20 & $1.60 E-21$ & $1.41 \mathrm{E}-20$ \\
\hline ASNS & -1.20 & $4.29 \mathrm{E}-106$ & $5.17 \mathrm{E}-104$ \\
\hline KIFAP3 & -1.20 & $4.03 E-26$ & $4.60 E-25$ \\
\hline C1R & -1.20 & $2.83 \mathrm{E}-07$ & $8.29 \mathrm{E}-07$ \\
\hline FRY & -1.20 & 0.000920901 & 0.001797881 \\
\hline ANO9 & -1.20 & $7.19 \mathrm{E}-07$ & $2.02 \mathrm{E}-06$ \\
\hline BCAM & -1.20 & $7.19 \mathrm{E}-33$ & $1.1 \mathrm{IE}-31$ \\
\hline MED30 & -1.20 & $1.06 \mathrm{E}-13$ & $5.46 \mathrm{E}-13$ \\
\hline LOC100127983 & -1.20 & $6.85 \mathrm{E}-06$ & $1.73 \mathrm{E}-05$ \\
\hline CBS & -1.20 & $1.10 E-55$ & $4.00 \mathrm{E}-54$ \\
\hline PNPLA2 & -1.19 & $7.09 E-37$ & $1.30 E-35$ \\
\hline C1QL4 & -1.19 & $1.08 \mathrm{E}-07$ & $3.32 \mathrm{E}-07$ \\
\hline LOC100129716 & -1.19 & 0.000363791 & 0.000749078 \\
\hline ANKRD36BP2 & -1.19 & 0.000287863 & 0.000599766 \\
\hline LCMT1 & -1.19 & $7.16 \mathrm{E}-13$ & $3.45 \mathrm{E}-12$ \\
\hline SHF & -1.19 & $3.46 \mathrm{E}-06$ & $9.04 \mathrm{E}-06$ \\
\hline RABGGTA & -1.19 & $2.76 \mathrm{E}-10$ & $1.07 \mathrm{E}-09$ \\
\hline ANKRA2 & -1.19 & 4.84E-15 & $2.76 \mathrm{E}-14$ \\
\hline
\end{tabular}


Table 3 continued

\begin{tabular}{|c|c|c|c|}
\hline Gene symbol & $\log \mathrm{FC}$ & P value & FDR \\
\hline SYT12 & -1.19 & $8.47 \mathrm{E}-20$ & $6.64 \mathrm{E}-19$ \\
\hline PYROXD2 & -1.19 & $2.34 \mathrm{E}-06$ & $6.25 E-06$ \\
\hline COPG2 & -1.19 & $2.42 \mathrm{E}-35$ & $4.16 E-34$ \\
\hline RAP1GAP & -1.19 & $1.26 \mathrm{E}-08$ & $4.24 \mathrm{E}-08$ \\
\hline LOC728743 & -1.18 & $2.13 E-05$ & $5.11 \mathrm{E}-05$ \\
\hline SRI & -1.18 & $5.42 \mathrm{E}-43$ & $1.27 \mathrm{E}-41$ \\
\hline DDX43 & -1.18 & $2.82 \mathrm{E}-23$ & $2.74 \mathrm{E}-22$ \\
\hline PRIM1 & -1.18 & $1.39 E-29$ & $1.85 E-28$ \\
\hline FAM125A & -1.18 & $2.67 \mathrm{E}-16$ & $1.65 E-15$ \\
\hline HCFC1R1 & -1.18 & $6.80 E-52$ & $2.20 E-50$ \\
\hline THBS3 & -1.18 & $3.57 \mathrm{E}-18$ & $2.51 \mathrm{E}-17$ \\
\hline C15orf48 & -1.18 & $6.58 \mathrm{E}-30$ & $8.85 E-29$ \\
\hline C11orf54 & -1.18 & $7.03 E-18$ & $4.86 \mathrm{E}-17$ \\
\hline CTSF & -1.18 & $5.63 E-26$ & $6.40 E-25$ \\
\hline $\mathrm{CDH} 3$ & -1.18 & $4.89 E-59$ & $1.96 \mathrm{E}-57$ \\
\hline ULK4 & -1.18 & 0.000777011 & 0.001532576 \\
\hline C1S & -1.17 & $6.98 \mathrm{E}-05$ & 0.00015741 \\
\hline VSIG1 & -1.17 & 0.000372512 & 0.00076579 \\
\hline MED25 & -1.17 & $6.05 E-19$ & $4.47 \mathrm{E}-18$ \\
\hline AlG1 & -1.17 & $7.65 E-17$ & $4.93 E-16$ \\
\hline VAV1 & -1.17 & $2.41 \mathrm{E}-14$ & $1.30 E-13$ \\
\hline PPA2 & -1.17 & $1.32 \mathrm{E}-33$ & $2.13 E-32$ \\
\hline FAM98C & -1.17 & 5.33E-05 & 0.000121815 \\
\hline FCGRT & -1.17 & $1.69 E-26$ & $1.95 \mathrm{E}-25$ \\
\hline EXOSC 8 & -1.17 & $1.71 \mathrm{E}-25$ & $1.88 \mathrm{E}-24$ \\
\hline TMEM160 & -1.17 & $1.88 \mathrm{E}-11$ & $8.15 E-11$ \\
\hline SREBF1 & -1.17 & $2.51 \mathrm{E}-32$ & $3.78 \mathrm{E}-31$ \\
\hline Clorf172 & -1.17 & $8.99 \mathrm{E}-06$ & $2.24 \mathrm{E}-05$ \\
\hline MSI2 & -1.17 & $1.73 \mathrm{E}-11$ & $7.52 \mathrm{E}-11$ \\
\hline IMPA2 & -1.17 & $6.70 E-36$ & $1.17 \mathrm{E}-34$ \\
\hline IGFBP6 & -1.17 & $1.04 \mathrm{E}-18$ & $7.55 \mathrm{E}-18$ \\
\hline EIF2D & -1.17 & $7.55 E-48$ & $2.12 \mathrm{E}-46$ \\
\hline LTA4H & -1.16 & $7.60 E-76$ & $4.88 \mathrm{E}-74$ \\
\hline ASL & -1.16 & $7.72 \mathrm{E}-28$ & $9.53 E-27$ \\
\hline ETHE1 & -1.16 & $1.72 \mathrm{E}-23$ & $1.69 E-22$ \\
\hline $\mathrm{RPH} 3 \mathrm{AL}$ & -1.16 & $4.72 \mathrm{E}-21$ & $3.99 E-20$ \\
\hline KLHDC2 & -1.16 & $2.62 \mathrm{E}-74$ & $1.59 E-72$ \\
\hline FAM171A2 & -1.16 & $2.02 \mathrm{E}-09$ & $7.29 E-09$ \\
\hline IFT88 & -1.16 & $2.41 \mathrm{E}-07$ & $7.15 E-07$ \\
\hline SIGIRR & -1.16 & $1.53 \mathrm{E}-05$ & $3.72 \mathrm{E}-05$ \\
\hline SUGT1 & -1.16 & $1.60 E-19$ & $1.23 E-18$ \\
\hline TXNIP & -1.16 & $3.34 \mathrm{E}-07$ & $9.72 \mathrm{E}-07$ \\
\hline GTF2H2D & -1.16 & 0.000102722 & 0.000227077 \\
\hline REEP6 & -1.15 & $1.93 E-18$ & $1.38 \mathrm{E}-17$ \\
\hline AAAS & -1.15 & $5.67 \mathrm{E}-34$ & $9.29 E-33$ \\
\hline CDKL2 & -1.15 & 0.000611109 & 0.001221929 \\
\hline MRC2 & -1.15 & $2.67 E-32$ & $4.02 E-31$ \\
\hline RPN2 & -1.15 & $4.07 \mathrm{E}-177$ & $1.26 \mathrm{E}-174$ \\
\hline FN3K & -1.15 & $5.62 E-11$ & $2.33 \mathrm{E}-10$ \\
\hline ST14 & -1.15 & $5.82 \mathrm{E}-11$ & $2.41 \mathrm{E}-10$ \\
\hline GRAPL & -1.15 & 0.002321122 & 0.004253204 \\
\hline CUEDC2 & -1.15 & $2.06 \mathrm{E}-28$ & $2.59 \mathrm{E}-27$ \\
\hline$|F| 30$ & -1.15 & $1.81 \mathrm{E}-08$ & $6.01 \mathrm{E}-08$ \\
\hline
\end{tabular}

Table 3 continued

\begin{tabular}{|c|c|c|c|}
\hline Gene symbol & $\log \mathrm{FC}$ & $P$ value & FDR \\
\hline C9orf46 & -1.15 & $1.24 \mathrm{E}-12$ & $5.89 \mathrm{E}-12$ \\
\hline ABCA5 & -1.15 & 1.85E-07 & $5.53 \mathrm{E}-07$ \\
\hline RPGR & -1.15 & $2.48 \mathrm{E}-07$ & $7.34 \mathrm{E}-07$ \\
\hline PKN1 & -1.15 & $2.23 \mathrm{E}-84$ & $1.80 \mathrm{E}-82$ \\
\hline ATG16L2 & -1.15 & $1.06 \mathrm{E}-06$ & $2.95 \mathrm{E}-06$ \\
\hline WBSCR27 & -1.15 & $3.77 \mathrm{E}-06$ & $9.80 \mathrm{E}-06$ \\
\hline LRRC45 & -1.14 & $1.24 \mathrm{E}-17$ & $8.40 \mathrm{E}-17$ \\
\hline PTMS & -1.14 & $1.81 \mathrm{E}-79$ & $1.31 \mathrm{E}-77$ \\
\hline CKLF-CMTM1 & -1.14 & $1.06 \mathrm{E}-16$ & $6.72 \mathrm{E}-16$ \\
\hline BTC & -1.14 & $3.10 E-05$ & 7.27E-05 \\
\hline TNFSF12-TNFS"13 & -1.14 & $7.55 E-19$ & $5.53 E-18$ \\
\hline PREX1 & -1.14 & 4.53E-09 & $1.58 \mathrm{E}-08$ \\
\hline FGD3 & -1.14 & $7.45 \mathrm{E}-05$ & 0.000167354 \\
\hline PCIF1 & -1.14 & $2.14 \mathrm{E}-34$ & $3.56 \mathrm{E}-33$ \\
\hline CALB2 & -1.14 & $3.17 \mathrm{E}-06$ & $8.33 \mathrm{E}-06$ \\
\hline PTGES & -1.14 & $3.74 \mathrm{E}-21$ & $3.18 \mathrm{E}-20$ \\
\hline HES7 & -1.13 & 0.003803794 & 0.00674057 \\
\hline FGFR4 & -1.13 & $8.06 \mathrm{E}-24$ & 8.07E-23 \\
\hline NFKBID & -1.13 & 0.00094651 & 0.001842867 \\
\hline BMP1 & -1.13 & $1.37 \mathrm{E}-31$ & $2.00 E-30$ \\
\hline MSI1 & -1.13 & 0.002464428 & 0.004500152 \\
\hline RPS6KB2 & -1.13 & $2.74 \mathrm{E}-20$ & $2.21 \mathrm{E}-19$ \\
\hline KCTD19 & -1.13 & $3.06 \mathrm{E}-06$ & $8.06 \mathrm{E}-06$ \\
\hline CCDC88B & -1.13 & $1.55 \mathrm{E}-11$ & $6.73 E-11$ \\
\hline SCNN1A & -1.13 & $4.23 E-35$ & $7.21 \mathrm{E}-34$ \\
\hline POMGNT1 & -1.13 & $8.85 E-41$ & $1.88 \mathrm{E}-39$ \\
\hline HECTD2 & -1.13 & 0.001588305 & 0.002987874 \\
\hline NUP107 & -1.13 & $2.10 \mathrm{E}-54$ & $7.31 \mathrm{E}-53$ \\
\hline CXCL16 & -1.13 & $5.14 \mathrm{E}-12$ & $2.33 \mathrm{E}-11$ \\
\hline GAPDHS & -1.13 & 0.001914622 & 0.003556771 \\
\hline CDC42BPG & -1.13 & $3.79 \mathrm{E}-08$ & $1.22 \mathrm{E}-07$ \\
\hline MLXIPL & -1.12 & $6.00 E-06$ & $1.53 E-05$ \\
\hline$|F| 27 L 1$ & -1.12 & $1.31 \mathrm{E}-13$ & $6.68 \mathrm{E}-13$ \\
\hline$A B C A 7$ & -1.12 & $5.03 E-32$ & 7.44E-31 \\
\hline CREB3L4 & -1.12 & $8.76 \mathrm{E}-17$ & $5.61 \mathrm{E}-16$ \\
\hline COPE & -1.12 & $1.68 \mathrm{E}-31$ & $2.44 \mathrm{E}-30$ \\
\hline PEMT & -1.12 & $4.08 \mathrm{E}-08$ & $1.31 \mathrm{E}-07$ \\
\hline PKN3 & -1.12 & $2.05 E-12$ & $9.57 \mathrm{E}-12$ \\
\hline UQCRC1 & -1.12 & $3.06 \mathrm{E}-84$ & $2.42 \mathrm{E}-82$ \\
\hline DNAJC4 & -1.12 & $2.58 \mathrm{E}-15$ & $1.50 \mathrm{E}-14$ \\
\hline FAM175A & -1.12 & 3.67E-05 & $8.54 \mathrm{E}-05$ \\
\hline FIBP & -1.12 & 1.34E -48 & $3.86 \mathrm{E}-47$ \\
\hline KCNN1 & -1.12 & $1.14 \mathrm{E}-05$ & $2.82 \mathrm{E}-05$ \\
\hline RQCD1 & -1.12 & $5.66 \mathrm{E}-19$ & $4.19 \mathrm{E}-18$ \\
\hline JUNB & -1.11 & $9.88 \mathrm{E}-50$ & $2.95 E-48$ \\
\hline ASPSCR1 & -1.11 & $5.66 \mathrm{E}-13$ & $2.76 \mathrm{E}-12$ \\
\hline QPCTL & -1.11 & $4.68 \mathrm{E}-25$ & $5.04 \mathrm{E}-24$ \\
\hline CD9 & -1.11 & $3.02 \mathrm{E}-94$ & $2.91 \mathrm{E}-92$ \\
\hline SH2B2 & -1.11 & $6.68 \mathrm{E}-05$ & 0.000151083 \\
\hline SSR4 & -1.11 & $1.05 \mathrm{E}-19$ & $8.16 \mathrm{E}-19$ \\
\hline NDUFA2 & -1.11 & $8.18 \mathrm{E}-19$ & $5.99 \mathrm{E}-18$ \\
\hline ALPK1 & -1.11 & $1.89 \mathrm{E}-16$ & $1.19 \mathrm{E}-15$ \\
\hline GFM2 & -1.11 & $1.22 \mathrm{E}-54$ & $4.29 E-53$ \\
\hline
\end{tabular}


Table 3 continued

\begin{tabular}{|c|c|c|c|c|c|c|c|}
\hline Gene symbol & $\log \mathrm{FC}$ & P value & FDR & Gene symbol & $\log F C$ & P value & FDR \\
\hline GPCPD1 & -1.11 & $8.79 E-19$ & $6.43 E-18$ & MRPL47 & -1.08 & $2.55 E-16$ & $1.58 \mathrm{E}-15$ \\
\hline NDRG2 & -1.11 & $1.37 \mathrm{E}-06$ & $3.74 \mathrm{E}-06$ & ERP44 & -1.08 & $4.10 E-42$ & $9.20 E-41$ \\
\hline PRSS22 & -1.11 & 0.002080435 & 0.003844256 & ARHGEF16 & -1.08 & $5.13 \mathrm{E}-13$ & $2.51 \mathrm{E}-12$ \\
\hline MST1P9 & -1.11 & 0.002266527 & 0.004161499 & TP53TG1 & -1.08 & 1.83E-05 & $4.40 \mathrm{E}-05$ \\
\hline TRIM9 & -1.11 & 0.000204924 & 0.000435644 & $\mathrm{FA} 2 \mathrm{H}$ & -1.08 & $1.77 \mathrm{E}-08$ & $5.89 E-08$ \\
\hline ATP2A3 & -1.11 & $4.09 \mathrm{E}-09$ & $1.44 \mathrm{E}-08$ & ADAM15 & -1.07 & $4.71 E-73$ & $2.73 \mathrm{E}-71$ \\
\hline TMEM161A & -1.11 & $2.06 \mathrm{E}-12$ & $9.63 \mathrm{E}-12$ & STAG3 & -1.07 & 0.005718352 & 0.00986248 \\
\hline ING4 & -1.11 & $5.53 \mathrm{E}-08$ & $1.75 \mathrm{E}-07$ & PTK2B & -1.07 & 4.07E-14 & $2.16 \mathrm{E}-13$ \\
\hline METTL5 & -1.11 & $9.00 \mathrm{E}-34$ & $1.46 \mathrm{E}-32$ & NSMCE1 & -1.07 & $5.38 \mathrm{E}-18$ & $3.74 \mathrm{E}-17$ \\
\hline IFT74 & -1.11 & $2.99 \mathrm{E}-11$ & $1.27 \mathrm{E}-10$ & ATXNIO & -1.07 & $9.31 \mathrm{E}-82$ & $6.97 \mathrm{E}-80$ \\
\hline GALT & -1.10 & $9.23 \mathrm{E}-14$ & $4.76 \mathrm{E}-13$ & CCDC53 & -1.07 & $3.48 \mathrm{E}-15$ & $2.01 \mathrm{E}-14$ \\
\hline ZCWPW2 & -1.10 & $2.10 E-32$ & $3.17 E-31$ & MIPEP & -1.07 & $4.92 \mathrm{E}-10$ & $1.87 E-09$ \\
\hline USH1G & -1.10 & 0.002619829 & 0.004769462 & TNFAIP2 & -1.07 & $1.57 E-146$ & $3.48 \mathrm{E}-144$ \\
\hline FAM162A & -1.10 & $1.90 \mathrm{E}-18$ & $1.36 \mathrm{E}-17$ & PSMA5 & -1.07 & $1.18 \mathrm{E}-41$ & $2.60 E-40$ \\
\hline BCL3 & -1.10 & $3.72 \mathrm{E}-46$ & $9.84 \mathrm{E}-45$ & INSIG1 & -1.07 & $8.19 \mathrm{E}-55$ & $2.90 \mathrm{E}-53$ \\
\hline TSPAN1 & -1.10 & $9.28 \mathrm{E}-12$ & $4.1 \mathrm{IE}-11$ & KIAA1383 & -1.07 & $4.15 E-06$ & $1.07 \mathrm{E}-05$ \\
\hline SIPA1 & -1.10 & $2.57 \mathrm{E}-25$ & $2.80 E-24$ & SDC2 & -1.07 & $3.27 \mathrm{E}-05$ & $7.64 \mathrm{E}-05$ \\
\hline WDR27 & -1.10 & $8.86 \mathrm{E}-07$ & $2.47 \mathrm{E}-06$ & COX5B & -1.07 & $7.29 \mathrm{E}-32$ & $1.08 \mathrm{E}-30$ \\
\hline LOC678655 & -1.10 & $2.98 \mathrm{E}-09$ & $1.06 \mathrm{E}-08$ & DTX4 & -1.07 & $2.75 E-06$ & $7.28 \mathrm{E}-06$ \\
\hline MATN2 & -1.10 & $3.00 \mathrm{E}-17$ & $1.98 \mathrm{E}-16$ & LOC100289495 & -1.07 & $7.59 \mathrm{E}-05$ & 0.000170296 \\
\hline SERPINI1 & -1.10 & $7.67 \mathrm{E}-07$ & $2.15 E-06$ & BIN1 & -1.07 & $8.92 \mathrm{E}-11$ & $3.62 \mathrm{E}-10$ \\
\hline NPRL2 & -1.10 & $8.74 \mathrm{E}-12$ & $3.88 \mathrm{E}-11$ & CLDN7 & -1.07 & $2.52 \mathrm{E}-17$ & $1.68 \mathrm{E}-16$ \\
\hline IRF6 & -1.10 & $3.53 \mathrm{E}-11$ & $1.49 \mathrm{E}-10$ & LMF1 & -1.07 & $1.18 \mathrm{E}-05$ & $2.90 \mathrm{E}-05$ \\
\hline C17orf57 & -1.10 & $9.25 E-06$ & $2.30 E-05$ & C11orf93 & -1.07 & 0.000180253 & 0.000386051 \\
\hline HSPB11 & -1.10 & $2.47 \mathrm{E}-11$ & $1.06 \mathrm{E}-10$ & $\mathrm{C} 1 \mathrm{RL}$ & -1.06 & $2.49 E-30$ & $3.42 E-29$ \\
\hline LOXL2 & -1.10 & $2.56 \mathrm{E}-119$ & $4.1 \mathrm{IE}-117$ & MTMR11 & -1.06 & $8.82 \mathrm{E}-20$ & $6.91 \mathrm{E}-19$ \\
\hline GATS & -1.10 & $3.88 \mathrm{E}-07$ & $1.12 E-06$ & CST6 & -1.06 & $4.12 \mathrm{E}-16$ & $2.53 \mathrm{E}-15$ \\
\hline POLD1 & -1.10 & $3.61 E-38$ & $6.98 \mathrm{E}-37$ & CRISPLD1 & -1.06 & $1.71 \mathrm{E}-07$ & $5.16 \mathrm{E}-07$ \\
\hline KREMEN2 & -1.10 & 0.000906345 & 0.001771925 & PFKL & -1.06 & $3.28 \mathrm{E}-73$ & $1.92 \mathrm{E}-71$ \\
\hline SH3YL1 & -1.09 & $7.15 E-18$ & $4.93 \mathrm{E}-17$ & IER5L & -1.06 & $1.03 \mathrm{E}-19$ & $8.04 \mathrm{E}-19$ \\
\hline HEXDC & -1.09 & $3.33 \mathrm{E}-08$ & $1.08 \mathrm{E}-07$ & NUDT17 & -1.06 & $2.65 E-07$ & $7.80 \mathrm{E}-07$ \\
\hline $\mathrm{CHIC2}$ & -1.09 & $5.08 \mathrm{E}-05$ & 0.000116308 & RABAC1 & -1.06 & $9.34 \mathrm{E}-31$ & $1.31 \mathrm{E}-29$ \\
\hline FLJ39051 & -1.09 & 0.000444045 & 0.000904903 & $\mathrm{ABCA} 2$ & -1.06 & $2.56 \mathrm{E}-49$ & $7.50 \mathrm{E}-48$ \\
\hline ALKBH6 & -1.09 & $4.88 \mathrm{E}-09$ & $1.70 \mathrm{E}-08$ & TRAP1 & -1.06 & $1.61 \mathrm{E}-76$ & $1.05 E-74$ \\
\hline $\mathrm{MAGOH}$ & -1.09 & $1.09 \mathrm{E}-14$ & $6.06 \mathrm{E}-14$ & BBS9 & -1.06 & $1.98 \mathrm{E}-11$ & $8.56 \mathrm{E}-11$ \\
\hline LOC100505783 & -1.09 & $1.52 \mathrm{E}-05$ & $3.70 E-05$ & MMP15 & -1.06 & $3.72 \mathrm{E}-27$ & $4.45 E-26$ \\
\hline C16orf62 & -1.09 & $1.35 E-24$ & $1.42 E-23$ & SCPEP1 & -1.06 & $4.13 E-22$ & $3.76 \mathrm{E}-21$ \\
\hline GAL3ST1 & -1.09 & 0.004091279 & 0.00721967 & TLL2 & -1.06 & $4.28 \mathrm{E}-05$ & $9.90 \mathrm{E}-05$ \\
\hline ZNF670-ZNF695 & -1.09 & $6.71 \mathrm{E}-07$ & $1.89 \mathrm{E}-06$ & VPS28 & -1.06 & $3.44 \mathrm{E}-19$ & $2.60 \mathrm{E}-18$ \\
\hline UGCG & -1.09 & $2.19 E-49$ & $6.44 E-48$ & TCN2 & -1.06 & $9.31 \mathrm{E}-07$ & $2.59 \mathrm{E}-06$ \\
\hline AS3MT & -1.09 & 0.000326442 & 0.000675804 & HS1BP3 & -1.06 & $5.55 \mathrm{E}-20$ & $4.41 \mathrm{E}-19$ \\
\hline GRTP1 & -1.09 & $2.37 \mathrm{E}-05$ & $5.64 \mathrm{E}-05$ & HMG20B & -1.06 & $9.18 \mathrm{E}-84$ & $7.22 \mathrm{E}-82$ \\
\hline AQP3 & -1.09 & $3.02 \mathrm{E}-08$ & $9.82 \mathrm{E}-08$ & FUCA1 & -1.06 & $4.76 \mathrm{E}-18$ & $3.32 \mathrm{E}-17$ \\
\hline TMEM45B & -1.09 & $7.62 \mathrm{E}-14$ & $3.95 E-13$ & ARHGEF7 & -1.05 & $1.63 \mathrm{E}-11$ & $7.10 \mathrm{E}-11$ \\
\hline ZP3 & -1.09 & $2.43 E-08$ & $7.96 \mathrm{E}-08$ & WDR33 & -1.05 & $6.18 \mathrm{E}-10$ & 2.33E-09 \\
\hline AP4M1 & -1.09 & $8.43 E-09$ & $2.89 \mathrm{E}-08$ & SYT13 & -1.05 & 0.004669962 & 0.008171303 \\
\hline PLD1 & -1.09 & $2.70 \mathrm{E}-06$ & $7.14 \mathrm{E}-06$ & C16orf13 & -1.05 & $3.16 \mathrm{E}-24$ & $3.26 \mathrm{E}-23$ \\
\hline CCBL2 & -1.09 & $2.76 \mathrm{E}-20$ & $2.23 E-19$ & KTN1 & -1.05 & $6.31 \mathrm{E}-91$ & $5.75 E-89$ \\
\hline NR4A1 & -1.08 & $4.86 \mathrm{E}-21$ & 4.10E-20 & GPX4 & -1.05 & $4.33 \mathrm{E}-82$ & $3.26 \mathrm{E}-80$ \\
\hline BRE & -1.08 & $1.97 \mathrm{E}-33$ & $3.15 E-32$ & RPS16 & -1.05 & $2.85 E-107$ & $3.46 E-105$ \\
\hline PCYOX1L & -1.08 & $3.06 \mathrm{E}-15$ & $1.77 \mathrm{E}-14$ & AGXT2L2 & -1.05 & $1.67 E-12$ & $7.88 \mathrm{E}-12$ \\
\hline KIAA1456 & -1.08 & $4.80 E-05$ & 0.000110264 & TMEM141 & -1.05 & $1.52 \mathrm{E}-18$ & $1.09 \mathrm{E}-17$ \\
\hline AARS & -1.08 & $1.30 \mathrm{E}-192$ & $4.43 \mathrm{E}-190$ & LAMP3 & -1.05 & $4.66 \mathrm{E}-06$ & $1.20 \mathrm{E}-05$ \\
\hline
\end{tabular}

Table 3 continued 
Table 3 continued

\begin{tabular}{|c|c|c|c|c|c|c|c|}
\hline Gene symbol & $\log F C$ & P value & FDR & Gene symbol & $\log F C$ & $P$ value & FDR \\
\hline CDKN1C & -1.05 & 0.000424019 & 0.000866884 & ANXA3 & -1.03 & $1.06 \mathrm{E}-78$ & $7.48 \mathrm{E}-77$ \\
\hline LOC100288846 & -1.05 & 0.000988006 & 0.001917938 & C15orf58 & -1.02 & 0.00133034 & 0.002534258 \\
\hline DHRS12 & -1.05 & 0.008237024 & 0.013823818 & RBX1 & -1.02 & $1.31 E-21$ & $1.16 \mathrm{E}-20$ \\
\hline ATP6AP1L & -1.05 & 0.008191315 & 0.013754406 & $A B C D 1$ & -1.02 & $4.71 \mathrm{E}-08$ & $1.50 \mathrm{E}-07$ \\
\hline ERCC2 & -1.05 & $4.13 E-23$ & $3.98 \mathrm{E}-22$ & P4HA3 & -1.02 & 0.000276213 & 0.00057711 \\
\hline FMO5 & -1.05 & 0.008652057 & 0.014449416 & KRBA2 & -1.02 & 0.004111753 & 0.007253308 \\
\hline ULK2 & -1.05 & $8.06 \mathrm{E}-20$ & $6.33 \mathrm{E}-19$ & GLS2 & -1.02 & 0.000259768 & 0.000544639 \\
\hline SMARCD3 & -1.05 & $2.06 \mathrm{E}-08$ & $6.82 \mathrm{E}-08$ & ENDOG & -1.02 & $5.93 \mathrm{E}-08$ & $1.87 \mathrm{E}-07$ \\
\hline PHYHD1 & -1.05 & $4.25 \mathrm{E}-11$ & $1.78 \mathrm{E}-10$ & $\operatorname{cox} 7 \mathrm{C}$ & -1.02 & $6.09 \mathrm{E}-67$ & $3.08 \mathrm{E}-65$ \\
\hline C10orf11 & -1.05 & 0.003354135 & 0.006000913 & C8orf59 & -1.02 & $2.88 \mathrm{E}-20$ & $2.32 \mathrm{E}-19$ \\
\hline KRTCAP3 & -1.05 & 0.000203547 & 0.000433154 & RAB11FIP4 & -1.02 & $6.08 \mathrm{E}-09$ & $2.11 \mathrm{E}-08$ \\
\hline SRP54 & -1.05 & $2.70 E-88$ & $2.32 \mathrm{E}-86$ & CDKL1 & -1.02 & $8.11 \mathrm{E}-06$ & 2.03E-05 \\
\hline IMMP2L & -1.04 & $2.06 \mathrm{E}-07$ & $6.13 \mathrm{E}-07$ & LOC100133957 & -1.02 & 0.001919501 & 0.003564787 \\
\hline CARS & -1.04 & $3.50 E-44$ & $8.52 E-43$ & DENND1A & -1.02 & $5.20 E-33$ & $8.18 \mathrm{E}-32$ \\
\hline RPL24 & -1.04 & $5.98 \mathrm{E}-76$ & $3.86 \mathrm{E}-74$ & TRAM1 & -1.02 & $1.47 \mathrm{E}-76$ & $9.69 \mathrm{E}-75$ \\
\hline GSN & -1.04 & $3.51 \mathrm{E}-17$ & $2.31 \mathrm{E}-16$ & UPK3B & -1.02 & $9.22 \mathrm{E}-07$ & $2.56 \mathrm{E}-06$ \\
\hline BAI2 & -1.04 & $9.31 \mathrm{E}-16$ & $5.58 \mathrm{E}-15$ & ANKRD29 & -1.02 & $1.13 \mathrm{E}-27$ & $1.38 \mathrm{E}-26$ \\
\hline WDR18 & -1.04 & $1.17 \mathrm{E}-46$ & $3.16 \mathrm{E}-45$ & CHMP5 & -1.02 & $7.09 \mathrm{E}-56$ & $2.61 \mathrm{E}-54$ \\
\hline $\mathrm{ZC} 4 \mathrm{H} 2$ & -1.04 & 0.009400904 & 0.015597066 & CCDC125 & -1.02 & 4.05E-07 & $1.17 \mathrm{E}-06$ \\
\hline EIF3M & -1.04 & $4.78 \mathrm{E}-59$ & $1.93 E-57$ & MEF2BNB-MEF2B & -1.01 & 0.000476068 & 0.000966579 \\
\hline SLC25A42 & -1.04 & $7.39 \mathrm{E}-08$ & $2.30 \mathrm{E}-07$ & PTPRE & -1.01 & $2.62 \mathrm{E}-47$ & $7.25 \mathrm{E}-46$ \\
\hline MTHFR & -1.04 & $2.62 \mathrm{E}-10$ & $1.02 \mathrm{E}-09$ & MAGIX & -1.01 & 0.012672093 & 0.020531485 \\
\hline $\mathrm{ABCG} 2$ & -1.04 & 0.003349706 & 0.005994684 & MDP1 & -1.01 & 0.000316356 & 0.000656213 \\
\hline $\mathrm{NR} 1 \mathrm{H} 3$ & -1.04 & 0.000505923 & 0.001023253 & SEMA4G & -1.01 & $2.18 \mathrm{E}-21$ & $1.90 E-20$ \\
\hline PAAF1 & -1.04 & $2.18 \mathrm{E}-21$ & $1.90 \mathrm{E}-20$ & TRMT11 & -1.01 & $7.49 \mathrm{E}-10$ & $2.80 \mathrm{E}-09$ \\
\hline GSTK1 & -1.04 & $1.65 E-37$ & $3.13 E-36$ & TNFRSF9 & -1.01 & 0.001333696 & 0.002540269 \\
\hline DEPDC4 & -1.04 & 0.000125031 & 0.000273146 & AMZ2P1 & -1.01 & $1.77 \mathrm{E}-07$ & $5.32 \mathrm{E}-07$ \\
\hline ZNF396 & -1.04 & $2.31 \mathrm{E}-05$ & $5.51 \mathrm{E}-05$ & C7orf10 & -1.01 & 0.000709162 & 0.001406426 \\
\hline BHLHE40 & -1.04 & $2.30 \mathrm{E}-66$ & $1.15 E-64$ & PRPF40B & -1.01 & $5.32 E-24$ & $5.39 E-23$ \\
\hline TECPR1 & -1.04 & $3.48 \mathrm{E}-13$ & $1.72 \mathrm{E}-12$ & NCOA7 & -1.01 & $8.97 E-40$ & $1.84 \mathrm{E}-38$ \\
\hline AMN1 & -1.04 & $1.59 \mathrm{E}-07$ & $4.80 E-07$ & MPND & -1.01 & 0.000182363 & 0.000390505 \\
\hline NTPCR & -1.04 & $3.26 \mathrm{E}-21$ & $2.79 E-20$ & C17orf28 & -1.01 & $1.33 \mathrm{E}-07$ & $4.04 \mathrm{E}-07$ \\
\hline MVD & -1.04 & $5.49 \mathrm{E}-40$ & $1.13 E-38$ & PFDN5 & -1.01 & $1.94 \mathrm{E}-57$ & $7.44 \mathrm{E}-56$ \\
\hline RRAS & -1.04 & $1.37 E-24$ & $1.44 \mathrm{E}-23$ & VWA1 & -1.01 & $1.13 E-18$ & $8.22 \mathrm{E}-18$ \\
\hline LOC144481 & -1.03 & 0.001555384 & 0.00293074 & VPS33B & -1.01 & $4.79 \mathrm{E}-11$ & $2.00 E-10$ \\
\hline SURF1 & -1.03 & $1.48 \mathrm{E}-25$ & $1.64 \mathrm{E}-24$ & PHYHIP & -1.00 & $2.49 \mathrm{E}-07$ & $7.35 \mathrm{E}-07$ \\
\hline MFF & -1.03 & $1.03 \mathrm{E}-98$ & $1.09 E-96$ & SUSD2 & -1.00 & $2.55 E-29$ & $3.35 E-28$ \\
\hline MAGED1 & -1.03 & $3.74 \mathrm{E}-72$ & $2.11 \mathrm{E}-70$ & CCNA1 & -1.00 & $1.64 \mathrm{E}-08$ & $5.47 \mathrm{E}-08$ \\
\hline TBL3 & -1.03 & $7.98 \mathrm{E}-25$ & $8.51 E-24$ & GAMT & -1.00 & $4.53 \mathrm{E}-10$ & $1.72 \mathrm{E}-09$ \\
\hline DYX1C1 & -1.03 & 0.000142357 & 0.000309076 & SLC44A2 & -1.00 & $2.72 \mathrm{E}-41$ & $5.85 \mathrm{E}-40$ \\
\hline SLC16A5 & -1.03 & $2.35 \mathrm{E}-23$ & $2.30 \mathrm{E}-22$ & ODF2L & -1.00 & $2.38 \mathrm{E}-16$ & $1.48 \mathrm{E}-15$ \\
\hline GPRIN2 & -1.03 & $1.03 \mathrm{E}-10$ & $4.17 E-10$ & HIST1H1C & -1.00 & $2.07 E-43$ & $4.93 E-42$ \\
\hline LOC100130015 & -1.03 & $2.39 \mathrm{E}-07$ & 7.07E-07 & TAF10 & -1.00 & $6.64 \mathrm{E}-28$ & $8.23 E-27$ \\
\hline DDX60 & -1.03 & 0.000267213 & 0.000559136 & AKT3 & -1.00 & $7.55 E-14$ & $3.92 \mathrm{E}-13$ \\
\hline MITD1 & -1.03 & $1.44 \mathrm{E}-11$ & $6.27 \mathrm{E}-11$ & MACROD2 & -1.00 & 0.008868792 & 0.014782098 \\
\hline RBP1 & -1.03 & 0.006467371 & 0.011039757 & ADAM23 & -1.00 & $1.90 \mathrm{E}-08$ & $6.31 \mathrm{E}-08$ \\
\hline TBCA & -1.03 & $5.18 \mathrm{E}-33$ & $8.15 E-32$ & COQ6 & -1.00 & $2.59 E-13$ & $1.29 E-12$ \\
\hline ICAM5 & -1.03 & $5.23 \mathrm{E}-14$ & $2.75 E-13$ & DLEU2 & -1.00 & 0.005572257 & 0.009628891 \\
\hline TNFRSF10C & -1.03 & 0.00023491 & 0.000494816 & CAT & -1.00 & $1.55 E-30$ & $2.14 \mathrm{E}-29$ \\
\hline CPE & -1.03 & $7.1 \mathrm{IE}-14$ & $3.70 E-13$ & MSMO1 & -1.00 & $4.14 \mathrm{E}-33$ & $6.57 \mathrm{E}-32$ \\
\hline ANK2 & -1.03 & $3.67 \mathrm{E}-11$ & $1.54 \mathrm{E}-10$ & LOC100506334 & -1.00 & $3.11 \mathrm{E}-06$ & $8.17 \mathrm{E}-06$ \\
\hline C22orf26 & -1.03 & 0.000452354 & 0.000920647 & TARS2 & -1.00 & $2.70 E-38$ & $5.25 E-37$ \\
\hline SNX2 & -1.03 & $6.73 E-33$ & $1.04 E-31$ & P4HTM & -1.00 & $1.17 \mathrm{E}-15$ & $6.93 E-15$ \\
\hline
\end{tabular}

Table 3 continued 
Table 3 continued

\begin{tabular}{|c|c|c|c|}
\hline Gene symbol & $\log \mathrm{FC}$ & $P$ value & FDR \\
\hline EBF4 & -1.00 & 0.001175315 & 0.002258326 \\
\hline ARHGEF26-AS1 & -1.00 & 0.000118469 & 0.000259887 \\
\hline OSGEPL1 & -1.00 & $1.23 \mathrm{E}-11$ & $5.41 \mathrm{E}-11$ \\
\hline PPFIA3 & -1.00 & $2.52 \mathrm{E}-05$ & 5.96E-05 \\
\hline C19orf71 & -1.00 & $1.03 \mathrm{E}-05$ & $2.56 \mathrm{E}-05$ \\
\hline CECR2 & -1.00 & 0.000117675 & 0.000258236 \\
\hline NAT14 & -0.99 & $1.20 E-13$ & $6.15 E-13$ \\
\hline FADS2 & -0.99 & $2.47 \mathrm{E}-79$ & $1.77 \mathrm{E}-77$ \\
\hline CALCOCOI & -0.99 & $3.84 \mathrm{E}-18$ & $2.69 E-17$ \\
\hline APOL1 & -0.99 & 0.000590629 & 0.00118340 \\
\hline ITFG3 & -0.99 & $2.53 \mathrm{E}-39$ & $5.08 \mathrm{E}-38$ \\
\hline KDELC1 & -0.99 & $1.11 \mathrm{E}-06$ & $3.05 E-06$ \\
\hline RPL3 & -0.99 & $1.72 E-158$ & $4.35 E-156$ \\
\hline PLCL2 & 0.99 & $1.02 \mathrm{E}-08$ & $3.47 \mathrm{E}-08$ \\
\hline $\mathrm{AOC2}$ & 0.99 & $5.20 \mathrm{E}-07$ & $1.48 \mathrm{E}-06$ \\
\hline ZBTB2 & 0.99 & $3.55 E-64$ & $1.61 \mathrm{E}-62$ \\
\hline LOC387647 & 0.99 & $2.94 \mathrm{E}-28$ & $3.68 \mathrm{E}-27$ \\
\hline GDF11 & 0.99 & $1.84 \mathrm{E}-42$ & 4.17E-41 \\
\hline LOC100130992 & 0.99 & $6.14 \mathrm{E}-14$ & $3.21 \mathrm{E}-13$ \\
\hline ZNF407 & 0.99 & $1.38 \mathrm{E}-21$ & $1.22 \mathrm{E}-20$ \\
\hline LOC100288615 & 0.99 & $2.15 E-11$ & $9.26 \mathrm{E}-11$ \\
\hline TEX15 & 0.99 & $1.21 \mathrm{E}-49$ & $3.59 E-48$ \\
\hline PMS2P5 & 0.99 & $2.22 \mathrm{E}-10$ & $8.68 \mathrm{E}-10$ \\
\hline TSPYL4 & 1.00 & $3.02 E-31$ & $4.33 \mathrm{E}-30$ \\
\hline FICD & 1.00 & $4.01 \mathrm{E}-07$ & $1.16 \mathrm{E}-06$ \\
\hline ZNF587 & 1.00 & $3.63 \mathrm{E}-30$ & 4.94E-29 \\
\hline ANKRD50 & 1.00 & $4.80 \mathrm{E}-50$ & $1.46 \mathrm{E}-48$ \\
\hline NR5A2 & 1.00 & $3.61 \mathrm{E}-06$ & $9.42 \mathrm{E}-06$ \\
\hline ZBTB40 & 1.00 & $9.91 \mathrm{E}-30$ & $1.32 \mathrm{E}-28$ \\
\hline SLAMF7 & 1.00 & $1.57 \mathrm{E}-11$ & $6.83 \mathrm{E}-11$ \\
\hline LOC100129046 & 1.00 & $2.73 \mathrm{E}-07$ & $8.03 E-07$ \\
\hline PHLPP2 & 1.00 & $2.77 \mathrm{E}-38$ & $5.37 \mathrm{E}-37$ \\
\hline ZNF267 & 1.00 & $7.57 \mathrm{E}-20$ & $5.95 \mathrm{E}-19$ \\
\hline FLNC & 1.00 & $9.43 E-158$ & $2.29 E-155$ \\
\hline ZNF850 & 1.00 & $1.62 \mathrm{E}-14$ & $8.85 E-14$ \\
\hline HOXB6 & 1.00 & $7.96 \mathrm{E}-27$ & $9.37 E-26$ \\
\hline RNF34 & 1.00 & $6.70 \mathrm{E}-44$ & $1.61 \mathrm{E}-42$ \\
\hline FOXO3 & 1.01 & $5.30 E-30$ & 7.17E-29 \\
\hline HUS1 & 1.01 & $1.05 E-20$ & $8.65 E-20$ \\
\hline ZNF185 & 1.01 & $1.74 \mathrm{E}-82$ & $1.33 E-80$ \\
\hline GJA1 & 1.01 & $6.19 E-16$ & $3.75 E-15$ \\
\hline AP1S2 & 1.01 & $1.54 \mathrm{E}-19$ & $1.19 E-18$ \\
\hline TUBB2A & 1.01 & $9.33 \mathrm{E}-18$ & $6.40 \mathrm{E}-17$ \\
\hline IL16 & 1.01 & 0.000167472 & 0.000360202 \\
\hline ZNF799 & 1.02 & 1.30E-09 & $4.76 \mathrm{E}-09$ \\
\hline LOC100505648 & 1.02 & 0.000565896 & 0.001136915 \\
\hline FAM160A1 & 1.02 & 0.004606923 & 0.008071049 \\
\hline KCTD7 & 1.02 & $8.21 \mathrm{E}-16$ & $4.95 E-15$ \\
\hline ZNF271 & 1.02 & $7.41 \mathrm{E}-78$ & $5.06 \mathrm{E}-76$ \\
\hline LOC401588 & 1.02 & $7.86 \mathrm{E}-08$ & $2.44 \mathrm{E}-07$ \\
\hline EIF5A & 1.02 & $1.72 \mathrm{E}-190$ & $5.72 E-188$ \\
\hline ABHD16B & 1.02 & $1.13 \mathrm{E}-13$ & $5.79 \mathrm{E}-13$ \\
\hline NBPF15 & 1.03 & $4.54 \mathrm{E}-51$ & $1.43 E-49$ \\
\hline
\end{tabular}

Table 3 continued

\begin{tabular}{|c|c|c|c|}
\hline Gene symbol & $\log F C$ & $P$ value & FDR \\
\hline LOC283922 & 1.03 & 0.001810781 & 0.003376264 \\
\hline GDAP1 & 1.03 & $2.93 \mathrm{E}-52$ & $9.56 \mathrm{E}-51$ \\
\hline KANSL1 & 1.03 & $2.80 \mathrm{E}-09$ & $9.97 \mathrm{E}-09$ \\
\hline HOXB5 & 1.03 & $4.62 \mathrm{E}-16$ & $2.83 \mathrm{E}-15$ \\
\hline LRRC37A4P & 1.03 & $4.01 \mathrm{E}-19$ & $3.00 \mathrm{E}-18$ \\
\hline RCBTB2 & 1.04 & 0.003040041 & 0.005483952 \\
\hline MYB & 1.04 & $7.95 \mathrm{E}-05$ & 0.000177891 \\
\hline SLC35F3 & 1.04 & $4.08 \mathrm{E}-27$ & $4.87 \mathrm{E}-26$ \\
\hline LOC100287314 & 1.04 & 0.00752343 & 0.012712245 \\
\hline ZNF33A & 1.04 & $7.90 \mathrm{E}-65$ & $3.71 \mathrm{E}-63$ \\
\hline TARDBP & 1.04 & $2.43 E-135$ & $4.87 E-133$ \\
\hline FL42627 & 1.04 & $3.98 \mathrm{E}-10$ & $1.52 \mathrm{E}-09$ \\
\hline ZNF239 & 1.04 & $4.56 \mathrm{E}-32$ & $6.76 \mathrm{E}-31$ \\
\hline FAM86DP & 1.04 & $1.66 \mathrm{E}-10$ & $6.54 \mathrm{E}-10$ \\
\hline IL1RL1 & 1.04 & $1.54 \mathrm{E}-08$ & $5.17 \mathrm{E}-08$ \\
\hline ZNF655 & 1.05 & $2.40 \mathrm{E}-34$ & $3.98 \mathrm{E}-33$ \\
\hline ZNF114 & 1.05 & $3.01 \mathrm{E}-18$ & $2.13 \mathrm{E}-17$ \\
\hline FAM35A & 1.05 & $9.15 \mathrm{E}-46$ & $2.38 \mathrm{E}-44$ \\
\hline SIX2 & 1.05 & 0.000341596 & 0.000705559 \\
\hline ETS1 & 1.05 & $3.20 E-96$ & $3.24 \mathrm{E}-94$ \\
\hline ERVK13-1 & 1.05 & 7.87E-08 & $2.45 E-07$ \\
\hline LOC100288123 & 1.05 & 0.003598851 & 0.006403414 \\
\hline SPATA13 & 1.05 & $5.28 \mathrm{E}-19$ & $3.92 \mathrm{E}-18$ \\
\hline PTGER2 & 1.06 & $9.55 E-10$ & $3.53 \mathrm{E}-09$ \\
\hline METTL12 & 1.06 & $1.30 \mathrm{E}-08$ & 4.37E-08 \\
\hline GNB3 & 1.06 & 0.000318505 & 0.000659914 \\
\hline NOG & 1.06 & 0.001463904 & 0.002772409 \\
\hline LOC100379224 & 1.06 & $1.78 \mathrm{E}-12$ & $8.34 \mathrm{E}-12$ \\
\hline ZNF514 & 1.06 & $2.92 \mathrm{E}-18$ & $2.07 E-17$ \\
\hline LOC100506649 & 1.06 & $1.27 \mathrm{E}-46$ & $3.41 \mathrm{E}-45$ \\
\hline CHORDC1 & 1.07 & $1.72 E-57$ & $6.60 E-56$ \\
\hline CDKN1A & 1.07 & $7.51 E-66$ & $3.68 E-64$ \\
\hline ARMCX4 & 1.07 & $1.38 \mathrm{E}-14$ & $7.62 \mathrm{E}-14$ \\
\hline NBPF1 & 1.07 & $1.78 \mathrm{E}-24$ & $1.86 \mathrm{E}-23$ \\
\hline TJP2 & 1.07 & $8.04 \mathrm{E}-145$ & $1.75 E-142$ \\
\hline LOC147804 & 1.07 & $1.07 \mathrm{E}-13$ & $5.51 \mathrm{E}-13$ \\
\hline PRDM13 & 1.07 & $2.87 \mathrm{E}-07$ & $8.40 E-07$ \\
\hline SON & 1.07 & $2.20 \mathrm{E}-170$ & $6.31 \mathrm{E}-168$ \\
\hline EPHB2 & 1.07 & 6.87E-09 & $2.37 \mathrm{E}-08$ \\
\hline POM121C & 1.08 & $7.93 E-52$ & $2.55 \mathrm{E}-50$ \\
\hline ZNF443 & 1.08 & $2.53 \mathrm{E}-07$ & $7.47 \mathrm{E}-07$ \\
\hline JRK & 1.08 & $7.15 \mathrm{E}-24$ & $7.18 \mathrm{E}-23$ \\
\hline KBTBD8 & 1.08 & 0.000226507 & 0.000478711 \\
\hline ASB16 & 1.08 & $1.81 \mathrm{E}-06$ & $4.90 E-06$ \\
\hline FAM86B1 & 1.08 & $4.25 E-08$ & $1.36 \mathrm{E}-07$ \\
\hline CREB5 & 1.08 & $8.91 \mathrm{E}-16$ & $5.35 \mathrm{E}-15$ \\
\hline VAMP1 & 1.08 & $4.97 E-14$ & $2.62 E-13$ \\
\hline USP32P1 & 1.08 & $3.37 \mathrm{E}-24$ & $3.47 \mathrm{E}-23$ \\
\hline IRGQ & 1.08 & $4.72 E-37$ & $8.74 \mathrm{E}-36$ \\
\hline RPS26 & 1.09 & $8.51 \mathrm{E}-106$ & $1.02 E-103$ \\
\hline CLCN4 & 1.09 & $2.07 E-11$ & $8.92 \mathrm{E}-11$ \\
\hline DPY19L2 & 1.09 & $1.60 \mathrm{E}-06$ & 4.36E-06 \\
\hline TMPPE & 1.10 & 0.000159821 & 0.000344921 \\
\hline
\end{tabular}


Table 3 continued

\begin{tabular}{|c|c|c|c|}
\hline Gene symbol & $\log \mathrm{FC}$ & $P$ value & FDR \\
\hline RP9P & 1.10 & $1.53 \mathrm{E}-14$ & $8.36 \mathrm{E}-14$ \\
\hline ZNF600 & 1.10 & $2.10 E-16$ & $1.32 \mathrm{E}-15$ \\
\hline C17orf51 & 1.10 & $5.46 \mathrm{E}-47$ & $1.48 \mathrm{E}-45$ \\
\hline ABL2 & 1.10 & $6.59 \mathrm{E}-118$ & $1.02 E-115$ \\
\hline ZRSR2 & 1.11 & $1.52 \mathrm{E}-05$ & $3.70 E-05$ \\
\hline ATAD3B & 1.11 & $3.55 \mathrm{E}-17$ & $2.34 \mathrm{E}-16$ \\
\hline ZBTB26 & 1.11 & $5.88 \mathrm{E}-14$ & $3.08 \mathrm{E}-13$ \\
\hline LOC100527964 & 1.11 & 0.000167054 & 0.00035964 \\
\hline RASSFIO & 1.11 & 0.001652544 & 0.003100419 \\
\hline WDR52 & 1.12 & 0.001376432 & 0.002616151 \\
\hline ENTPD7 & 1.12 & $2.86 \mathrm{E}-59$ & $1.16 \mathrm{E}-57$ \\
\hline KLHL21 & 1.12 & $1.76 \mathrm{E}-47$ & $4.90 E-46$ \\
\hline SERPINB7 & 1.13 & $5.41 \mathrm{E}-06$ & $1.39 E-05$ \\
\hline TFCP2L1 & 1.13 & $4.61 \mathrm{E}-16$ & $2.82 \mathrm{E}-15$ \\
\hline RFTN1 & 1.13 & $4.04 \mathrm{E}-18$ & $2.83 \mathrm{E}-17$ \\
\hline PTHLH & 1.13 & $1.75 \mathrm{E}-07$ & $5.26 \mathrm{E}-07$ \\
\hline C10rf216 & 1.13 & $3.58 \mathrm{E}-29$ & $4.66 \mathrm{E}-28$ \\
\hline MGC57346 & 1.13 & $1.40 \mathrm{E}-09$ & $5.11 \mathrm{E}-09$ \\
\hline MALAT1 & 1.14 & $3.24 \mathrm{E}-113$ & $4.51 \mathrm{E}-111$ \\
\hline NSUN5P1 & 1.14 & $1.10 \mathrm{E}-06$ & $3.03 E-06$ \\
\hline C3orf52 & 1.14 & $8.59 E-13$ & $4.12 \mathrm{E}-12$ \\
\hline MRPS25 & 1.14 & $4.61 \mathrm{E}-67$ & $2.35 E-65$ \\
\hline C11orf41 & 1.14 & $1.89 \mathrm{E}-08$ & $6.29 \mathrm{E}-08$ \\
\hline EPHA4 & 1.14 & $1.27 \mathrm{E}-05$ & $3.12 E-05$ \\
\hline LOC283624 & 1.14 & $1.05 E-22$ & $9.88 \mathrm{E}-22$ \\
\hline FRMD6 & 1.15 & $1.79 \mathrm{E}-118$ & $2.83 E-116$ \\
\hline XRCC2 & 1.15 & $5.36 E-36$ & $9.41 E-35$ \\
\hline ATF5 & 1.15 & $7.98 \mathrm{E}-35$ & $1.34 \mathrm{E}-33$ \\
\hline NOV & 1.15 & 0.000586861 & 0.00117642 \\
\hline RPL23AP64 & 1.15 & 0.000182902 & 0.00039146 \\
\hline FGF5 & 1.15 & $7.83 E-05$ & 0.00017528 \\
\hline DNAH17 & 1.16 & $5.10 E-06$ & $1.31 \mathrm{E}-05$ \\
\hline PPARGC1B & 1.16 & $8.77 E-12$ & $3.89 \mathrm{E}-11$ \\
\hline PEA15 & 1.16 & $1.76 \mathrm{E}-127$ & $3.19 E-125$ \\
\hline $\mathrm{MIR} 22 \mathrm{HG}$ & 1.16 & $1.55 E-27$ & $1.89 E-26$ \\
\hline LOC219731 & 1.16 & $5.88 \mathrm{E}-05$ & 0.000133586 \\
\hline SLC7A2 & 1.16 & 4.67E-05 & 0.000107518 \\
\hline ZEB1 & 1.16 & $2.44 E-37$ & $4.58 \mathrm{E}-36$ \\
\hline MOB3C & 1.17 & $1.91 \mathrm{E}-22$ & 1.77E-21 \\
\hline SBDSP1 & 1.17 & $6.56 \mathrm{E}-27$ & $7.74 E-26$ \\
\hline LCAT & 1.17 & $3.08 \mathrm{E}-08$ & $9.99 \mathrm{E}-08$ \\
\hline HBEGF & 1.17 & $2.63 E-45$ & $6.70 E-44$ \\
\hline MGC70870 & 1.17 & $1.69 E-109$ & $2.14 \mathrm{E}-107$ \\
\hline CDC42EP2 & 1.18 & $6.61 \mathrm{E}-33$ & $1.03 \mathrm{E}-31$ \\
\hline LOC440300 & 1.18 & $1.60 E-20$ & $1.31 \mathrm{E}-19$ \\
\hline TMED10P1 & 1.19 & $1.35 \mathrm{E}-14$ & $7.42 \mathrm{E}-14$ \\
\hline B3GALT5 & 1.19 & 0.000161499 & 0.000348482 \\
\hline BMPER & 1.19 & $4.12 \mathrm{E}-14$ & $2.19 E-13$ \\
\hline HERC2P7 & 1.19 & $1.08 \mathrm{E}-15$ & $6.44 \mathrm{E}-15$ \\
\hline SEMA3A & 1.20 & $3.81 E-10$ & $1.46 \mathrm{E}-09$ \\
\hline HNRNPU-AS1 & 1.20 & $1.86 \mathrm{E}-28$ & $2.35 E-27$ \\
\hline C20orf118 & 1.20 & $1.01 \mathrm{E}-08$ & $3.43 E-08$ \\
\hline LOC154761 & 1.21 & $1.58 \mathrm{E}-05$ & $3.84 \mathrm{E}-05$ \\
\hline
\end{tabular}

Table 3 continued

\begin{tabular}{|c|c|c|c|}
\hline Gene symbol & $\log \mathrm{FC}$ & $P$ value & FDR \\
\hline BTBD6 & 1.21 & $3.31 \mathrm{E}-124$ & $5.74 \mathrm{E}-122$ \\
\hline ALG10 & 1.21 & $3.97 \mathrm{E}-15$ & $2.28 \mathrm{E}-14$ \\
\hline LINC00338 & 1.22 & $2.07 E-17$ & $1.38 \mathrm{E}-16$ \\
\hline RPL23AP7 & 1.22 & $5.87 \mathrm{E}-08$ & $1.85 \mathrm{E}-07$ \\
\hline CLDN15 & 1.22 & $3.94 \mathrm{E}-17$ & $2.60 \mathrm{E}-16$ \\
\hline TUBA4A & 1.22 & $3.74 E-64$ & $1.69 E-62$ \\
\hline ZNF860 & 1.22 & $8.13 \mathrm{E}-19$ & $5.96 \mathrm{E}-18$ \\
\hline NBPFIO & 1.23 & $1.33 \mathrm{E}-13$ & $6.78 \mathrm{E}-13$ \\
\hline EFNB2 & 1.23 & $5.00 \mathrm{E}-20$ & $3.98 \mathrm{E}-19$ \\
\hline C15orf52 & 1.24 & $3.83 E-77$ & $2.56 \mathrm{E}-75$ \\
\hline RRS1 & 1.24 & $1.88 \mathrm{E}-119$ & $3.05 E-117$ \\
\hline OXTR & 1.24 & $1.09 E-16$ & $6.95 \mathrm{E}-16$ \\
\hline CRMP1 & 1.25 & 1.15E-06 & $3.18 \mathrm{E}-06$ \\
\hline ZNF440 & 1.25 & $3.58 \mathrm{E}-18$ & $2.52 \mathrm{E}-17$ \\
\hline EIF4EBP3 & 1.26 & 0.000648201 & 0.001292417 \\
\hline DUSP7 & 1.26 & $1.51 \mathrm{E}-29$ & $1.99 \mathrm{E}-28$ \\
\hline EXOG & 1.26 & $8.37 \mathrm{E}-22$ & $7.50 \mathrm{E}-21$ \\
\hline MAMLD1 & 1.27 & $1.94 \mathrm{E}-25$ & $2.14 \mathrm{E}-24$ \\
\hline SMPD3 & 1.27 & $6.68 \mathrm{E}-09$ & $2.31 \mathrm{E}-08$ \\
\hline PNN & 1.28 & $1.20 E-105$ & $1.42 E-103$ \\
\hline PMEPA1 & 1.28 & $1.35 E-87$ & $1.14 \mathrm{E}-85$ \\
\hline SCARF1 & 1.29 & $2.58 \mathrm{E}-10$ & $1.00 \mathrm{E}-09$ \\
\hline LOC100505815 & 1.29 & $1.06 \mathrm{E}-07$ & $3.24 \mathrm{E}-07$ \\
\hline FBXL19-AS1 & 1.29 & $1.55 E-13$ & $7.86 \mathrm{E}-13$ \\
\hline $\mathrm{HIST} 1 \mathrm{H} 4 \mathrm{H}$ & 1.29 & $1.12 \mathrm{E}-08$ & $3.80 \mathrm{E}-08$ \\
\hline TUBB & 1.30 & $1.63 E-74$ & $9.98 \mathrm{E}-73$ \\
\hline LOC100289230 & 1.30 & 0.000190102 & 0.000406114 \\
\hline FAM111B & 1.30 & $2.83 \mathrm{E}-117$ & $4.27 \mathrm{E}-115$ \\
\hline ZNF33B & 1.30 & $1.31 \mathrm{E}-57$ & $5.07 E-56$ \\
\hline ZNF121 & 1.30 & $1.57 \mathrm{E}-28$ & $1.99 \mathrm{E}-27$ \\
\hline ZNF780A & 1.30 & $1.31 \mathrm{E}-25$ & $1.45 \mathrm{E}-24$ \\
\hline NEFM & 1.30 & $2.06 \mathrm{E}-10$ & $8.07 E-10$ \\
\hline DGCR11 & 1.30 & $1.08 \mathrm{E}-13$ & $5.52 \mathrm{E}-13$ \\
\hline ST20 & 1.31 & $5.79 \mathrm{E}-08$ & $1.83 \mathrm{E}-07$ \\
\hline ADAM1 & 1.32 & $7.15 E-10$ & $2.68 \mathrm{E}-09$ \\
\hline SRSF1 & 1.32 & $1.55 \mathrm{E}-170$ & $4.54 E-168$ \\
\hline LOC642846 & 1.33 & $2.29 \mathrm{E}-09$ & $8.22 \mathrm{E}-09$ \\
\hline LOC730755 & 1.33 & $4.02 \mathrm{E}-07$ & $1.16 \mathrm{E}-06$ \\
\hline ZNF594 & 1.33 & $2.96 \mathrm{E}-18$ & $2.10 \mathrm{E}-17$ \\
\hline ITGA2 & 1.33 & $7.36 \mathrm{E}-102$ & $8.02 E-100$ \\
\hline RRN3P3 & 1.33 & $4.14 \mathrm{E}-10$ & $1.58 \mathrm{E}-09$ \\
\hline MXD1 & 1.34 & $2.31 \mathrm{E}-28$ & $2.90 \mathrm{E}-27$ \\
\hline PKI55 & 1.35 & $3.94 \mathrm{E}-10$ & $1.51 \mathrm{E}-09$ \\
\hline LOC100507433 & 1.35 & $9.28 \mathrm{E}-07$ & $2.58 \mathrm{E}-06$ \\
\hline PPAPDC1A & 1.35 & $5.00 E-27$ & $5.95 E-26$ \\
\hline PIGW & 1.35 & $7.76 \mathrm{E}-78$ & $5.28 \mathrm{E}-76$ \\
\hline NBPF9 & 1.35 & $3.18 \mathrm{E}-46$ & $8.45 E-45$ \\
\hline ZNF782 & 1.36 & $4.73 E-11$ & $1.97 \mathrm{E}-10$ \\
\hline RRP7B & 1.36 & $4.18 \mathrm{E}-08$ & $1.33 \mathrm{E}-07$ \\
\hline MICA & 1.36 & $1.68 \mathrm{E}-22$ & $1.56 \mathrm{E}-21$ \\
\hline SCARNA12 & 1.36 & $4.69 E-05$ & 0.000108075 \\
\hline DDX12P & 1.36 & 1.67E-09 & $6.07 E-09$ \\
\hline RPSAP9 & 1.36 & $5.75 E-08$ & $1.81 \mathrm{E}-07$ \\
\hline
\end{tabular}


Table 3 continued

\begin{tabular}{|c|c|c|c|}
\hline Gene symbol & $\log \mathrm{FC}$ & $P$ value & FDR \\
\hline PLEKHM1 & 1.37 & $2.14 \mathrm{E}-08$ & $7.05 E-08$ \\
\hline CLDN1 & 1.37 & $1.78 \mathrm{E}-123$ & $2.99 E-121$ \\
\hline TUBB1 & 1.37 & $1.35 \mathrm{E}-07$ & $4.10 E-07$ \\
\hline SERHL & 1.37 & $2.41 \mathrm{E}-09$ & 8.64E-09 \\
\hline YY2 & 1.38 & $1.99 E-15$ & $1.16 \mathrm{E}-14$ \\
\hline LOC344595 & 1.38 & $8.64 \mathrm{E}-13$ & $4.14 \mathrm{E}-12$ \\
\hline LOC654342 & 1.39 & 1.44E-08 & 4.83E-08 \\
\hline HCN2 & 1.39 & $1.10 E-05$ & $2.71 \mathrm{E}-05$ \\
\hline TSSK2 & 1.39 & $5.96 \mathrm{E}-06$ & $1.52 \mathrm{E}-05$ \\
\hline SERTAD4 & 1.40 & $4.02 \mathrm{E}-18$ & $2.81 \mathrm{E}-17$ \\
\hline PTGDR2 & 1.40 & $1.65 E-14$ & $8.98 \mathrm{E}-14$ \\
\hline HTR7P1 & 1.40 & $5.99 \mathrm{E}-16$ & $3.63 \mathrm{E}-15$ \\
\hline C10rf63 & 1.41 & $2.97 \mathrm{E}-32$ & $4.44 \mathrm{E}-31$ \\
\hline $\mathrm{OBFC2A}$ & 1.41 & $1.26 \mathrm{E}-72$ & $7.20 E-71$ \\
\hline ICOSLG & 1.41 & $3.58 \mathrm{E}-23$ & $3.46 \mathrm{E}-22$ \\
\hline PPP1R3E & 1.42 & $8.05 E-22$ & $7.22 \mathrm{E}-21$ \\
\hline $\mathrm{F} 13 \mathrm{~A} 1$ & 1.42 & $1.56 \mathrm{E}-21$ & $1.37 \mathrm{E}-20$ \\
\hline WASH1 & 1.43 & $1.32 \mathrm{E}-13$ & $6.69 \mathrm{E}-13$ \\
\hline GNRH1 & 1.43 & $7.51 \mathrm{E}-09$ & $2.59 \mathrm{E}-08$ \\
\hline TLR2 & 1.44 & $2.19 \mathrm{E}-07$ & $6.50 \mathrm{E}-07$ \\
\hline PXDN & 1.45 & $2.57 \mathrm{E}-18$ & $1.83 \mathrm{E}-17$ \\
\hline LOX & 1.45 & $4.42 \mathrm{E}-65$ & $2.1 \mathrm{IE}-63$ \\
\hline $\mathrm{EIF} 3 \mathrm{C}$ & 1.46 & $6.70 \mathrm{E}-21$ & $5.60 \mathrm{E}-20$ \\
\hline EIF3CL & 1.46 & $6.74 \mathrm{E}-21$ & $5.62 \mathrm{E}-20$ \\
\hline DHRS4L2 & 1.46 & $4.24 \mathrm{E}-11$ & $1.78 \mathrm{E}-10$ \\
\hline CD274 & 1.46 & $6.02 \mathrm{E}-65$ & $2.85 \mathrm{E}-63$ \\
\hline LOC646329 & 1.46 & $4.89 \mathrm{E}-07$ & $1.40 E-06$ \\
\hline ZNF767 & 1.46 & $6.55 \mathrm{E}-20$ & $5.19 E-19$ \\
\hline SPNS2 & 1.46 & $4.72 E-21$ & $3.99 \mathrm{E}-20$ \\
\hline LOC401431 & 1.47 & $1.10 E-13$ & $5.62 \mathrm{E}-13$ \\
\hline SHISA7 & 1.47 & $1.52 \mathrm{E}-07$ & 4.60E-07 \\
\hline WASH3P & 1.47 & $1.01 \mathrm{E}-15$ & $6.05 E-15$ \\
\hline C12orf34 & 1.47 & $6.88 \mathrm{E}-13$ & $3.32 \mathrm{E}-12$ \\
\hline LOC728643 & 1.47 & $6.16 \mathrm{E}-10$ & $2.32 \mathrm{E}-09$ \\
\hline PI4KAP1 & 1.48 & $3.1 \mathrm{IE}-15$ & $1.80 E-14$ \\
\hline HSPA8 & 1.48 & 0 & 0 \\
\hline BCL2A1 & 1.48 & $1.71 \mathrm{E}-11$ & $7.41 \mathrm{E}-11$ \\
\hline ADAMTS6 & 1.49 & $3.58 \mathrm{E}-06$ & $9.33 \mathrm{E}-06$ \\
\hline SPIN2B & 1.49 & $1.12 \mathrm{E}-09$ & $4.12 \mathrm{E}-09$ \\
\hline TUBAIB & 1.49 & $4.03 E-278$ & $2.32 E-275$ \\
\hline TNFAIP3 & 1.50 & $3.05 E-159$ & 7.86E-157 \\
\hline CCDC39 & 1.50 & $3.75 E-05$ & $8.72 E-05$ \\
\hline WASH5P & 1.51 & $3.91 \mathrm{E}-50$ & $1.19 E-48$ \\
\hline SPHK1 & 1.52 & $4.08 \mathrm{E}-27$ & $4.87 \mathrm{E}-26$ \\
\hline ZNF417 & 1.53 & 1.87E-17 & $1.25 \mathrm{E}-16$ \\
\hline LOC100289019 & 1.53 & $3.60 \mathrm{E}-10$ & $1.38 \mathrm{E}-09$ \\
\hline TUBA1C & 1.54 & 0 & 0 \\
\hline BMS1P5 & 1.54 & $2.70 E-06$ & $7.16 \mathrm{E}-06$ \\
\hline BMS1P1 & 1.54 & $2.71 \mathrm{E}-06$ & 7.17E-06 \\
\hline SHISA9 & 1.54 & $1.40 E-48$ & $4.04 \mathrm{E}-47$ \\
\hline SOX9 & 1.54 & $1.14 \mathrm{E}-50$ & $3.52 E-49$ \\
\hline ENC1 & 1.55 & $3.65 E-104$ & $4.24 \mathrm{E}-102$ \\
\hline PLEKHA8P1 & 1.55 & $4.63 \mathrm{E}-10$ & 1.76E-09 \\
\hline
\end{tabular}

Table 3 continued

\begin{tabular}{|c|c|c|c|}
\hline Gene symbol & $\log \mathrm{FC}$ & $P$ value & FDR \\
\hline NEAT1 & 1.55 & $2.74 \mathrm{E}-226$ & $1.24 \mathrm{E}-223$ \\
\hline LOC100506123 & 1.55 & $6.41 E-12$ & $2.88 \mathrm{E}-11$ \\
\hline LOC100506599 & 1.56 & $1.30 E-08$ & 4.37E-08 \\
\hline FOXO3B & 1.56 & $4.19 E-17$ & $2.76 \mathrm{E}-16$ \\
\hline PDIA3P & 1.56 & $1.88 \mathrm{E}-19$ & $1.44 \mathrm{E}-18$ \\
\hline MMP1 & 1.56 & $6.14 \mathrm{E}-19$ & $4.53 E-18$ \\
\hline FERMT1 & 1.57 & $9.62 E-144$ & $2.06 \mathrm{E}-141$ \\
\hline NPTX2 & 1.57 & $2.39 \mathrm{E}-07$ & 7.07E-07 \\
\hline MSTO2P & 1.58 & $3.96 \mathrm{E}-15$ & $2.27 \mathrm{E}-14$ \\
\hline ZFP112 & 1.58 & $2.53 \mathrm{E}-18$ & $1.80 \mathrm{E}-17$ \\
\hline AFG3L1P & 1.59 & $3.41 \mathrm{E}-74$ & $2.05 E-72$ \\
\hline TFRC & 1.60 & $1.56 \mathrm{E}-210$ & $6.16 \mathrm{E}-208$ \\
\hline SPRN & 1.63 & $3.15 E-21$ & $2.70 E-20$ \\
\hline LOC100133091 & 1.64 & $4.17 \mathrm{E}-08$ & $1.33 \mathrm{E}-07$ \\
\hline GKN2 & 1.64 & $1.01 \mathrm{E}-19$ & $7.88 \mathrm{E}-19$ \\
\hline LOC100272217 & 1.64 & $8.20 \mathrm{E}-08$ & $2.54 \mathrm{E}-07$ \\
\hline LOC100132247 & 1.66 & $1.26 \mathrm{E}-11$ & $5.53 \mathrm{E}-11$ \\
\hline UBC & 1.67 & 0 & 0 \\
\hline LOC440894 & 1.69 & $4.98 \mathrm{E}-07$ & $1.42 \mathrm{E}-06$ \\
\hline HERC2P2 & 1.70 & $1.86 \mathrm{E}-84$ & $1.51 \mathrm{E}-82$ \\
\hline CBWD2 & 1.70 & $2.67 \mathrm{E}-09$ & $9.56 \mathrm{E}-09$ \\
\hline DQX1 & 1.71 & $1.13 \mathrm{E}-10$ & $4.53 \mathrm{E}-10$ \\
\hline CHRM3 & 1.72 & $1.40 \mathrm{E}-14$ & $7.68 \mathrm{E}-14$ \\
\hline TMEM158 & 1.72 & $1.85 E-29$ & $2.44 \mathrm{E}-28$ \\
\hline G0S2 & 1.73 & $4.26 \mathrm{E}-70$ & $2.29 E-68$ \\
\hline LOC100288778 & 1.77 & $5.61 \mathrm{E}-13$ & $2.74 E-12$ \\
\hline CCZ1 & 1.81 & $6.97 \mathrm{E}-29$ & $9.02 \mathrm{E}-28$ \\
\hline GPR89A & 1.81 & $6.1 \mathrm{IE}-21$ & $5.12 \mathrm{E}-20$ \\
\hline DOK3 & 1.83 & 1. $O O E-10$ & $4.05 E-10$ \\
\hline C6orf141 & 1.85 & 7.97E-58 & $3.1 \mathrm{IE}-56$ \\
\hline NAV3 & 1.85 & $1.21 \mathrm{E}-68$ & $6.33 \mathrm{E}-67$ \\
\hline HERC2P9 & 1.85 & $9.07 E-20$ & 7.09E-19 \\
\hline GOLGA8B & 1.86 & $5.17 E-113$ & $7.03 E-111$ \\
\hline OPHN1 & 1.93 & $1.05 E-64$ & $4.92 \mathrm{E}-63$ \\
\hline TAGLN & 1.94 & $2.23 E-95$ & $2.24 \mathrm{E}-93$ \\
\hline PRG4 & 1.95 & $6.72 E-29$ & $8.72 E-28$ \\
\hline NBPF16 & 1.95 & $1.02 \mathrm{E}-114$ & $1.48 \mathrm{E}-112$ \\
\hline AGAP6 & 1.96 & $2.09 E-25$ & $2.30 E-24$ \\
\hline PFN1P2 & 2.05 & $1.19 \mathrm{E}-30$ & $1.65 E-29$ \\
\hline PPP1R11 & 2.18 & $2.28 \mathrm{E}-16$ & $1.42 \mathrm{E}-15$ \\
\hline HMGA2 & 2.19 & $7.78 \mathrm{E}-56$ & $2.85 \mathrm{E}-54$ \\
\hline SRSFIO & 2.22 & $1.64 \mathrm{E}-22$ & $1.53 \mathrm{E}-21$ \\
\hline GOLGA8A & 2.30 & $1.62 \mathrm{E}-88$ & $1.41 \mathrm{E}-86$ \\
\hline LOC100216001 & 2.32 & $1.88 \mathrm{E}-13$ & $9.49 E-13$ \\
\hline NBPF14 & 2.34 & $4.08 \mathrm{E}-85$ & $3.35 E-83$ \\
\hline LOC284454 & 2.42 & $2.30 E-69$ & $1.22 \mathrm{E}-67$ \\
\hline ESM1 & 2.55 & $6.08 \mathrm{E}-25$ & $6.53 E-24$ \\
\hline LOC613037 & 2.70 & $2.83 E-23$ & $2.74 \mathrm{E}-22$ \\
\hline
\end{tabular}

library were determined by the University of Missouri DNA core. Deep sequencing was performed by the MU DNA core using Illumina HiSeq 2000 following the 
Table 4 Gene ontology analysis of Esrrb-dependent DY131-altered genes

\begin{tabular}{|c|c|c|}
\hline Term (down-regulated genes) & Count & $P$ value \\
\hline GO:0042273 ribosomal large subunit biogenesis & 4 & 0.007 \\
\hline GO:0006297 nucleotide-excision repair, DNA gap filling & 4 & 0.032 \\
\hline GO:0006541 glutamine metabolic process & 4 & 0.042 \\
\hline GO:0009083 branched chain family amino acid catabolic process & 5 & 0.001 \\
\hline GO:0042274 ribosomal small subunit biogenesis & 5 & 0.001 \\
\hline GO:0009081 branched chain family amino acid metabolic process & 5 & 0.004 \\
\hline GO:0006904 vesicle docking during exocytosis & 5 & 0.016 \\
\hline GO:0048278 vesicle docking & 5 & 0.021 \\
\hline GO:0006958 complement activation, classical pathway & 5 & 0.031 \\
\hline GO:0022406 membrane docking & 5 & 0.038 \\
\hline GO:0002455 humoral immune response mediated by circulating immunoglobulin & 6 & 0.008 \\
\hline GO:0009060 aerobic respiration & 6 & 0.014 \\
\hline GO:0006635 fatty acid beta-oxidation & 7 & 0.001 \\
\hline GO:0009062 fatty acid catabolic process & 7 & 0.003 \\
\hline GO:0019395 fatty acid oxidation & 7 & 0.005 \\
\hline GO:0034440 lipid oxidation & 7 & 0.005 \\
\hline GO:0033559 unsaturated fatty acid metabolic process & 7 & 0.019 \\
\hline GO:0009064 glutamine family amino acid metabolic process & 7 & 0.020 \\
\hline GO:0019228 regulation of action potential in neuron & 7 & 0.024 \\
\hline GO:0006289 nucleotide-excision repair & 7 & 0.026 \\
\hline GO:0051591 response to CAMP to CAMP & 8 & 0.002 \\
\hline GO:0006800 oxygen and reactive oxygen species metabolic process & 8 & 0.021 \\
\hline GO:0001508 regulation of action potential & 8 & 0.023 \\
\hline GO:0009566 fertilization & 8 & 0.046 \\
\hline GO:0044242 cellular lipid catabolic process & 9 & 0.013 \\
\hline GO:0007160 cell-matrix adhesion & 9 & 0.032 \\
\hline GO:0060627 regulation of vesicle-mediated transport & 9 & 0.046 \\
\hline GO:0009063 cellular amino acid catabolic process & 10 & 0.002 \\
\hline GO:0045333 cellular respiration & 10 & 0.020 \\
\hline GO:0007568 aging & 10 & 0.040 \\
\hline GO:0016485 protein processing & 10 & 0.044 \\
\hline GO:0006364 rRNA processing & 11 & 0.005 \\
\hline GO:0016072 rRNA metabolic process & 11 & 0.007 \\
\hline GO:0006887 exocytosis & 11 & 0.022 \\
\hline GO:0009310 amine catabolic process & 12 & 0.000 \\
\hline GO:0008203 cholesterol metabolic process & 12 & 0.001 \\
\hline GO:0016125 sterol metabolic process & 12 & 0.003 \\
\hline GO:0042391 regulation of membrane potential & 12 & 0.024 \\
\hline GO:0015980 energy derivation by oxidation of organic compounds & 12 & 0.038 \\
\hline GO:0042254 ribosome biogenesis & 13 & 0.005 \\
\hline GO:0016053 organic acid biosynthetic process & 14 & 0.013 \\
\hline GO:0046394 carboxylic acid biosynthetic process & 14 & 0.013 \\
\hline GO:0022613 ribonucleoprotein complex biogenesis & 14 & 0.038 \\
\hline GO:0016042 lipid catabolic process & 15 & 0.013 \\
\hline GO:0006457 protein folding & 15 & 0.016 \\
\hline GO:0034470 ncRNA processing & 15 & 0.025 \\
\hline GO:0022900 electron transport chain & 16 & 0.000 \\
\hline GO:0032940 secretion by cell & 16 & 0.026 \\
\hline GO:0016054 organic acid catabolic process & 17 & 0.000 \\
\hline
\end{tabular}


Table 4 continued

\begin{tabular}{|c|c|c|}
\hline Term (down-regulated genes) & Count & $P$ value \\
\hline GO:0046395 carboxylic acid catabolic process & 17 & 0.000 \\
\hline GO:0034660 ncRNA metabolic process & 19 & 0.008 \\
\hline GO:0006631 fatty acid metabolic process & 21 & 0.000 \\
\hline GO:0046903 secretion & 22 & 0.014 \\
\hline GO:0006414 translational elongation & 25 & 0.000 \\
\hline GO:0008610 lipid biosynthetic process & 26 & 0.002 \\
\hline GO:0006091 generation of precursor metabolites and energy & 31 & 0.000 \\
\hline GO:0006412 translation & 38 & 0.000 \\
\hline GO:0016192 vesicle-mediated transport & 39 & 0.003 \\
\hline GO:0055114 oxidation reduction & 54 & 0.000 \\
\hline Term (up-regulated genes) & Count & $P$ value \\
\hline GO:0002220 innate immune response activating cell surface receptor signaling pathway & 2 & 0.045 \\
\hline GO:0048712 negative regulation of astrocyte differentiation & 2 & 0.045 \\
\hline GO:0000724 double-strand break repair via homologous recombination & 3 & 0.020 \\
\hline GO:0000725 recombinational repair & 3 & 0.020 \\
\hline GO:0045987 positive regulation of smooth muscle contraction & 4 & 0.001 \\
\hline GO:0045933 positive regulation of muscle contraction & 4 & 0.002 \\
\hline GO:0006940 regulation of smooth muscle contraction & 4 & 0.009 \\
\hline GO:0050768 negative regulation of neurogenesis & 4 & 0.015 \\
\hline GO:0010721 negative regulation of cell development & 4 & 0.018 \\
\hline GO:0006937 regulation of muscle contraction & 4 & 0.050 \\
\hline GO:0048704 embryonic skeletal system morphogenesis & 5 & 0.004 \\
\hline GO:0048706 embryonic skeletal system development & 5 & 0.012 \\
\hline GO:0031344 regulation of cell projection organization & 5 & 0.019 \\
\hline GO:0007411 axon guidance & 5 & 0.035 \\
\hline GO:0051258 protein polymerization & 6 & 0.000 \\
\hline GO:0043623 cellular protein complex assembly & 6 & 0.039 \\
\hline GO:0050767 regulation of neurogenesis & 6 & 0.042 \\
\hline GO:0048705 skeletal system morphogenesis & 7 & 0.002 \\
\hline GO:0060284 regulation of cell development & 7 & 0.031 \\
\hline GO:0007018 microtubule-based movement & 8 & 0.000 \\
\hline GO:0051960 regulation of nervous system development & 8 & 0.007 \\
\hline GO:0006916 anti-apoptosis & 8 & 0.010 \\
\hline GO:0007017 microtubule-based process & 8 & 0.027 \\
\hline GO:0001501 skeletal system development & 9 & 0.031 \\
\hline GO:0006917 induction of apoptosis & 9 & 0.031 \\
\hline GO:0012502 induction of programmed cell death & 9 & 0.032 \\
\hline GO:0045596 negative regulation of cell differentiation & 10 & 0.001 \\
\hline GO:0040008 regulation of growth & 10 & 0.017 \\
\hline GO:0043066 negative regulation of apoptosis & 10 & 0.021 \\
\hline GO:0043069 negative regulation of programmed cell death & 10 & 0.023 \\
\hline GO:0060548 negative regulation of cell death & 10 & 0.023 \\
\hline GO:0022403 cell cycle phase & 10 & 0.049 \\
\hline GO:0006928 cell motion & 12 & 0.021 \\
\hline GO:0042127 regulation of cell proliferation & 17 & 0.018 \\
\hline GO:0042981 regulation of apoptosis & 18 & 0.011 \\
\hline GO:0043067 regulation of programmed cell death & 18 & 0.012 \\
\hline GO:0010941 regulation of cell death & 18 & 0.012 \\
\hline GO:0006355 regulation of transcription, DNA-dependent & 29 & 0.047 \\
\hline
\end{tabular}


Table 4 continued

\begin{tabular}{|c|c|c|}
\hline Term (up-regulated genes) & Count & $P$ value \\
\hline GO:0051252 regulation of RNA metabolic process & 30 & 0.038 \\
\hline GO:0006350 transcription & 43 & 0.000 \\
\hline GO:0045449 regulation of transcription & 48 & 0.001 \\
\hline
\end{tabular}

manufacture's instruction. Briefly, samples ( 8 total) were pooled into one lane with each sample annealed to a specific indexed adaptor. 50 bp single end reads were generated. For each sample, approximately 18 million reads were generated in.fastq format (NCBI-GEO, accession number: GES71208). The sequencing reads were trimmed and filtered using FASTX-Toolkit (V 0.0.13) (http://hannonlab.cshl.edu/fastx_toolkit), and mapped to genome (UCSC hg18) using TopHat2 [39, 40]. Gene expression values were determined by gene raw read counts using an in-house tool MULTICOM-MAP [41-43]. Raw reads were normalized to each sample's library size and differentially expressed genes were calculated using R/Bioconductor package edgeR [44]. Specifically, we kept the genes that have at least 1 count-per-million (cpm) in at least 2 samples and computed the effective library sizes. Pairwise gene expression tests were carried out using exact test. Differentially expressed genes were determined by $\log 2$ fold change $(\log 2 \mathrm{FC})(\log 2 \mathrm{FC} \geq 1$, or $\log 2 \mathrm{FC} \leq-1)$, $\mathrm{p}$ value $(\mathrm{p}<0.05)$ and false discovery rate $(\mathrm{FDR}<0.05)[45]$.

\section{Gene set function enrichment}

Gene ontology (GO) analysis was performed using DAVID bioinformatics sources 6.7 [46, 47]. Differentially expressed genes from certain pairwise comparisons were uploaded to DAVID server (http://david.abcc.ncifcrf.gov) and GO analysis were performed for biological process (BP). Minimum counts were set as default value (two counts) and maximum EASE score ( $p$ value) was set to 0.05 . Differentially expressed genes pathway enrichment analysis was performed using Kyoto Encyclopedia of Genes and Genomes (KEGG) pathway [48, 49]. Gene expression profiles Spearman ranking correlation analysis was analyzed using R (version 3.0.2). Gene expression heat map and hierarchical clustering were created by $R /$ Bioconductor (version 2.13) package gplot.

\section{Statistical analysis}

qPCR experiments were performed in triplicate on both biological replicates. $T$ test was employed to statistically analyze whether the differences in gene expression is significant $(\mathrm{p}<0.05)$. Statistical significance of gene set overlap (Venn Diagram) are tested according to previous reported method [17].

\section{Availability of supporting data}

The data sets supporting the results of this article are available in the NCBI-GEO repository, accession number: GSE71208, URL: http://www.ncbi.nlm.nih.gov/geo/ query/acc.cgi?acc $=$ GSE71208.

\section{Additional files}

Additional file 1: Figure S1. DY131-activated Esrrb regulates p21 Figure S2. Full gel images.

Additional file 2: Table S1. Gene ontology analysis result. Table S2. Esrrb expression with DY131 treatment (control vs. Esrrb + DY131).

\section{Abbreviations}

Esrrb: estrogen related receptor beta; ERRE: estrogen related receptor response element; SFRE: steroid factor response element; iPSC: induced pluripotent stem cells; OSKM: Oct4, Sox2, KIf4, cMyc; FBS: fetal bovine serum; RT: reverse transcriptase; KEGG: Kyoto encyclopedia of genes and genomes; GO: gene ontology; FC: fold change; Esrrg: estrogen related receptor gamma.

\section{Authors' contributions}

YL established the model cell line and performed RNA isolation, Esrrb expression status test, western blot, cell growth assay, differentially expressed gene analysis, functional enrichment of gene sets by GO and KEGG pathway, construct gene regulation network and statistical analysis. $\mathrm{YL}, J \mathrm{~L}, J \mathrm{~J}$ performed sequence alignment and generated the gene expression count table for RNA-seq data analysis. YL and DBL conceived of the study, participated in its design and drafted the manuscript. All authors read and approved the final manuscript.

\section{Author details}

${ }^{1}$ Department of Biochemistry, University of Missouri, Columbia, MO 65211 , USA. ${ }^{2}$ MU Center for Botanical Interaction Studies, University of Missouri, Columbia, MO 65211, USA. ${ }^{3}$ Computer Science Department, University of Missouri, Columbia, MO 65211, USA. ${ }^{4}$ Informatics Institute, University of Missouri, Columbia, MO 65211, USA. ${ }^{5}$ Xiphophorus Genetic Stock Center, Texas State University, San Marcos, TX 78666, USA.

\section{Acknowledgements}

We thank Dr. Wei Zhou for cloning Esrrb. We also thank Nicholas Starkey, Benjamin Merideth and Yufei Li for helpful discussions. This publication or project was made possible in part by Grant Number P50AT006273 from the National Center for Complementary and Integrative Health $(\mathrm{NCCIH})$, the Office of Dietary Supplements (ODS), and the National Cancer Institute (NCI). Its contents are solely the responsibility of the authors and do not necessarily represent the official views of the NCCAM, ODS, NCl, or the National Institutes of Health.

\section{Competing interests}

The authors declare that they have no competing interests.

Received: 28 June 2015 Accepted: 13 November 2015

Published online: 01 December 2015 


\section{References}

1. Giguere $V$, Yang N, Segui P, Evans RM. Identification of a new class of steroid hormone receptors. Nature. 1988;331:91-4.

2. Vanacker JM, Pettersson K, Gustafsson JA, Laudet V. Transcriptional targets shared by estrogen receptor-related receptors (ERRs) and estrogen receptor (ER) alpha, but not by ERbeta. EMBO J. 1999;18:4270-9.

3. Luo J, Sladek R, Bader JA, Matthyssen A, Rossant J, et al. Placental abnormalities in mouse embryos lacking the orphan nuclear receptor ERR-beta. Nature. 1997:388:778-82.

4. Zhou W, Liu Z, Wu J, Liu JH, Hyder SM, et al. Identification and characterization of two novel splicing isoforms of human estrogen-related receptor beta. J Clin Endocrinol Metab. 2006;91:569-79.

5. Welstead GG, Brambrink T, Jaenisch R. Generating iPS cells from MEFS through forced expression of Sox-2, Oct-4, c-Myc, and KIf4. J Vis Exp. 2008;14.

6. Feng B, Jiang J, Kraus $\mathrm{P}, \mathrm{Ng} J \mathrm{H}$, Heng JC, et al. Reprogramming of fibroblasts into induced pluripotent stem cells with orphan nuclear receptor Esrrb. Nat Cell Biol. 2009;11:197-203.

7. Buganim Y, Faddah DA, Cheng AW, Itskovich E, Markoulaki S, et al. Singlecell expression analyses during cellular reprogramming reveal an early stochastic and a late hierarchic phase. Cell. 2012;150:1209-22.

8. Cheung CP, Yu S, Wong KB, Chan LW, Lai FM, et al. Expression and functional study of estrogen receptor-related receptors in human prostatic cells and tissues. J Clin Endocrinol Metab. 2005;90:1830-44.

9. Yu S, Wong YC, Wang XH, Ling MT, Ng CF, et al. Orphan nuclear receptor estrogen-related receptor-beta suppresses in vitro and in vivo growth of prostate cancer cells via p21(WAF1/CIP1) induction and as a potential therapeutic target in prostate cancer. Oncogene. 2008;27:3313-28.

10. Fujimura T, Takahashi S, Urano T, ljichi N, Ikeda K, et al. Differential expression of estrogen-related receptors beta and gamma (ERRbeta and ERRgamma) and their clinical significance in human prostate cancer. Cancer Sci. 2010;101:646-51.

11. Zhou W, Lo SC, Liu JH, Hannink M, Lubahn DB. ERRbeta: a potent inhibitor of Nrf2 transcriptional activity. Mol Cell Endocrinol. 2007;278:52-62.

12. Bombail V, Collins F, Brown P, Saunders PT. Modulation of ER alpha transcriptional activity by the orphan nuclear receptor ERR beta and evidence for differential effects of long- and short-form splice variants. Mol Cell Endocrinol. 2010;314:53-61.

13. Chen $X, X u H$, Yuan $P$, Fang F, Huss $M$, et al. Integration of external signaling pathways with the core transcriptional network in embryonic stem cells. Cell. 2008;133:1106-17.

14. Ouyang Z, Zhou Q, Wong WH. ChIP-Seq of transcription factors predicts absolute and differential gene expression in embryonic stem cells. Proc Natl Acad Sci USA. 2009;106:21521-6.

15. Percharde M, Lavial F, Ng JH, Kumar $V$, Tomaz RA, et al. Ncoa3 functions as an essential Esrrb coactivator to sustain embryonic stem cell self-renewal and reprogramming. Genes Dev. 2012;26:2286-98.

16. Nishiyama A, Sharov AA, Piao Y, Amano M, Amano T, et al. Systematic repression of transcription factors reveals limited patterns of gene expression changes in ES cells. Sci Rep. 2013;3:1390.

17. Zhou Q, Chipperfield H, Melton DA, Wong WH. A gene regulatory network in mouse embryonic stem cells. Proc Natl Acad Sci USA. 2007;104:16438-43.

18. Carter MG, Stagg CA, Falco G, Yoshikawa T, Bassey UC, et al. An in situ hybridization-based screen for heterogeneously expressed genes in mouse ES cells. Gene Expr Patterns. 2008;8:181-98.

19. van den Berg DL, Zhang W, Yates A, Engelen E, Takacs K, et al. Estrogenrelated receptor beta interacts with Oct4 to positively regulate Nanog gene expression. Mol Cell Biol. 2008;28:5986-95.

20. Zhang X, Zhang J, Wang T, Esteban MA, Pei D. Esrrb activates Oct4 transcription and sustains self-renewal and pluripotency in embryonic stem cells. J Biol Chem. 2008:283:35825-33.

21. Storm MP, Kumpfmueller B, Thompson B, Kolde R, Vilo J, et al. Characterization of the phosphoinositide 3-kinase-dependent transcriptome in murine embryonic stem cells: identification of novel regulators of pluripotency. Stem Cells. 2009;27:764-75.

22. Gao M, Sun P, Wang J, Zhao D, Wei L. Expression of estrogen receptorrelated receptor isoforms and clinical significance in endometrial adenocarcinoma. Int J Gynecol Cancer. 2006;16:827-33.

23. Wang SC, Myers S, Dooms C, Capon R, Muscat GE. An ERRbeta/gamma agonist modulates GRalpha expression, and glucocorticoid responsive gene expression in skeletal muscle cells. Mol Cell Endocrinol. 2010:315:146-52
24. Byerly MS, Al Salayta M, Swanson RD, Kwon K, Peterson JM, et al. Estrogen-related receptor beta deletion modulates whole-body energy balance via estrogen-related receptor gamma and attenuates neuropeptide Y gene expression. Eur J Neurosci. 2013;37:1033-47.

25. Byerly MS, Swanson RD, Wong GW, Blackshaw S. Estrogen-related receptor beta deficiency alters body composition and response to restraint stress. BMC Physiol. 2013;13:10

26. Castet A, Herledan A, Bonnet S, Jalaguier S, Vanacker JM, et al. Receptorinteracting protein 140 differentially regulates estrogen receptor-related receptor transactivation depending on target genes. Mol Endocrinol. 2006:20:1035-47

27. Sumi D, Ignarro LJ. Estrogen-related receptor alpha 1 up-regulates endothelial nitric oxide synthase expression. Proc Natl Acad Sci USA 2003;100:14451-6

28. Vanacker JM, Bonnelye E, Chopin-Delannoy S, Delmarre C, Cavailles $\checkmark$, et al. Transcriptional activities of the orphan nuclear receptor ERR alpha (estrogen receptor-related receptor-alpha). Mol Endocrinol. 1999:13:764-73.

29. Abe S, Usami S, Nakamura Y. Mutations in the gene encoding KIAA1199 protein, an inner-ear protein expressed in Deiters' cells and the fibrocytes, as the cause of nonsyndromic hearing loss. J Hum Genet. 2003:48:564-70.

30. He QY, Liu XH, Li Q, Studholme DJ, Li XW, et al. G8: a novel domain associated with polycystic kidney disease and non-syndromic hearing loss. Bioinformatics. 2006;22:2189-91.

31. Guo J, Cheng H, Zhao S, Yu L. GG: a domain involved in phage LTF apparatus and implicated in human MEB and non-syndromic hearing loss diseases. FEBS Lett. 2006;580:581-4.

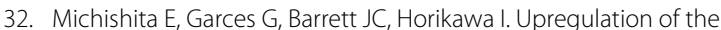
KIAA1199 gene is associated with cellular mortality. Cancer Lett. 2006;239:71-7.

33. Collin RW, Kalay E, Tariq M, Peters T, van der Zwaag B, et al. Mutations of ESRRB encoding estrogen-related receptor beta cause autosomalrecessive nonsyndromic hearing impairment DFNB35. Am J Hum Genet. 2008;82:125-38.

34. Ben Said M, Ayedi L, Mnejja M, Hakim B, Khalfallah A, et al. A novel missense mutation in the ESRRB gene causes DFNB35 hearing loss in a Tunisian family. Eur J Med Genet. 2011;54:e535-41.

35. Lee K, Khan S, Ansar M, Santos-Cortez RL, Ahmad W, et al. A novel ESRRB deletion is a rare cause of autosomal recessive nonsyndromic hearing impairment among Pakistani families. Genet Res Int. 2011;2011:368915.

36. Safka Brozkova D, Lastuvkova J, Machalova E, Lisonova J, Trkova M, et al. DFNB35 due to a novel mutation in the ESRRB gene in a Czech consanguineous family. Int J Pediatr Otorhinolaryngol. 2012;76:1681-4.

37. Lee EK, Han GY, Park HW, Song YJ, Kim CW. Transgelin promotes migration and invasion of cancer stem cells. J Proteom Res. 2010;9:5108-17.

38. Welshons WV, Grady LH, Engler KS, Judy BM. Control of proliferation of MCF-7 breast cancer cells in a commercial preparation of charcoalstripped adult bovine serum. Breast Cancer Res Treat. 1992;23:97-104.

39. Langmead B, Trapnell C, Pop M, Salzberg SL. Ultrafast and memoryefficient alignment of short DNA sequences to the human genome. Genome Biol. 2009;10:R25

40. Trapnell C, Pachter L, Salzberg SL. TopHat: discovering splice junctions with RNA-Seq. Bioinformatics. 2009;25:1105-11.

41. Sun L, Fernandez HR, Donohue RC, Li J, Cheng J, et al. Male-specific lethal complex in Drosophila counteracts histone acetylation and does not mediate dosage compensation. Proc Natl Acad Sci USA. 2013;110:E808-17.

42. Sun L, Johnson AF, Donohue RC, Li J, Cheng J, et al. Dosage compensation and inverse effects in triple X metafemales of Drosophila. Proc Natl Acad Sci USA. 2013;110:7383-8.

43. Sun L, Johnson AF, Li J, Lambdin AS, Cheng J, et al. Differential effect of aneuploidy on the $X$ chromosome and genes with sex-biased expression in Drosophila. Proc Natl Acad Sci USA. 2013;110:16514-9.

44. Robinson MD, McCarthy DJ, Smyth GK. edgeR: a Bioconductor package for differential expression analysis of digital gene expression data. Bioinformatics. 2010;26:139-40.

45. Li H, Lovci MT, Kwon YS, Rosenfeld MG, Fu XD, et al. Determination of tag density required for digital transcriptome analysis: application to an androgen-sensitive prostate cancer model. Proc Natl Acad Sci USA. 2008:105:20179-84 
46. da Huang W, Sherman BT, Lempicki RA. Systematic and integrative analy sis of large gene lists using DAVID bioinformatics resources. Nat Protoc. 2009:4:44-57.

47. da Huang W, Sherman BT, Lempicki RA. Bioinformatics enrichment tools: paths toward the comprehensive functional analysis of large gene lists. Nucleic Acids Res. 2009;37:1-13.
48. Kanehisa M, Goto S, Sato Y, Kawashima M, Furumichi M, et al. Data, information, knowledge and principle: back to metabolism in KEGG. Nucleic Acids Res. 2014;42:D199-205.

49. Kanehisa M, Goto S. KEGG: kyoto encyclopedia of genes and genomes. Nucleic Acids Res. 2000;28:27-30.
Submit your next manuscript to BioMed Central and we will help you at every step:

- We accept pre-submission inquiries

- Our selector tool helps you to find the most relevant journal

- We provide round the clock customer support

- Convenient online submission

- Thorough peer review

- Inclusion in PubMed and all major indexing services

- Maximum visibility for your research

Submit your manuscript at www.biomedcentral.com/submit
() Biomed Central 